\title{
Mediterranean cyclones: current knowledge and open questions on dynamics, prediction, climatology and impacts
}

\author{
Emmanouil Flaounas ${ }^{1}$, Silvio Davolio ${ }^{2}$, Shira Raveh-Rubin ${ }^{3}$, Florian Pantillon ${ }^{4}$, Mario Marcello Miglietta ${ }^{5}$, \\ Miguel Angel Gaertner ${ }^{6}$, Maria Hatzaki ${ }^{7}$, Victor Homar ${ }^{8}$, Samira Khodayar ${ }^{9}$, Gerasimos Korres ${ }^{1}$, \\ Vassiliki Kotroni ${ }^{10}$, Jonilda Kushta ${ }^{11}$, Marco Reale ${ }^{12,13}$, and Didier Ricard ${ }^{14}$ \\ ${ }^{1}$ Institute of Oceanography, Hellenic Centre for Marine Research, Athens, Greece \\ ${ }^{2}$ Institute of Atmospheric Sciences and Climate (CNR-ISAC), National Research Council of Italy, Bologna, Italy \\ ${ }^{3}$ Department of Earth and Planetary Sciences, Weizmann Institute of Science, Rehovot, Israel \\ ${ }^{4}$ Laboratoire d'Aérologie, Université de Toulouse, CNRS, UPS, IRD, Toulouse, France \\ ${ }^{5}$ Institute of Atmospheric Sciences and Climate (CNR-ISAC), National Research Council of Italy, Padua, Italy \\ ${ }^{6}$ Faculty of Environmental Sciences and Biochemistry, University of Castilla-La Mancha, Toledo, Spain \\ ${ }^{7}$ Department of Geology and Geoenvironment, National and Kapodistrian University of Athens, 10679 Athens, Greece \\ ${ }^{8}$ Meteorology Group, Physics Department, Universitat de les Illes Balears, Palma, Mallorca, Spain \\ ${ }^{9}$ Mediterranean Centre for Environmental Studies (CEAM), Valencia, Spain \\ ${ }^{10}$ Institute of Environmental Research and Sustainable Development, National Observatory of Athens (NOA), Athens, Greece \\ ${ }^{11}$ Climate and Atmosphere Research Centre (CARE-C), The Cyprus Institute, Nicosia 2121, Cyprus \\ ${ }^{12}$ National Institute of Oceanography and Applied Geophysics - OGS, Via Beirut, 2, 34151, Trieste, Italy \\ ${ }^{13}$ Abdus Salam International Centre for Theoretical Physics (ICTP), Trieste, Italy \\ ${ }^{14}$ CNRM, Université de Toulouse, Météo-France, CNRS, Toulouse, France
}

Correspondence: Emmanouil Flaounas (em.flaounas@hcmr.gr)

Received: 17 August 2021 - Discussion started: 24 August 2021

Revised: 14 December 2021 - Accepted: 4 January 2022 - Published: 14 February 2022

\begin{abstract}
A large number of intense cyclones occur every year in the Mediterranean basin, one of the climate change hotspots. Producing a broad range of severe socio-economic and environmental impacts in such a densely populated region, Mediterranean cyclones call for coordinated and interdisciplinary research efforts. This article aims at supporting these efforts by reviewing the status of knowledge in the broad field of Mediterranean cyclones.

First, we focus on the climatology of Mediterranean cyclone tracks, their relationship to large-scale atmospheric circulation and their future trends. Second, we discuss the dynamics and atmospheric processes that govern the genesis and development of Mediterranean cyclones. Then, we present the different subtypes of Mediterranean cyclones, devoting special attention to medicanes, i.e. cyclones with tropical characteristics and subjects of numerous recent studies. In a subsequent section, we review the state of the art in forecasting cyclones and relevant high-impact weather, and we
\end{abstract}

discuss in detail the challenges and recent efforts to increase their forecast skill. Finally, we discuss the main impacts produced by cyclones, namely heavy precipitation, windstorms, dust transport, storm surges and sea wave extremes.

In the last section of this review article, we thoroughly outline the future directions of research that would advance the broader field of Mediterranean cyclones.

\section{Introduction}

The Mediterranean basin is a relatively small region but of unique and complex geography. It is characterised by a nearly enclosed basin with sharp land-sea transitions. It is surrounded by high mountain chains, and it has long ago been identified as a distinct region in the globe of frequent cyclogenesis (Petterssen, 1956). The complex topographical features, as well as its transitional location between the trop- 
ics and the mid-latitudes downstream of the North Atlantic storm tracks, influence Mediterranean cyclones through a large variety of atmospheric processes. Mediterranean cyclones typically present weaker intensities, smaller sizes and shorter lifetimes than mid-latitude cyclones that develop over open oceans (Trigo, 2006; Čampa and Wernli, 2012; Flaounas et al., 2014). Nevertheless, Mediterranean cyclones often have a high impact, being responsible for the great majority of precipitation and wind climate extremes that affect both the regional environment and the population of more than 480 million.

Over the last decades, the main research efforts on Mediterranean cyclones focused not only on atmospheric and climate sciences but also on environmental and socioeconomic impacts. At international level, the Mediterranean Experiment (MEDEX, 2000-2010; Jansa et al., 2014) strongly contributed to improving our understanding of Mediterranean cyclone dynamics, modelling and impacts. The lessons learned from MEDEX were of great importance in the planning phase of the field campaigns of the Hydrological Cycle in the Mediterranean Experiment (HyMeX, 20102020; Drobinski et al., 2014). Indeed, the HyMeX special observation periods are, to date, the most ambitious and comprehensive observing campaigns internationally coordinated to investigate the water cycle in the Mediterranean (Ducrocq et al., 2014). In later years, new modelling capabilities and observational datasets were made available to the scientific community, while new results from interdisciplinary studies emerged. Such results also addressed fundamental questions on cyclone interactions with the Mediterranean Sea and aerosols, showing a strong effect of cyclones on the regional environment and its water cycle, in addition to their socioeconomic impact.

Scientific research in the broader field of Mediterranean cyclones is currently advancing rather asymmetrically. For instance, numerous studies have recently been devoted to tropical-like cyclones, known in the scientific literature as medicanes, a portmanteau of the words "Mediterranean hurricanes" (Emanuel, 2005; Miglietta, 2019). However, medicanes represent a very limited number of intense cyclones, which may not correspond to those with the greatest environmental and socio-economic impacts. In addition, the number of studies that focus on the western Mediterranean is higher compared to those focusing on the eastern Mediterranean or on African coasts. Aiming to the advancement of the broader field of Mediterranean cyclones as a whole, this article provides a review of the knowledge accumulated in the last decades on Mediterranean cyclones in three main sections: Sect. 2 focuses on the climatology of Mediterranean cyclone tracks, their relationship to large-scale atmospheric circulation and their future trends. In Sect. 3, we discuss cyclone dynamics, particularly the physical processes that turn cyclones into severe storms. Gaining insights into these processes, Sect. 4 presents the different subtypes of Mediterranean cyclones. In this section, medicane dynamics and fu- ture trends are discussed in detail. In Sect. 5, we review current challenges in modelling and forecasting Mediterranean cyclones, while Sect. 6 provides an overview of the variety of high-impact weather conditions produced by cyclones, along with the physical processes involved. Finally Sect. 7 identifies open questions, proposes new research priorities on the topics that need further investigation, and highlights the observational and modelling approaches that will contribute in this direction.

\section{Climatological perspective of Mediterranean cyclones}

Mediterranean cyclones represent a very distinct element of the global climate system. Several studies between the 1950s and 1960s brought to light the high frequency of cyclogenesis in the Mediterranean (Pisarski, 1955; Petterssen, 1956; HMSO, 1962; Radinović, 1965). Notably, the analysis of Petterssen indicated the Mediterranean as the most active cyclogenetic area in the Northern Hemisphere in winter. In later years, the effort to unveil the climatological aspects of Mediterranean cyclones continued through the use of gridded datasets and objective identification methods. This section provides an overview of the main results of these efforts, focusing on the climatology of cyclone tracks, the different cyclone types that develop in the region and their future trends.

\subsection{Spatial variability in and seasonal cycle of Mediterranean cyclone tracks}

Alpert et al. (1990) performed one of the first studies focusing on the climatology of Mediterranean cyclones. The authors used a 5-year (1983-1987) climatological dataset of ECMWF operational analyses with a grid spacing of $2.5^{\circ} \times 2.5^{\circ}$ and a time interval of $12 \mathrm{~h}$. The monthly variations in cyclonic tracks in the entire Mediterranean showed a pronounced seasonal cycle. Cyclone occurrences are more frequent in winter, with tracks located along the northern and central part of the Mediterranean basin, while in summer, cyclone occurrences become frequent over North Africa. In later years, a high number of studies were devoted to producing a climatology of cyclones, with various results on the spatial and temporal variability in their tracks (e.g. Trigo et al., 1999; Maheras et al., 2001; Campins et al., 2000; Picornell et al., 2001; Bartholy et al., 2009; Flocas et al., 2010; Campins et al., 2011). As an example, Fig. 1 shows the spatial distribution and the seasonal cycle of cyclones but only for the most intense systems (about 30 cyclones per year), defined by the geostrophic circulation in their centres exceeding a threshold of $7 \times 10^{7} \mathrm{~m}^{2} \mathrm{~s}^{-1}$ (Homar et al., 2006). Most of the intense cyclones in Fig. 1 are formed in the northwest Mediterranean and more precisely within the Tyrrhenian and Adriatic seas, whereas cyclogenesis is frequent in the vicinity of the Alps (see Sect. 3.4). Another branch of cyclone 


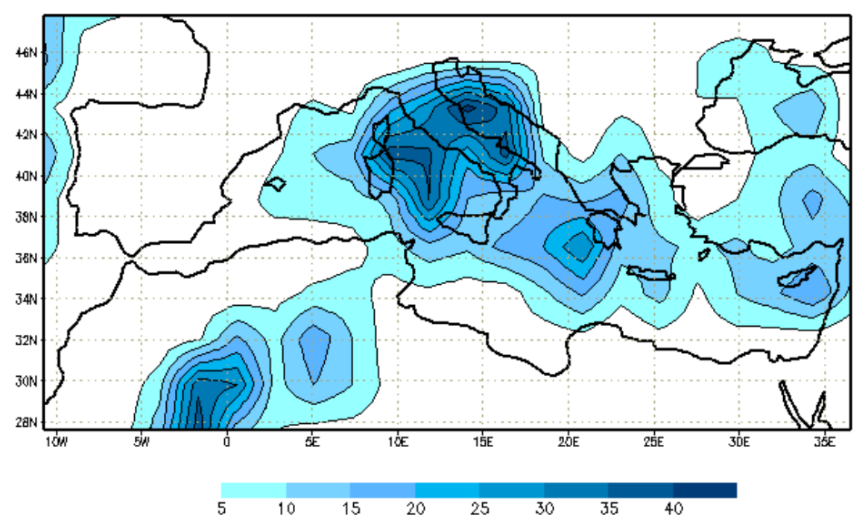

Figure 1. Number of intense cyclones over the 45 years of the ERA40 period at mature stage per squares of $2.25^{\circ} \times 2.25^{\circ}$. Reprinted from Homar et al. (2007).

tracks departs close to the Atlas Mountains and enters the central part of the basin from the southwest, while other areas of high track density are located in the Ionian, Aegean and Black seas, as well as Levantine basin close to Cyprus.

Regarding the seasonal cycle of intense cyclones, there is a substantial agreement among studies that cyclogenesis is more frequent in winter and exhibits a flat minimum in summer (Campins et al., 2011; Lionello et al., 2016; Flaounas et al., 2018). More precisely, winter cyclones that develop in the Gulf of Genoa are often deep systems, and, once formed, they travel southeastwards, affecting with high-impact weather the Alpine region, the Italian Peninsula, the Adriatic Sea, and the central and eastern part of Mediterranean Sea (Horvath et al., 2008; Ulbrich et al., 2012; Reale and Lionello, 2013). Cyclones around Cyprus, usually called Cyprus Lows (e.g. Alpert et al., 1990; Flocas et al., 2010; Ulbrich et al., 2012), play a fundamental role in shaping the variability in precipitation in the eastern Mediterranean basin (Goldreich, 2003; Saaroni et al., 2010; Hochman et al., 2018). Autumn and spring are transitional periods for cyclogenesis frequency, sharing to some extent similar characteristics with the climatological spatial variability of winter. However, in spring, cyclone occurrence shows a distinct local maximum in northwest Africa, at the leeward side of the Atlas Mountains corresponding to a favourite area of spring cyclogenesis, from which cyclones travel eastwards, along the northern Africa coastlines, towards the Middle East (Egger et al., 1995; Thorncroft and Flocas, 1997). Finally, in summer, several shallow cyclones may occur close to Cyprus, in the Sahara, the Iberian Peninsula, the Gulf of Cadiz, the Gulf of Genoa and the Algerian Sea. Although identified as cyclones, these systems do not correspond to organised, mesoscale wind vortices. Such thermal shallow depressions, confined to the atmospheric boundary layer, should not be confused with active and deeper cyclones. Indeed, the summer position of the polar jet renders upper-tropospheric systems less likely to intrude on the Mediterranean and trigger cyclogenesis (Flaounas et al., 2018).

The actual number of Mediterranean cyclones varies significantly among climatological studies from hundreds to even thousands of occurrences per year. Such high uncertainty on the number of tracks in the Mediterranean is related to the sensitivity of the cyclone tracking methods, the criteria used to identify cyclones and the properties of the input dataset (e.g. grid spacing, temporal interval of fields). It is thus not surprising that the actual number of Mediterranean cyclones and the characteristics of their tracks are highly dependent on the cyclone tracking method (Neu et al., 2013). For instance, Lionello et al. (2016) and Flaounas et al. (2018) found substantial differences in the number of cyclone tracks when comparing the outputs of different cyclone tracking methods. However, consensus on the spatial and seasonal variability in the tracks is high considering intense Mediterranean cyclones. On the other hand, results for the relatively weak cyclones present high variability, even their seasonal cycles of occurrence (Campins et al., 2011; Lionello et al., 2016). Consequently, new results on the climatological analysis of Mediterranean cyclone tracks should always be discussed along with the physical and technical criteria of the various methods used to identify and track cyclone centres. In addition, it is imperative to compare new results with those of the rich bibliography on the climatology of Mediterranean cyclone tracks. This is a crucial issue not only for the effective advancement of the state of the art but also for the community to contextualise the existing climatological results to the dynamics and physical aspects of the included cyclones.

\subsection{Large-scale circulation and Mediterranean cyclones}

In the Northern Hemisphere circulation, especially for winter, teleconnections account for a significant portion of the atmospheric variability (e.g. Nigam and Baxter, 2015). The most prominent teleconnection pattern, in terms of influence on the Euro-Mediterranean climate, is the North Atlantic Oscillation (NAO), which has a wide spectrum of scales ranging from the intraseasonal to the decadal timescales. Nevertheless, different atmospheric oscillations coexist with each other, namely the Arctic Oscillation (AO), the East Atlantic (EA), Scandinavian (SCAN) and East Atlantic-West Russian (EAWR) patterns. These evolve and interact simultaneously, thus increasing the complexity of their impacts on the regional climate (e.g. Krichak and Alpert 2005a, b; Trigo et al., 2008).

It is largely accepted that the NAO and the Atlantic storm track are closely related (e.g. Hurrell and van Loon, 1997; Woolings and Blackburn, 2012): positive NAO phases are related to northward-shifted and intensified storm tracks, while negative NAO phases are related to more cyclones in the western Mediterranean and southern Europe (Raible, 2007; 
Pinto et al., 2009). The latter was confirmed by Nissen et al. (2010), who found more cyclones crossing the Mediterranean during a negative NAO phase (approx. 20\%) compared to its positive phase. On the other hand, they found that positive NAO and EAWR are both associated with strong wind events in the eastern Mediterranean, while the positive EAWR phase is connected with a decrease in wind tracks in the central Mediterranean. More recently, Hofstätter and Blöschl (2019) found that Vb events (typically referred as low-pressure systems propagating through northern Italy, from the western Mediterranean Sea to northeastern Europe) tend to occur during negative NAO phases, while NAO and $\mathrm{AO}$ appear to be synchronised with $\mathrm{Vb}$ clustering (i.e. successive $\mathrm{Vb}$ cyclones), which is more frequent when both $\mathrm{NAO}$ and $\mathrm{AO}$ are negative. On the other hand, $\mathrm{Vb}$ cyclones were less frequent from 1988 to 1997 when a sustained positive phase of both NAO and AO prevailed.

Storm track and NAO studies on Mediterranean cyclones have mainly focused on winter, when most intense cyclones are expected to occur. However, intense Mediterranean cyclones have also taken place in summer, and more studies are needed to address this issue. Dong et al. (2013) studied the summertime variability in the North Atlantic storm track and found that its dominant mode is closely associated with the negative phase of summer NAO. During this summer mode, a southward shift of the Atlantic storm track is linked with a weaker Mediterranean storm track and reduced precipitation over southern Europe in contrast to its corresponding winter mode, in which the Mediterranean storm track is strengthened when the Atlantic jet is shifted south. Even though the summer NAO is weaker and confined to northern latitudes compared to its winter counterpart, it significantly affects precipitation in the Mediterranean which is anomalously wet during high summer NAO (Bladé et al., 2012) and relates to the relative cooling of the surface and lower troposphere, enhanced meridional circulation, and cloudiness over the eastern Mediterranean (Chronis et al., 2011).

From an energetic perspective, Nasr-Esfahany et al. (2011) and Rezaeian et al. (2016) selected critical positive and negative NAO winter months spanning 1950-2011. They showed that there is energy transfer from the western Atlantic and northern Europe to the Mediterranean region, which is stronger during the negative phase of NAO. Conversely, during the positive phase, more energy is radiated from the central Mediterranean towards the Red Sea and North Africa. This indicates that while in the negative phase, the Mediterranean is more affected by the North Atlantic storm track, and it forms an independent centre of action in the positive phase radiating energy southeastwards. Wave activity is expected to spread to the Mediterranean storm track through an equatorward refraction process from the North Atlantic wave packets toward the North African and South Asian regions (Hakim, 2003). According to that, Ahmadi-Givi et al. (2014), studying the propagation of Rossby wave packets linking the North Atlantic and Mediterranean storm tracks in winter
2004/05, demonstrated the presence of energy flux on the upstream and downstream sides of the troughs associated with the wave packets. This suggests that the downstream wave packet over the Mediterranean develops by receiving energy from the upstream wave packet in the North Atlantic which at the same time weakens.

\subsection{Current and future trends of Mediterranean cyclones}

The Mediterranean is considered as particularly vulnerable to climate change (e.g. Giorgi, 2006; Solomon et al., 2007). In these regards, cyclones play a crucial role in climate variability and its extremes. Several studies used global (GCMs) and regional climate models (RCMs) to analyse the future trends of cyclone occurrences and intensity (Lionello et al., 2002; Bengtsson et al., 2006; Lionello and Giorgi, 2007; Raible et al., 2010; Zappa et al., 2013; Nissen et al., 2014; Zappa et al., 2015; Hochman et al., 2018; Reale et al., 2021). Both modelling approaches have been shown to reproduce realistic cyclone climatologies in the region. For instance, Zappa et al. (2015) showed that CMIP5 GCMs are able to capture Mediterranean storm tracks and cyclone-related precipitation in the region. However, Flaounas et al. (2013) showed that the use of coarse horizontal resolution (of the order of $2^{\circ}$ ) is detrimental for the reproduction of the relatively small-scale cyclones in the region. In this context, the MED-CORDEX initiative (Ruti et al., 2016) has been beneficial to climate studies by downscaling CMIP5 simulations through coupled and uncoupled ocean-atmosphere RCMs.

Flaounas et al. (2018) used a suite of seven coupled and uncoupled RCMs laterally forced by ERA-Interim reanalysis (Dee et al., 2011) and showed that all models capture the main climatological characteristics of cyclone tracks. Furthermore, RCM simulations were shown to provide valuable detailed information on cyclone climatology with respect to the fine geographical features of the region that include sharp land-sea transitions, narrow maritime areas and mountain chains. Reale et al. (2021) found that the Med-CORDEX ensemble of coupled regional climate system models (RC$\mathrm{SMs}$ ) performs realistic reproduction of the main features of Mediterranean cyclone tracks, including areas of origin, path direction, maximum adjusted deepening rate, size, seasonality and maximum depth for the last part of the 20th century. However, a considerable spread was found among the RCMs, especially concerning the number of cyclones crossing the area. Reale et al. (2021) suggested that this spread is mainly related to different large-scale forcings of RCSMs and potentially to different RCM parameterisations.

Among the first studies to address future changes in Mediterranean cyclones, Lionello et al. (2002) used the ECHAM4 global model forced by the doubled $\mathrm{CO}_{2}$ emissions experiment and found a diminished overall cyclone occurrence in the region. This overall reduction in cyclones was also proposed by Raible et al. (2010) and Nissen et al. (2014) 
who used A2 and B2 Special Report on Emissions Scenarios to show a weaker rate of cyclone occurrences towards the end of the 21st century. Similar results were also confirmed by more recent studies that used simulation ensembles from CMIP5 (e.g. Zappa et al., 2015; Hochman et al., 2018), while the reduction in cyclones has been characterised as "robust" by the recent IPCC AR6 report (IPCC, 2021). Raible et al. (2010) attributed changes in cyclone intensity and frequency of occurrence to changes in baroclinicity, static stability, transformation from eddy kinetic energy to kinetic energy of the mean flow, and stationary wave activity particularly in the western Mediterranean and along the coastline of North Africa. In addition, Nissen et al. (2014) suggested a shift of NAO to a more positive state, which can explain $10 \%-50 \%$ of the negative cyclone trend over the Gulf of Lion. This reduction of cyclone occurrence comes in accordance with the climatological studies of Trigo et al. (2000) and Flocas et al. (2010), who showed similar negative trends in reanalyses of the recent past decades.

In fact, recent past reanalysis shows that a climatological reduction of Mediterranean cyclone occurrences is consistent with an overall precipitation decrease in the region (Trigo et al., 2000). Such a relationship between cyclones and regional precipitation was also found in future climate. Reale et al. (2021) recently used a Med-CORDEX ensemble of seven regional coupled system models that downscaled CMIP5 RCP8.5 scenarios. They showed an overall increase (decrease) in cyclone-related wind intensity and precipitation. However, the non-negligible spread between MedCORDEX simulations on the future trends of cyclone deepening rates, seasonality, and cyclone-related wind and precipitation patterns, especially over the Ionian Sea and Levantine basin, highlights the necessity for ensemble approaches and model improvements

\section{Mediterranean cyclone dynamics}

Mediterranean cyclones are mostly developed by baroclinic instability and affected by diabatic processes similarly to other extratropical cyclones in the mid-latitude storm track. However, Mediterranean cyclones are further influenced by the abrupt land-sea transitions and by the prominent mountain chains that surround the basin. In addition, due to its location between the tropics and the mid-latitudes, the Mediterranean basin has the potential of hosting subtropical or even tropical-like storms. In this section, we review recent advancements in understanding Mediterranean cyclone dynamics, the wide variety of involved atmospheric processes and their complex interactions with topography.

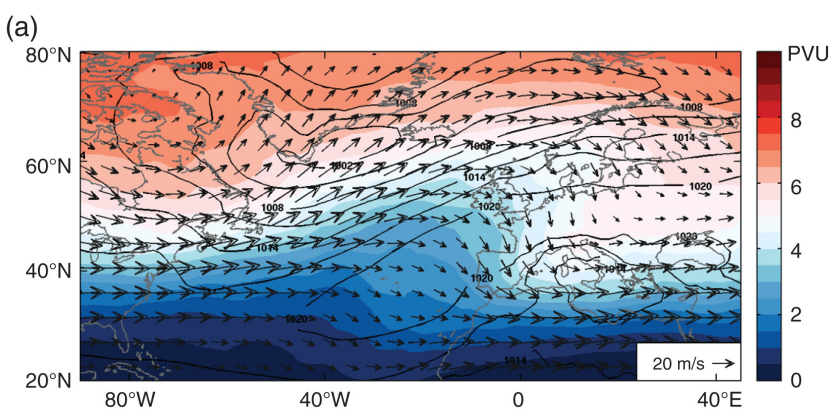

(b)

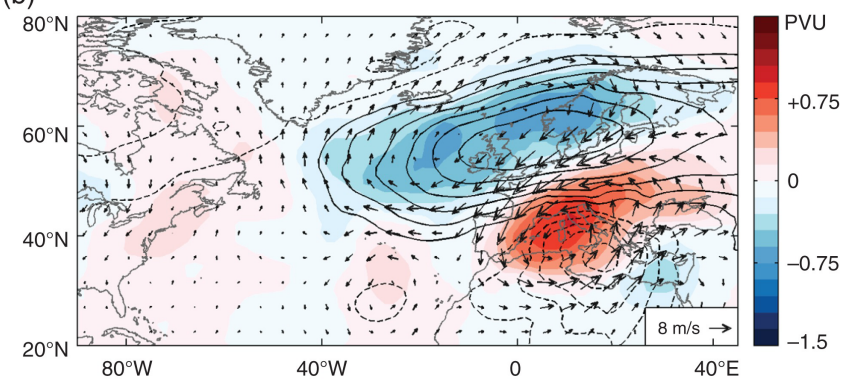

Figure 2. (a) ERA-Interim average fields of sea-level pressure (black contours), PV (shaded) and wind (arrows) on the $330 \mathrm{~K}$ isentropic surface, centred at the time of maximum intensity of the 200 Mediterranean cyclones. Panel (b) is like (a) but for monthly anomalies (contours every $1 \mathrm{hPa}$, dashed for negative and solid for positive values). Reprinted from Raveh-Rubin and Flaounas (2017).

\subsection{Large-scale forcing of Mediterranean cyclogenesis}

The formation of intense Mediterranean cyclones is typically related to southward deviations of the polar jet that cause air masses with high potential vorticity (PV) to intrude into the Mediterranean region. This triggers baroclinic instability similarly to extratropical cyclones over open oceans (Flocas, 2000; Trigo et al., 2002; Nicolaides et al., 2006; Fita et al., 2007; Claud et al., 2010; Kouroutzoglou et al., 2011; Flaounas et al., 2015). Raveh-Rubin and Flaounas (2017) showed that Rossby wave breaking (RWB) is a common precursor of Mediterranean cyclogenesis. Figure 2 shows composite fields of PV and sea-level pressure (SLP) at the time of the mature stage of 200 intense Mediterranean cyclones. A characteristic of RWB in Fig. 2a is an amplified ridge in the mid-latitude jet upstream of the Mediterranean (depicted in Fig. $2 b$ by negative PV anomalies overlaid by positive SLP anomalies) and the intruding stratospheric air masses downstream of the polar jet (positive PV anomalies in Fig. 2b). The consequent cyclogenesis is depicted in Fig. $2 b$ by negative SLP anomalies in the central Mediterranean basin.

Stratospheric air mass intrusions southward into the Mediterranean upper troposphere typically manifest as PV streamers (Prezerakos and Flocas, 1996; Homar et al., 2007; Claud et al., 2010; Flaounas et al., 2015). However, it is not uncommon for PV streamers to disconnect from the stratospheric high-PV reservoir eventually forming a PV cut-off 
(Homar et al., 2003; Porcù et al., 2007; Fita and Flaounas, 2018; Portmann et al., 2020). In fact, both PV streamers and cut-offs are common precursors for the development of deep cyclones, including medicanes (Tous et al., 2013; Miglietta et al., 2017). Portmann et al. (2021) showed that cut-offs in the western Mediterranean typically form in winter under anticyclonic RWB over Europe and subsequent cyclonic RWB on the cyclonic shear side of the subtropical jet (baroclinic life cycles as described in Thorncroft et al., 1993). However, several case studies illustrate the possible association of both RWB types with Mediterranean cyclogenesis (e.g. Flocas, 2000; Argence et al., 2008; Raveh-Rubin and Wernli, 2016; Raveh-Rubin and Flaounas, 2017; Portmann et al., 2020; Givon et al., 2021). When intruding into the Mediterranean, the polar jet can merge with the subtropical jet (Prezerakos et al., 2006), similar to the dominant polar jet events described in Winters et al. (2020), in which the polar jet merges with the subtropical jet near the climatological location of the latter. This superposition is also expected to further accelerate both jets (Martius and Wernli, 2012; Raveh-Rubin and Wernli, 2015). Consistently, Flaounas et al. (2015) suggested that the cyclogenesis environment is characterised by strong horizontal shear that, in turn, forces Mediterranean cyclones to follow a common baroclinic cyclone life cycle. Compared to cyclones over open oceans, Mediterranean cyclogenesis takes place across lower-tropospheric temperature gradients where baroclinicity is partly due to a land-sea-surface temperature contrast (Lionello et al., 2006; Trigo et al., 2002). Therefore, the low-level atmospheric baroclinic forcing to the surface cyclone is expected to be comparably weak. Indeed, Flocas (2000) used PV inversion diagnostics to show that surface temperature anomalies contributed the least to the surface circulation of an intense Mediterranean cyclone over the Aegean Sea with respect to mid-tropospheric and upper-tropospheric PV anomalies. The latter PV anomalies were shown to dominate the development of the cyclone; however, more studies are needed to thoroughly address this issue.

\subsection{Airstreams and fronts}

The organisation of air masses within the cyclone is key for determining the cyclone life cycle and its variable impact. The conceptual conveyor belt model integrated by Carlson (1980) for extratropical cyclones includes three cyclonerelative airstreams, namely the warm conveyor belt (WCB), a moist poleward ascending airstream, the cold conveyor belt (CCB), flowing in the lower troposphere from the cold side of the warm front cyclonically towards the cyclone centre, and the dry air intrusion (DI), which descends slantwise into the cold sector behind the cold front. Based on five case studies, Raveh-Rubin and Wernli (2016) provided a schematic that presents the main features of Mediterranean cyclone dynamics including airstreams, frontal structures, wind gusts and precipitation. This schematic is shown in Fig. 3.

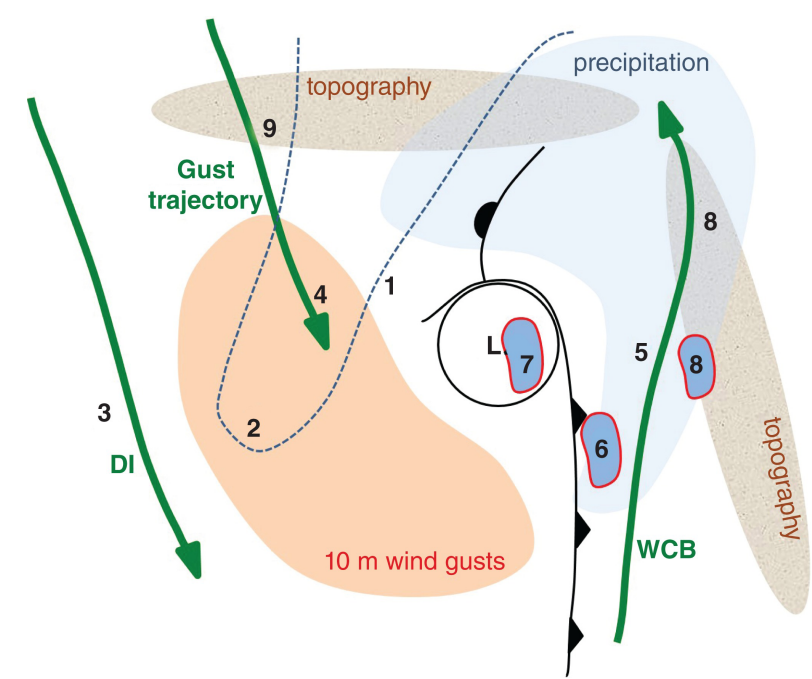

Figure 3. Schematic illustration of possible features related to combined precipitation and wind impact of a cyclone in the Mediterranean, based on the five events studied in Raveh-Rubin and Wernli (2016). Note that this schematic does not represent any individual event but rather summarises the variable possible features of importance. The cyclone centre is denoted by the letter "L", accompanied by a cold and a warm front. Shading shows areas with precipitation impact (light blue) and with $10 \mathrm{~m}$ gust impact (light red). Areas with convection (and thus co-located precipitation and wind gust impact) are shaded blue and encircled by a red line. High topography is represented by grey regions. The $320 \mathrm{~K} 2$-PVU contour is shown as a dashed line, and typical WCB, DI and gust trajectories are denoted as green arrows. The numbers mark the location of the following: (1) a prominent upper-level feature (PV streamer/trough/ridge), (2) tropopause fold and downward momentum transfer, (3) DI trajectories around high gusts, (4) low-level gust trajectory, (5) WCB slantwise ascent associated with precipitation, (6) convective precipitation at cold front, (7) convective precipitation in cyclone centre, (8) orography enhancing precipitation (and/or convection), and (9) orography accelerating gust trajectories. Reprinted from Raveh-Rubin and Wernli (2016) with permission.

In a first methodological approach to place Mediterranean cyclones in the context of the general conveyor belt model, Ziv et al. (2010) indeed identified the major airstreams in eight representative mature cyclones, although with limited spatial extent compared to oceanic systems. Compositing the 200 most intense cyclones in a 20 -year period, Flaounas et al. (2015) found an overall frontal structure and the existence of strongly ascending WCB trajectories (depicted as feature 5 in Fig. 3) and stratospheric DIs (feature 3 in Fig. 3) in almost all cyclones, respectively ahead and behind the PV streamer (feature 1 in Fig. 3). WCBs have been specifically identified in a number of case studies in the Mediterranean, showing a large case-to-case variability with regard to their spatial extent and contribution to precipitation mainly to the east and north of the cyclone (Flaounas et al., 2016, Raveh-Rubin and Wernli, 2016). Climatologically, Pfahl et 
al. (2014) found that WCBs are associated with 50\%-60\% of extreme precipitation events in the Mediterranean (blue area in Fig. 3), while Flaounas et al. (2018) highlighted the key role of WCBs, along with deep convection (features 6-8 in Fig. 3), for rainfall intensities. In terms of strong winds, it is only recently that Brâncuş et al. (2019) showed the possible presence of sting jets (Clark et al., 2005; Clark and Gray, 2018) in Mediterranean cyclones. Raveh-Rubin and Wernli (2016) identified DI trajectories around five Mediterranean cyclones, encircling the region of the highest winds (feature 4 in Fig. 3). In one case, DIs reaching the cold front were co-located with convective wind gusts and precipitation. On average, cold fronts trailing from Mediterranean cyclones are sharper and longer when they are immediately followed by a DI, similar to cold fronts trailing from extratropical cyclones over the main ocean basins (Catto and RavehRubin, 2019). For oceanic fronts, a general correlation exists between front intensity and precipitation such that stronger frontal precipitation occurs for fronts that are followed by DIs compared to fronts that are not. However, when Mediterranean cold trailing fronts are followed by DIs, frontal precipitation is weaker on average despite the stronger front intensity. This is likely a result of the limited moisture supply into the Mediterranean from the south, compared to the North Atlantic or Pacific oceans, and/or the suppression of convection by the DI.

\subsection{Role of diabatic processes in cyclone development}

After cyclones are formed, baroclinic instability may further intensify surface cyclonic circulation (e.g. Prezerakos et al., 2006; Lagouvardos et al., 2007) and in parallel may favour convection in cyclones' centres due to upper-level forcing. Latent heat release is thus expected to deepen cyclones' central SLP and to intensify cyclonic circulation through diabatically produced PV anomalies in the lower troposphere. The synergistic forcing of baroclinic and diabatic processes to cyclone development is consistent with previous results of Homar et al. (2002) and Fita et al. (2006). The authors applied factor separation techniques to 11 cases of intense Mediterranean cyclones and showed that the systems' intensification was the result of interactions between upper-tropospheric PV streamers and low-level diabatically produced PV. Such interactions have been also analysed in medicane cases by Cioni et al. (2016) and Fita and Flaounas (2018). The latter showed that, in the December 2005 case, the PV streamer intruding over the northwest African coast triggered cyclogenesis, but the sharp deepening of the cyclone was related to convection triggered by the PV streamer. A similar scenario was documented in the well-studied medicane that took place in September 2006: the medicane presented a clear PV-tower structure that was directly related to deep convection (Miglietta et al., 2017), while the explosive intensification was due to the interaction of convection with the upward forcing induced by the PV streamer (Chaboureau et al., 2012).

In a recent analysis, Flaounas et al. (2021) applied piecewise PV inversion to two different components of PV for 100 intense Mediterranean cyclones at the time of their mature stage. These PV components corresponded to the conserved, adiabatically transported PV (dominated by the upper-tropospheric PV streamer or cut-off) and to the nonconserved, diabatically produced PV (dominated in most cases by convection). Figure 4 shows in a scatterplot the contribution of the two PV components to relative vorticity at $850 \mathrm{hPa}$ for each of the 100 cyclones. Results show that diabatic and baroclinic forcings are both typically involved in cyclones' mature stage. Furthermore, Fig. 4 shows that the more baroclinically driven a cyclone is, the less it is expected to be intensified by diabatic processes and vice-versa. Such a negative relationship between baroclinic and diabatic forcing is still an open question and needs to be addressed with additional studies. For instance, numerical sensitivity tests should investigate the possible role of convection in producing negative PV anomalies in the upper troposphere and therefore reducing the contribution of upper-tropospheric PV streamers to the development of surface cyclones. In fact, only a small fraction of the 100 cyclones in Fig. 4 can be considered as being dominantly driven by diabatic forcing (upper end of the scatter plot distribution in Fig. 4). This is consistent with climatological analysis by Galanaki et al. (2016) and Flaounas et al. (2018) who used lightning observations to show that it is only about one third of the most intense Mediterranean cyclones that presented deep convection in their centre during their mature stage. In such cases, convection is expected to significantly contribute to the development of the cyclones and even to play a leading role in their intensification (Kouroutzoglou et al., 2011, 2012; Raveh-Rubin and Wernli, 2016). In these regards, the availability of humidity within the Mediterranean and from remote sources, the air-sea interactions, and the underlying sea surface temperatures (SSTs) are expected to be crucial for the intensity of convection and its role in cyclone development (Miglietta et al., 2011; Romaniello et al., 2015; Messmer et al., 2017; Pytharoulis, 2018; Flaounas et al., 2019).

\subsection{Role of the orography in cyclone dynamics}

The Mediterranean region presents unique topographical characteristics, with pronounced mountain chains in northwest Africa and in a long zonally extended area that encompasses the northern side of the basin. Climatological studies clearly showed that Mediterranean cyclogenesis is favoured close to and to the south of mountains, suggesting that the distribution and frequency of cyclones in the Mediterranean is markedly modulated by the orography (Campins et al., 2011; Buzzi, 2012; Lionello et al., 2016). Although a primary baroclinic disturbance (synoptic-scale trough or cyclone) is almost invariably required to provoke cyclogenesis, it is not 


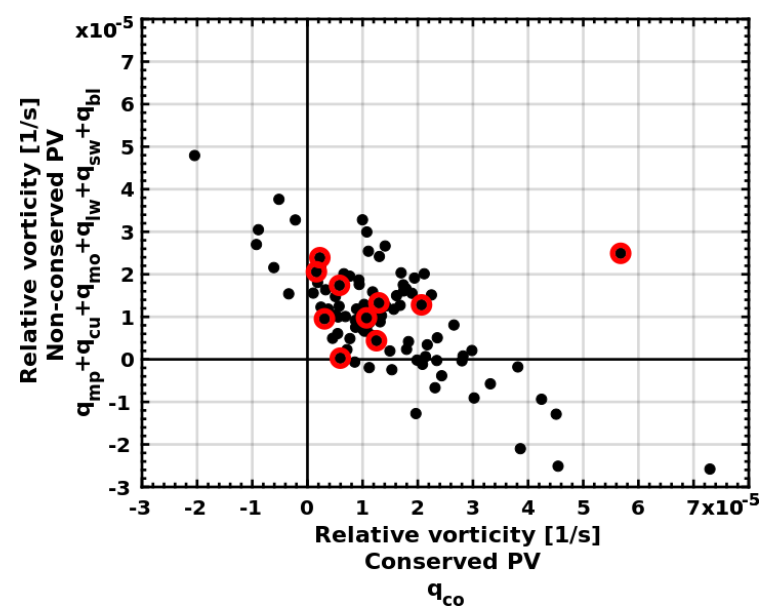

Figure 4. Scatterplot relating the contribution of different PV sources to the relative vorticity at $850 \mathrm{hPa}$, in the centre of 100 intense cyclones: contributions of conserved, adiabatically transported PV are shown on the $x$ axis and non-conserved, diabatically produced PV are shown on the $y$ axis. Red circles depict 10 medicane cases. Reprinted from Flaounas et al. (2021).

uncommon that its interaction with the orography favours cyclogenesis in specific preferred locations (Fantini and Davolio, 2001, and references therein) and determines the characteristics of the "secondary" Mediterranean cyclone (Buzzi et al., 2003; Jansa et al., 2014), which often has the characteristics of a lee cyclone (Lin, 2007). A detailed review of Alpine cyclogenesis theories and models has been recently presented by Buzzi et al. (2020).

Although many intense Mediterranean cyclones are not necessarily the fruit of lee cyclogenesis, this is a distinct feature with respect to mid-latitude cyclones that drew most of the research efforts in the last decades of the last century. A widely accepted conceptual model describes lee cyclogenesis as a two-step process (Buzzi and Tibaldi, 1978). First, as a synoptic-scale trough approaches the mountain chain, the cold air advection is retarded on the upwind slopes, while on the lee side a positive thermal anomaly and rapid pressure drop is produced, along with wind acceleration (feature 9 in Fig. 3). Second, as the primary wave decouples and crosses the obstacle, baroclinic instability, modified by the presence of the mountain, dominates and leads to a secondary (lee) cyclone that organises itself, acquiring a larger (synoptic) scale (McTaggart-Cowan et al., 2010; Tsidulko and Alpert, 2001), while in intense cases diabatic processes like latent heat release, heat surface fluxes and low-level filaments of PV generated from the airflow interaction with the mountains (PV banners; Aebisher and Schär, 1998) can contribute to the formation of low-level PV maxima. Considering this phase by means of the PV-thinking framework, baroclinic cyclone growth occurs as an overlapping and phase locking between the upper-level PV streamer and the lower-level PV (or thermal) anomaly, as in type-B cyclogenesis (Pettersen and Sme- bye, 1971). Thus, orography constantly affects cyclonic systems in the region, depending on the development stage and location of cyclone centres. Direct effects include lee cyclogenesis and deepening close to mountain chains, while indirect effects include contribution to the development of the cyclone through the interaction of the atmospheric flow and cyclones themselves.

\section{Subtypes of Mediterranean cyclones}

Several studies identified a large variety of cyclone subtypes. The criteria to identify a cyclone subtype are of different natures: geographical origin, cyclogenesis processes, deepening rate, etc. Among these subtypes, medicanes have undeniably attracted the most attention in the recent past. Indeed, a large part of the bibliography has been devoted to their dynamics and climatological aspects. Therefore, in this section, we first outline the climatological aspects of the different cyclone subtypes that were specifically addressed in past and recent studies, and then we focus on medicanes. In particular, we discuss their physical definition, potentially unique dynamics and future trends in the context of climate change.

\subsection{Cyclones of similar physical characteristics}

\subsubsection{Cyclones forming over the Atlantic Ocean}

It is not uncommon for cyclones forming over the Atlantic to intrude into the Mediterranean region and cause substantial damage (Nissen et al., 2010). Such an example is storm Klaus that intruded into the Mediterranean in January 2009 (Liberato et al., 2011). In a more recent study, Lionello et al. (2016) used 14 different cyclone tracking methods from the IMILAST dataset (Neu et al., 2013) and showed that the Mediterranean cyclones that form within the Mediterranean represent $61 \%-85 \%$ of the total Mediterranean tracks.

\subsubsection{Medicanes}

The dynamics of known medicane cases are discussed in detail in Sect. 4.2. Regarding their climatology, several studies focused on tracking medicanes in multi-year datasets. However, the lack of a physical definition of medicanes produced different climatologies. The criteria used varied from subjective identification of tropical-like characteristics (Tous et al., 2013) to the application of cyclone phase-space analysis (Hart, 2003) and wind thresholds in high-resolution simulations (e.g. Cavicchia et al., 2014a). Recent studies used dynamical downscaling of ERA-Interim reanalysis (Gaertner et al., 2018; Ragone et al., 2018) and ERA5 reanalysis (Zhang et al., 2020; de la Vara et al., 2021) to identify medicanes in a climatological framework. Results showed rather large differences in their climatologies even among the same model simulations but using different parameterisations. In particular, the study of Gaertner et al. (2018) showed that medicane 
climatologies were sensitive to the wind speed criteria and thus to the model horizontal resolutions, while air-sea coupled models produced a seasonal shift to a winter frequency maximum compared to a maximum in autumn in uncoupled models.

\subsubsection{North African cyclones}

A high number of cyclones form on the leeward side of the Atlas Mountains. These fast-travelling systems are known as desert depressions (Pedgley, 1972) or "Sharav cyclones" (Winstanley, 1972), and, as discussed in the previous section, they present a clear climatological peak during spring time. Their formation over the arid areas of North Africa means Sharav cyclones have a low moisture content and are associated with dust storms (Alpert and Ziv, 1989; Egger et al., 1995; Saaroni et al., 1998; Bou Karam et al., 2010; Flaounas et al., 2015). Sharav cyclones are usually smaller and propagate faster than Mediterranean winter cyclones (Alpert and Ziv, 1989), and, due to their location, it is rather likely that the subtropical jet plays an important role in the dynamics of these systems (Prezerakos et al., 2006).

\subsubsection{Explosive cyclones}

An explosive cyclone, or weather bomb, is characterised by a strong deepening over a relatively short time range. For the Mediterranean, Kouroutzoglou et al. (2011) suggested a deepening rate of 20 and $14 \mathrm{hPa}$ in $24 \mathrm{~h}$ for the northern and southern Mediterranean, respectively. A broad range of processes of the upper and lower troposphere have been associated with the surface rapid deepening, including baroclinic forcing of PV streamers and latent heat release due to convection (Kouroutzoglou et al., 2012; Reale et al., 2019). In the Mediterranean, explosive cyclogenesis is a rather rare maritime phenomenon with five to six occurrences per year. These occurrences follow the same climatology of intense cyclones, presenting a maximum from November to March and typically taking place within northern locations up to $40^{\circ} \mathrm{N}$. More than half $(57 \%)$ of the cyclones that deepen explosively in the Mediterranean form within the region itself, with $43 \%$ in the western and $14 \%$ in the eastern Mediterranean (Kouroutzoglou et al., 2011; Reale et al., 2019). The rest of the systems that become explosive within the Mediterranean form outside the basin, and they mainly intrude into the region from the northwest, like storm Klaus or Gong (Liberato, 2014).

\subsubsection{Vb cyclones}

Vb cyclones (van Bebber, 1891) are described as lowpressure systems, with the highest occurrence in spring (Messmer et al., 2015), propagating northeastwards from the western Mediterranean Sea to Central Europe through northern Italy and leaving the Alpine ridge on the left. They are responsible for high-impact weather over the northern side of the Alpine range and Central Europe (Nissen et al., 2013). However, $\mathrm{Vb}$ cyclones are rather rare systems, constituting only $5 \%$ of all Central European cyclones, with about $2.3 \mathrm{Vb}$ appearances per year according to Messmer et al. (2015). Regarding the onset of a $\mathrm{Vb}$ event, the superposition of the polar jet stream and the subtropical jet stream over the western Mediterranean has been identified as a prominent feature (Hofstätter and Blöschl, 2019).

\subsubsection{Secondary (“daughter”) cyclones}

These systems refer to cyclones that form within the periphery of existing cyclones and have received separate interest. Their climatological characteristics have been investigated by Ziv et al. (2015) who found that the majority of Mediterranean cyclones are "daughters" of "parent" cyclones that are located in the Mediterranean itself. Parents of Genoa lows are mostly located east of their daughters, implying that cyclogenesis takes place within the northerly flow that crosses the Alps. Parents of Aegean Sea lows are located mainly west of the daughters, implying that the cyclogenesis takes place within the southerly flow ahead of the parent cyclones, i.e. within their warm sector or at the warm front of the parents. Further analysis by Saaroni et al. (2017) showed that over half of "daughters" formed on the frontal system of the "parent", one third on a separate frontal system and about $10 \%$ within the warm sector of the "parent" cyclone.

\subsection{The special case of medicanes: processes and classification}

Medicanes are identified in scientific literature as peculiar cases of Mediterranean cyclones. At first, they were distinguished due to their visual resemblance to tropical cyclones in satellite images. In fact, a Mediterranean cyclone was qualified as a medicane if it presented a central "eye" and spiral cloud bands around the core (Fita et al., 2007; Tous et al., 2013), thus sharing some visual similarities also to polar lows (Rasmussen and Zick, 1987). Such a phenomenological method suggested that medicanes are rare events occurring about 1-3 times per year. Several climatological studies applied various wind speed criteria and the cyclone phase-space analysis (Hart, 2003) to cyclone tracks from model simulations and reanalysis, confirming the rarity of medicanes (e.g. Cavicchia et al., 2014a; Picornell et al., 2014; Gaertner et al., 2018; Zhang et al., 2020). However, such studies used different methods and datasets, failing to reach consensus on the physical definition of medicanes. In contrast to typical tropical cyclogenesis, results from several case studies regard medicanes as baroclinic cyclones that evolve in the mature stage into vortices with structural characteristics similar to tropical cyclones, i.e. an axisymmetric, deep warm core, generally with a windless centre surrounded by strong winds. This is a consequence of the different environmental conditions in which medicanes and tropical cyclones de- 
velop. The first difference is the wind shear, which is weak near the tropics, while it systematically affects the Mediterranean region due to the southern deviations of the polar jet and the possible presence of the subtropical jet. The second is the SST. Tous et al. (2013) showed that the systems visually identified as medicanes develop over SSTs of $15-23^{\circ} \mathrm{C}$, well below the threshold of $26.5^{\circ} \mathrm{C}$ for tropical cyclones. In fact, the intrusion of very cold air in the upper troposphere may allow a high conversion efficiency of thermal energy into kinetic energy even in the presence of relatively low SST (Palmén, 1948). This mechanism is also relevant for the subset of tropical cyclones that develop at higher latitudes, over SSTs within the range of 22 to $26.5^{\circ} \mathrm{C}$ (McTaggart-Cowan et al., 2015). Finally, there is seasonality: cases qualified as medicanes present a distinct climatology in which their peak of occurrence is observed between late autumn and winter, i.e. slightly earlier compared to extratropical cyclones. This lag time is typically attributed to the warm SSTs that favour stronger convection in cyclones' centres than in winter.

Due to their rare occurrence, the mechanisms responsible for the development of medicanes were analysed in a relatively limited number of case studies. Typically, the beginning of medicane life cycles is similar. All systems tend to grow through the interaction of an upper-tropospheric PV streamer with a low-level baroclinic area, as typically expected for extratropical cyclones. Nevertheless, different evolutions can be identified during maturity when baroclinic forcing, air-sea interactions and convection may all play an important role in cyclone development (Moscatello et al., 2008; Flaounas et al., 2021). Based on a limited number of cyclone cases identified as medicanes, Miglietta and Rotunno (2019) recently categorised medicanes in three main representative groups with similar dynamical processes during their mature stage (a similar classification was provided recently in Dafis et al., 2020):

- Group 1. Baroclinic instability plays an important role throughout the cyclones' lifetime, and warm seclusion is sufficient to explain the presence of the warm core; nevertheless, most of their intensification can be attributed to convection. Fita and Flaounas (2018) analysed the medicane of December 2005 and showed that the system presented a clear frontal structure, in which the cloudless "eye" was a result of DIs, similarly to mid-latitude storms. Convection was relevant to cyclogenesis and was responsible for the rapid intensification of the system. In contrast, convection was weak during the mature phase of the medicane when the system was propagating in phase with an upper-tropospheric PV cut-off.

- Group 2. Baroclinicity is relevant only in the initial stage, and, as for tropical cyclones, the theory of windinduced surface heat exchange (WISHE; Emanuel, 1986; Rotunno and Emanuel, 1987) can explain their intensification through a positive feedback between latent heat release and air-sea interactions. However, WISHE may only take place after the occurrence of tropical transition, i.e. after organised convection near the cyclone centre is capable of sustaining the vortex (Davis and Bosart, 2004). For such medicanes, the vertical thermodynamic structure is similar to that of tropical cyclones, as presented in Fig. 5a for the case of October 1996 (Mazza et al., 2017), and very different from that of a cyclone of group 1 (December 2005 case in Fig. 5b). Medicane Rolf (6-9 November 2011) is another characteristic example: Miglietta et al. (2013) and Dafis et al. $(2018,2020)$ showed that deep convective clouds occurred mainly during the intensification period, while lightning activity was mostly pronounced about $1 \mathrm{~d}$ before the maximum cyclone strength. This reveals that the spatial and temporal distribution of deep convection and lightning activity is more similar to those of tropical cyclones than to intense Mediterranean extratropical cyclones. Romaniello et al. (2015) showed a significant sensitivity of model simulations to the SST field (weaker cyclone for colder SST).

- Group 3. This group includes smaller-scale vortices that develop within the circulation associated with a synoptic-scale cyclone, as in the case of 24-26 September 2006. The latter cyclone is paradigmatic of the different roles that orography can play in their life cycle, either favouring cyclogenesis (in the lee of the Atlas Mountains in that case) or triggering convection near the system during the interaction with an upper-level PV streamer just before the tropical transition (Moscatello et al., 2008; Chaboureau et al., 2012). A more recent example concerns medicane Qendresa (7-8 November 2014). Bouin and Lebeaupin-Brossier (2020) showed that the deepening and tropical transition of Qendresa, initially having developed as an extratropical cyclone, are the result of the synergy between baroclinic and diabatic processes, identifying, as did Pytharoulis et al. (2018), a strong control of SST over the cyclone intensity. Conversely, Carriò et al. (2017) stressed the importance of the upper-level dynamics to support the tropical transition of the system. In this case, latent heat release and surface heat fluxes, as individual processes, seem to be of secondary importance.

Flaounas et al. (2021) highlighted the need to objectively quantify the relative contribution of baroclinic and diabatic processes to the development of medicanes, showing that both play an important role in the mature stage of several known cases of medicanes. The latter considerations for classification are not unique to hybrid cyclones, such as medicanes, but can be extended to Mediterranean extratropical cyclones, considering that sea surface fluxes and latent heat release can significantly modify the cyclone evolution even when baroclinic instability is the main forcing. 

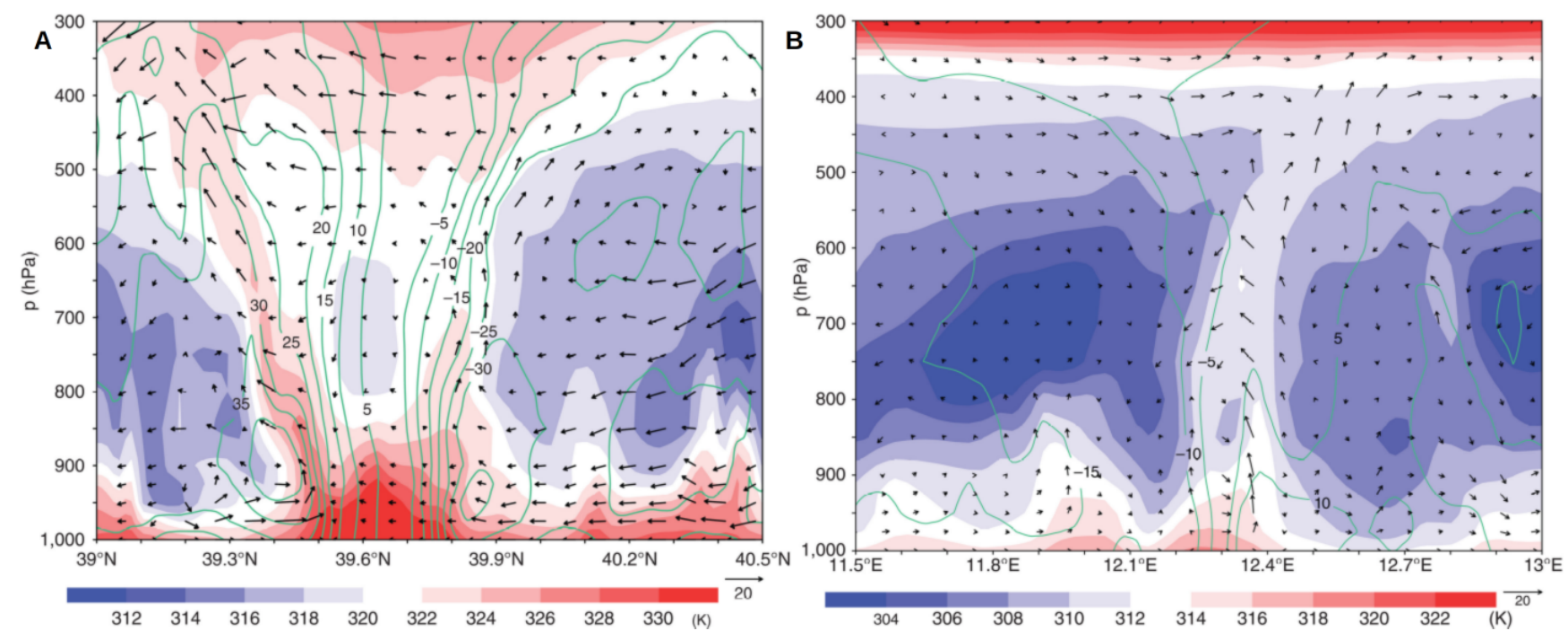

Figure 5. (a) The October 1996 case: vertical cross-section of $\theta_{\mathrm{e}}$ (colours), storm-relative winds (vectors) and absolute momentum (lines, contour interval $=5 \mathrm{~m} \mathrm{~s}^{-1}$; zero not shown) near the cyclone centre (longitude $\left.=12.45^{\circ} \mathrm{E}\right)(\mathrm{WRF}$ model run, $3 \mathrm{~km}$ grid spacing) at 10:00 UTC on 9 October 1996; (b) like in (a) but for the December 2005 case (latitude $=34.1^{\circ} \mathrm{N}$; 06:00 UTC on 15 December 2005). The wind vectors are drawn every five grid points in the horizontal. Typical tropical cyclone features can be identified, such as upward motion along isosurfaces of absolute momentum, large-scale moisture convergence in low levels and near-moist-neutrality for ascending particles. Reprinted from Miglietta and Rotunno (2019) with permission.

\subsection{The special case of medicanes: future trends}

The future trend of medicanes has been the object of several studies in the recent past. Gaertner et al. (2007) used an ensemble of RCMs to dynamically downscale a single climate projection under the A2 emission scenario. Despite the large uncertainty among the RCMs, they found an intensity increase for early-autumn cyclones. At least for the most sensitive model, the future intensity increase in several cyclones was associated with the development of clear tropical characteristics. Later, a rather general agreement was reached about two main aspects of the future evolution of medicanes: a frequency decrease in parallel to an intensity increase (Walsh et al., 2014; Cavicchia et al., 2014b; Tous et al., 2016; Romera et al., 2017). Romera et al. (2017) used a large ensemble of models and of long multi-decadal reference and future periods (1951-2000, 2051-2100). They confirmed this trend considering a higher number of medicanes, though an important inter-model uncertainty remained as few GCM-RCM pairs showed decreasing intensities as well. More recently, González-Alemán et al. (2019) and Gutiérrez-Fernández et al. (2021) used coupled RCM models to further investigate the effect of explicitly resolved air-sea interactions on medicanes' future trends. Despite the possible impacts of a negative intensity feedback in coupled simulations due to the SST cooling effect of strong winds, the main future trends of medicanes were not different in these two studies.

The overall analysis of medicane physical characteristics and climatology is based on a rather small number of cyclones. In these regards, the application of a statistical- deterministic method to the study of medicanes by Romero and Emanuel $(2013,2017)$ strengthened the statistical robustness of the increasing intensity trend. However, their methods strongly relied on medicanes sharing similar dynamics with tropical cyclones (as in group 2 in Sect. 4.2). The overall agreement of different studies on the future increase in medicane intensity has been largely attributed to an increase in SST in the Mediterranean basin. In future atmospheric conditions, higher SSTs are expected to enhance convection in contrast to the atmospheric temperature increase (higher in the upper troposphere) which favours atmospheric stability. This contrasting effect on cyclone dynamics was investigated by Koseki et al. (2021) through the application of a pseudo-global warming approach (Schär et al., 1996) to medicane Rolf (2011). Results showed that competing effects resulted in a moderate increase in the intensity of the medicane. Despite the relative agreement among the different studies on medicane future evolution, it is noteworthy that all studies applied different criteria for medicane detection. As discussed in Sect. 4.2, this is due to the absence of a commonly accepted medicane definition. Consequently, more studies need to address future trends of medicane dynamics with regards to other implicated atmospheric processes, especially upper-tropospheric forcing.

\section{Forecast challenges in Mediterranean cyclones}

The close link between Mediterranean cyclones and severe weather phenomena has historically been at the basis of inter- 
national coordinated efforts devoted to improve the practical predictability of the broad range of these cyclones. Despite the intrinsic predictability limits of these systems, linked to the predictability of mid-latitude weather (Zhang et al., 2019), the practical forecast limits of societally relevant aspects of Mediterranean cyclones, such as associated winds and precipitation, are assumed to be much shorter. This can be attributed to the multiscale nature of Mediterranean cyclones, the high contrast in the density of observations between terrestrial and maritime areas, and the diversity of geographical features in the basin. Performing more accurate, reliable and timely forecasts of Mediterranean cyclones is a complex issue that comprises advances in large- and convective-scale initial condition uncertainty representations but also in modelling techniques and capabilities. In this section, we review the latest efforts in these two directions.

\subsection{Dependence of predictability on processes taking place at different scales}

As discussed in Sect. 2, an upper-level precursor is essential for Mediterranean cyclogenesis. Such precursors usually involve RWBs that take place over the central Atlantic Ocean and eventually evolve into PV streamers or cut-offs that intrude into the Mediterranean region. In this mechanism, diabatic processes in upstream cyclones play an important role in provoking RWB over the Atlantic (Massacand et al., 2001; Grams et al., 2011; Raveh-Rubin and Flaounas, 2017). Consequently, the predictability of Mediterranean cyclogenesis strongly relies on the accurate prediction of the wave guide evolution over the Atlantic Ocean and the processes involved therein.

Several case studies focusing on medicanes have shown that large-scale conditions often pose a challenge to the predictability of Mediterranean cyclogenesis. For instance, Chaboureau et al. (2012) suggested a link between the poor skill of operational forecasts of the European Centre for Medium-Range Weather Forecasts (ECMWF) for the September 2006 medicane and the extratropical transition of Hurricane Helene taking place upstream. To gain deeper insights into the large-scale atmospheric circulation relevant to the poor forecast of the medicane, Fig. 6 compares different representations of Hurricane Helene and an event of RWB that eventually triggers cyclogenesis downstream in the Mediterranean. While short-term forecasts predict well both Hurricane Helene and the medicane until $36 \mathrm{~h}$ in advance (panels $\mathrm{a}-\mathrm{c}$ ), forecasts at longer lead times progressively miss the position of the hurricane over the Atlantic, the amplification of the Rossby wave train and the occurrence of Mediterranean cyclogenesis (panels d-e). The link between these dynamical features was confirmed by Pantillon et al. (2013) using ECMWF ensemble forecasts. The fraction of ensemble members capturing the medicane formation dropped for lead times beyond $2 \mathrm{~d}$. This was due to the sensitive phasing between the hurricane and a Rossby wave train, a situation characterised by high forecast uncertainty as measured by the ensemble spread (Anwender et al., 2008).

A similar pattern was found by Portmann et al. (2020), who showed a large spread of the ECMWF ensemble members in the position of a Mediterranean PV streamer beyond $3 \mathrm{~d}$ lead time. The spread originated from a shortwave perturbation over Newfoundland and affected the position and thermal structure of medicane Zorbas (September 2018). These results are consistent with those of Di Muzio et al. (2019), who used the ensemble forecasts of ECMWF to perform a systematic analysis of medicanes' predictability. The ensemble members presented a predictability jump with decreasing lead time often between 5 and $7 \mathrm{~d}$ ahead, suggesting the existence of predictability barriers. The processes and atmospheric conditions that impose predictability barriers are still an open question. Nevertheless, it seems that Mediterranean cyclogenesis is the final link of a chain of events of exceptional forecasting difficulty. Indeed, Rodwell et al. (2013) analysed the atmospheric conditions that led the ECMWF model to have poor forecast skill for a series of high-impact events over Europe. Composite fields of the large-scale flow revealed a similar pattern, with the one of RWB triggering Mediterranean cyclogenesis, as shown in Fig. $2 b$.

These studies raise the need for a better numerical representation of the upper-level waveguide. Detailed observations are rare and restricted to dedicated field campaigns such as the recent North Atlantic Waveguide and Downstream Impact Experiment (NAWDEX; Schäfler et al., 2018), which documented a case of low predictability associated with a cut-off low triggering heavy precipitation over the Mediterranean. Beyond such rare campaign data, more efforts based on model data are still needed to question the limits of predictability and investigate their case-to-case variability and origin. The representation of cloud diabatic processes is often seen as a source of error growth and forecast uncertainty, but initial conditions may still dominate.

\subsection{Predictability and forecasting strategies}

The fundamental role of the upper-level dynamics in forecasting western Mediterranean cyclogenetic cases was emphasised by Vich et al. (2011a, b). The authors used two main approaches of ensemble prediction systems (EPSs), respectively based on multiphysics simulations and on perturbations to the PV field of the large-scale flow, generated by targeting zones either of adjoint-derived sensitivity or of intense values and gradients. All three approaches were evaluated for a series of high-impact cyclones responsible for heavy precipitation. Results showed similar forecast skill among the multiphysics and PV-based approaches, whereas the latter ones were slightly more proficient. In addition, pragmatic methods to generate initial condition perturbations that target large upper-level PV gradients showed a cyclone and precipitation forecast skill equivalent to more complex and compu- 

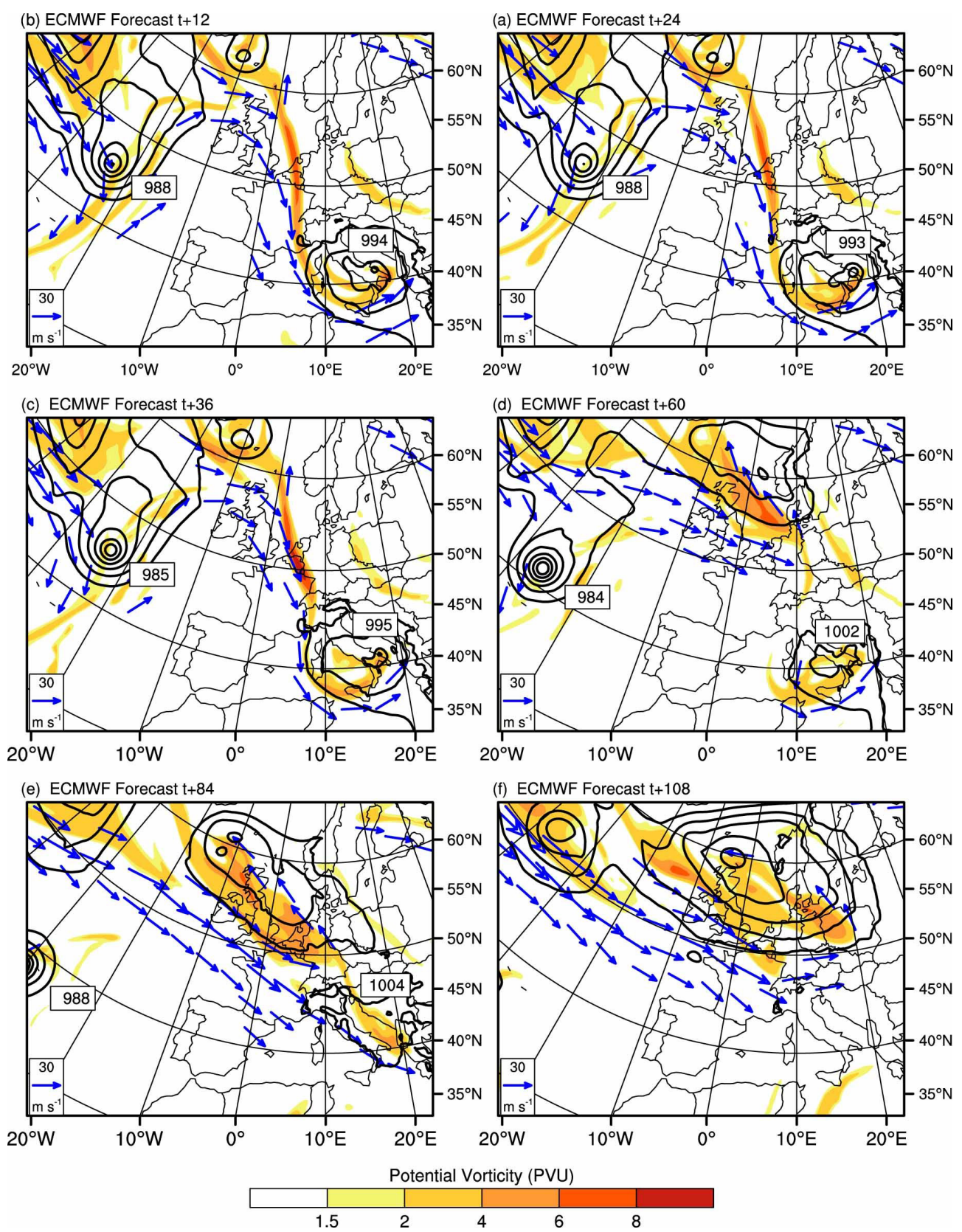

Figure 6. ECMWF forecasts at 12:00 UTC on 26 September 2006: $\mathrm{PV}$ at $300 \mathrm{hPa}$ (shaded, $\mathrm{PVU}=10^{-6} \mathrm{~K} \mathrm{~m}^{-2} \mathrm{~s}^{-1} \mathrm{~kg}^{-1}$ ), wind at $300 \mathrm{hPa}$ (vectors, for winds greater than $30 \mathrm{~m} \mathrm{~s}^{-1}$ ) and mean sea-level pressure (solid lines, every $4 \mathrm{hPa}$ between 976 and $1008 \mathrm{hPa}$ ). Forecasts are at (a) $t+12$, (b) $t+24$, (c) $t+36$, (d) $t+60$, (e) $t+84$ and (f) $t+108$. The figures (when applicable) indicate the local mean SLP minima over the North Atlantic Ocean and the Mediterranean Sea associated with Hurricane Helene and the medicane, respectively. Reprinted from Chaboureau et al. (2012) with permission.

tationally expensive adjoint-based methods. Regarding multiphysics approaches, recent studies on medicanes (Miglietta et al., 2015; Pytharoulis et al., 2018; Ragone et al., 2018; Mylonas et al., 2019) showed that tracks, intensity and duration of the cyclones were highly sensitive to convection, microphysics and boundary-layer parameterisations. However, all studies converged to the conclusion that there is no "perfect" model configuration to adequately predict all synoptic-scale characteristics, while the timing of model initial conditions was crucial for the credible representation of cyclones.

The effect of prominent orography on the predictability of cyclone evolution and impacts is a clear example of the complexity of possible non-linear feedbacks. Flow channelling and the interaction with local topographic features shape 
the low-level flow and usually determine the triggering, location and intensity of damage-causing convective systems (e.g. Sotillo et al., 2003; Davolio et al., 2016; Amengual et al., 2017; Carrió et al., 2019). Again, the multiscale forcings of geographical features - such as coastal transitions and orographic interactions - pose one of the main current predictability challenges to the evolution of Mediterranean cyclones. Indeed, a wide range of scales is typically relevant to forecast accurately the timing, location, mode and intensity of the damaging impacts (e.g. Delrieu et al., 2005; LorenzoLacruz et al., 2019). Forecast strategies accounting for uncertainties linked to moisture sources and evolution, such as surface fluxes, boundary layer flows and microphysical processes, must be investigated to face those challenges.

In a systematic study, the performance of two convectionpermitting ensembles (AROME-EPS and COSMO-H2-EPS) has been assessed over the whole HyMeX (Hydrological Cycle in the Mediterranean Experiment) SOP1 (special observation period 1; Nuissier et al., 2016). Both ensembles exhibited a good probabilistic skill in forecasting heavy precipitation at a relatively high spatial and temporal resolution and were considered as promising tools for operational forecasts. Another comparison in the HyMeX SOP1 among AROMEEPS, the global PEARP ensemble prediction system and the AROME-France high-resolution deterministic system shows that a high-resolution ensemble $(2.5 \mathrm{~km}$ horizontal resolution) with few members can outperform a lower-resolution ensemble ( $15.5 \mathrm{~km}$ horizontal resolution) with many more members (Bouttier et al., 2016). Hermoso et al. (2020) recently proposed a multiscale-consistent ensemble generation method that adapts to the scaling requirements of the "flow of the day" by means of a seamless scale bred vector technique. This is especially suitable for Mediterranean cyclone prediction applications due to the wide range of process scales involved. Indeed, such scale-adaptive ensemble generation techniques produce large mesoscale perturbations during the initial baroclinic phase of cyclogenesis, while they are capable of exciting convective-scale modes at the mature and more diabatically influenced phases of the cyclone life cycle. In the context of representing uncertainties, Hermoso et al. (2021) tested model error representation through the application of stochastic perturbations to physical parameterisations. Their application concerned a heavy precipitation event and showed that perturbations to specific parameters within the microphysics parameterisation outperform a multiphysics-based approach. The positive impact of stochastic parameterisations for the forecast of extreme events in the region is attributable to the generation of EPS spread at small scales, which is a rather difficult and rarely sampled source of important uncertainties for these events. This also simplifies the technical management of model data in forecasting applications since there is no need to maintain multiple parameterisation codes and data streamflows as in other EPSs based on multiphysics or multi-model approaches.

\subsection{Use of observations and data assimilation}

Having insufficient routine observations for data assimilation requires the adoption of strategies that account for regional specificities, such as severe coastal impact of intense convective systems initiated over the sea within cyclones and interactions between the airflow and the mountains. A systematic investigation of the forecast challenges related to Mediterranean cyclones was performed during MEDEX through the production of one of the first databases of Mediterranean cyclone tracks (Campins et al., 2011; Picornell et al., 2011). In this framework, high-impact weather prediction in the Mediterranean was improved as a direct result of advancements in understanding the most important (thermo-)dynamical processes in Mediterranean cyclones and of the onset of observational targeting strategies (Jansa et al., 2014). Running a data targeting system (DTS) was one of the emblematic coordinated milestones of MEDEX, which aimed at identifying sensitive areas where improvements in type and number of observations are likely to reduce forecast errors.

However, Campins et al. (2013) found that the benefits of DTS on operational analyses and forecasts are very variable and highly dependent on the relative location of the sensitive areas with respect to the distribution of the operational network of observations, as well as on the particular predictability characteristics of the case under analysis. Similarly, Garcies and Homar (2014) verified the skill of the sensitivity products used in the MEDEX-DTS campaign. They found that objective sensitivity fields fail to recognise the best location where extra observational means should be deployed. Indeed, observing system experiments run in that campaign revealed that pseudo-soundings placed in areas identified by objective sensitivity calculation hardly influence the forecast of intense cyclones. In fact, the influence was even weaker than pseudo-soundings in operational sounding sites, allegedly unrelated to the dynamics of the day. Therefore, the challenge of identifying useful targeting strategies to improve Mediterranean cyclone prediction remains open. It is noteworthy that, despite the limitations imposed by their linear character, sensitivity calculation methods allow significant sensitivity information in climatic mode to be derived. Indeed, Garcies and Homar $(2009,2010)$ point towards the European Atlantic, the "Mediterranean Storm Track" from the Atlantic to the Ionian Sea and the northwestern African lands as the areas showing the highest sensitivity for the 24 $48 \mathrm{~h}$ forecast of intense Mediterranean cyclones.

Regarding the scarcity of observations, Carrió and Homar (2016) proposed the use of ensemble Kalman filters (EnKFs) for calculating an ensemble of temporally and spatially evolving forecast errors and thus to derive a dynamical background error covariance matrix. Modern EnKFs typically employ "continuous cycling" that unifies ensemble forecasting and analysis steps. This seamless integration renders initial ensembles dynamically consistent in contrast to 
initial ensembles generated by downscaling external models. This cycling configuration shows promising applications to forecasting Mediterranean cyclones since it can effectively transport observational information from land and coastal areas towards less densely observed regions, significantly improving the representation of maritime cyclogenetic environments. In fact, ensemble data assimilation methods based on Kalman filtering, combined with stochastic physics and the comprehensive ingestion of remote sensing measurements, is the cutting edge framework to tackle the challenge of efficient forecasting of Mediterranean cyclones and their impacts. Carrió and Homar (2016) and Carrió et al. (2019) show that improved analysis of key cyclogenetic fields such as low temperature, specific humidity, or wind levels improves the $12-18 \mathrm{~h}$ prediction of small-scale aspects of the cyclone structure and thermodynamic settings. This, in turn, contributes to forecasting high-impact weather associated with cyclones better. In this context, Lagouvardos et al. (2013) have highlighted the positive impact of lightning assimilation in the representation of the precipitation field of a Mediterranean cyclone that affected southern France. However, the assimilation of remote sensing data, such as radar and satellite radiances or motion vectors, has proven very challenging for a distinctly multiscale problem such as the Mediterranean cyclogenesis and its impacts. In fact, these remote sensing measurements are non-linearly related to the model state, which itself is a product of highly non-linear dynamicalmicrophysical processes (Aksoy et al., 2010).

\subsection{New modelling opportunities and challenges}

Continuous developments in model physics and increase in computing power have opened new opportunities in numerical weather prediction, which have been applied to several case studies of Mediterranean cyclones. A straightforward improvement is the increase in resolution as global forecasting systems typically cannot fully resolve the structure and intensity of compact vortices such as medicanes. During HyMeX, the flagship model contribution was the AROME-WMED (Fourrié et al., 2015, 2019), which featured a kilometric-resolution analysis over the western Mediterranean, covering the special observation period (SOP; Ducrocq et al., 2014) at an unprecedented resolution for the region, and with very significant improvements in moisture representation from Navigation Satellite System data (Fourrié et al., 2021). As an example of the usefulness of highresolution simulations, Carrió et al. (2020) analysed the genesis of a rather small cyclone with a characteristic scale of a few kilometres that was embedded within the broader cyclonic circulation of a Mediterranean cyclone. The latter travelled along the northern half of the western Mediterranean and produced heavy rainfall over Italy (Flaounas et al., 2016). Figure 7 shows the development of the small-scale cyclone and its clear relationship to convection. Carrió et al. (2020) used piecewise PV inversion to further show that diabatic heating within the small-scale cyclone was crucial to intensify the encompassing Mediterranean cyclone. The highresolution outputs of AROME-WMED were the key to diagnose the intense winds produced by the embedded cyclone that affected the Balearic Islands.

Horizontal grid spacings of a few kilometres or less, which alleviate the need for a parameterisation of deep convection ("convection-permitting" or "storm-resolving"), have been widely adopted for quantitative precipitation forecasts in the Mediterranean region. For instance, Cioni et al. (2018) found explicit convection necessary to capture the track, intensity and thermal structure of the November 2014 medicane. They also observed further improvement by adding a nested subkilometre-scale domain. The sensitivity to the representation of convection was attributed to the crucial interaction between convectively produced PV at low levels and a PV streamer aloft. Although this result appears promising, a systematic gain from kilometre-scale resolution has not been generally demonstrated for cyclones yet. Besides, improvements of physical parameterisations are needed, in particular for microphysics and turbulence, since they remain two major sources of uncertainty. Embedded convection in WCBs is sensitive to the representation of subgrid turbulence, which has been shown to be underestimated in convective clouds (Verrelle et al., 2017; Strauss et al., 2019). Furthermore, the PV development in WCBs is strongly modified by the latent heating associated with microphysical processes (Joos and Wernli, 2012). Changes in their parameterisation can thus lead to differences in the position of the WCB outflow (Joos and Forbes, 2016; Mazoyer et al., 2021). Thus, their accurate representation is important both locally for predicting precipitation and non-locally when latent heating in North Atlantic WCBs potentially affects the prediction of the Mediterranean cyclone downstream (Raveh-Rubin and Flaounas, 2017).

Recent years have also seen the emergence of coupled modelling systems for the atmosphere, ocean and/or waves. Due to the analogy with tropical cyclones, for which oceanatmosphere coupling reduces SST due to upwelling and weakens the cyclone, research has mainly focused on medicane case studies so far. Low sensitivity to coupling has been found in climatological studies, partly attributed to the currently relatively coarse resolution of regional climate models (Flaounas et al., 2018; Gaertner et al., 2018). Such low sensitivity of cyclone dynamics was however confirmed by recent tests applied to case studies. For instance, the November 2011 medicane exhibited weak dependence on ocean-waveatmosphere coupling with $5 \mathrm{~km}$ grid spacing, while model uncertainty was dominated by initial conditions (Ricchi et al., 2017). Similarly, the track and intensity of the November 2014 medicane were weakly impacted by ocean-atmosphere coupling, even at kilometre-scale resolution; this was ascribed to surface cooling 1 order of magnitude smaller than that for tropical cyclones (Bouin and Lebeaupin Brossier, 2020). For the September 2018 medicane, Varlas et al. (2020) showed that coupling ocean and atmosphere models with 

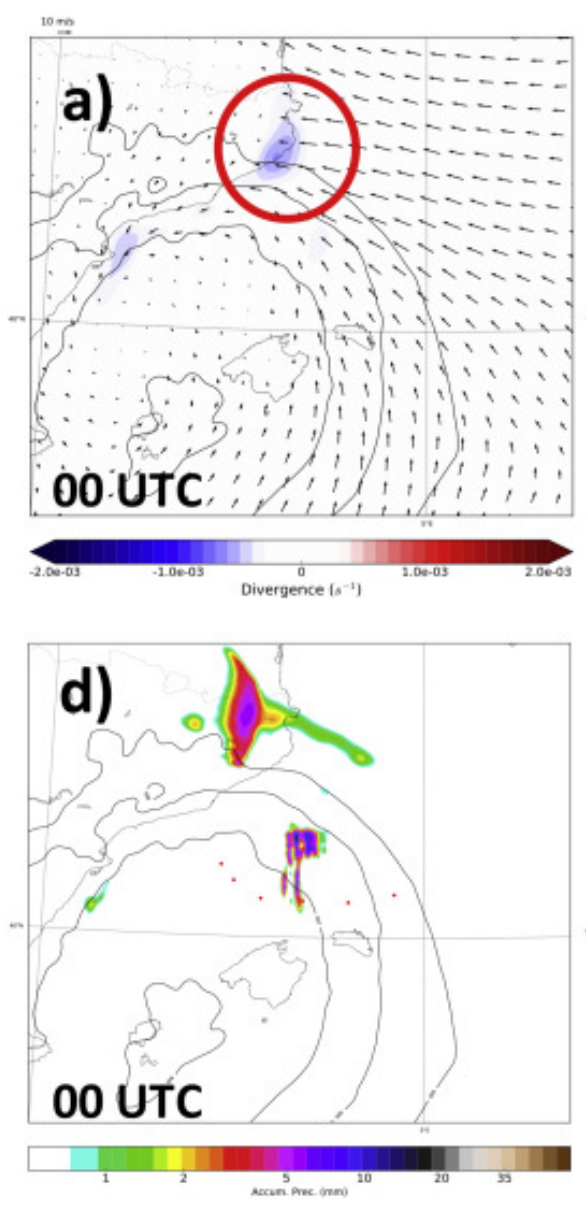
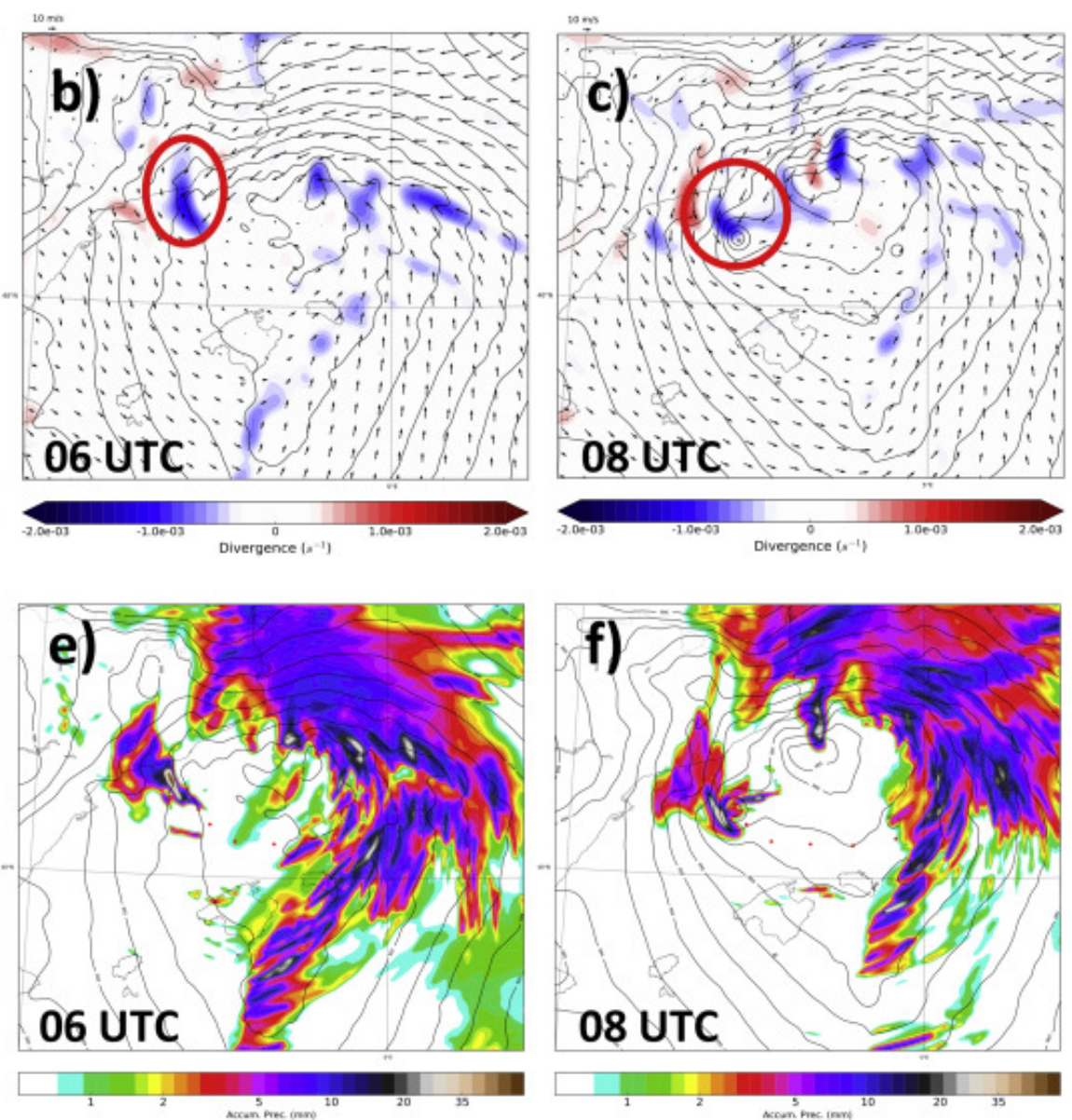
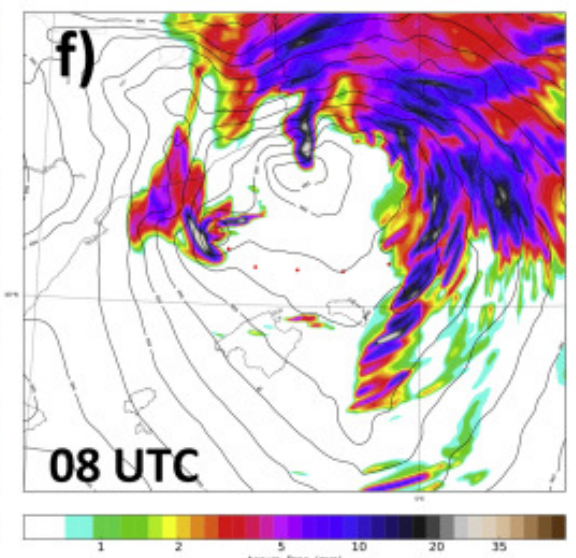

Figure 7. Control surface divergence, horizontal winds and mean sea-level pressure (a-c), as well as hourly accumulated precipitation, together with mean sea-level pressure (d-f), depicted at (a, d) 00:00 UTC, (b, e) 06:00 UTC and (c, f) 08:00 UTC on 31 October 2012. The red circle highlights locations of low-level convergence associated with triggering of the secondary cyclone. Reprinted from Carrio et al. (2020).

$\sim 10 \mathrm{~km}$ grid spacing cooled the ocean surface by up to 2$3{ }^{\circ} \mathrm{C}$ with respect to the model initial conditions. Additional three-way coupling with a wave model reduced $10 \mathrm{~m}$ wind speed by a maximum of $2-3 \mathrm{~m} \mathrm{~s}^{-1}$ during the mature stage of the cyclone. Finally, similar conclusions were reached by Stathopoulos et al. (2020) who showed that the dynamics of three medicanes (Trixie, October 2016; Numa, November 2017; Zorbas, September 2018) were rather insensitive to different modelling approaches on SST (including coupled and stand-alone atmospheric, high-resolution simulations). Despite the weak impact of explicitly resolved air-sea interactions on cyclone dynamics, more research efforts are needed to elucidate the potential benefits brought to dedicated forecasting systems, e.g. to coastal oceanography. In addition, further research is needed to expand the impact of explicitly resolved air-sea interactions to cyclone cases other than medicanes.

\section{Mediterranean cyclones as major environmental risks}

A wide range of weather-induced natural hazards in the Mediterranean are related to Mediterranean cyclones (Lionello et al., 2006) with severe socio-economic consequences. Indeed, in the natural hazards report of Munich Re at global scales for 2019, the Mediterranean region was pointed out because of the storms that produce flash floods and inundation. Such storms have recurrently affected Italy, France and Spain, inflicting damage and billions of Euros in losses (Munich Re, 2022). Mediterranean cyclones with strong circulation, embedded convection and frontal structures produce high-impact weather including heavy rainfall and flooding, thunderstorms with intense lightning activity, windstorms and dust storms, tornadoes, storm surges, and landslides, including compounding effects. 


\subsection{Heavy precipitation and relevant impacts}

The important role of cyclones in provoking the majority of heavy rainfall was established by Jansa et al. (2001) in the context of MEDEX. The authors used observations and cyclone databases to show that $90 \%$ of heavy rainfall events in the western Mediterranean were indeed associated with cyclones of diverse intensity. More recently, Flaounas et al. (2018) showed that weak and intense Mediterranean cyclones are both capable of producing high precipitation amounts. On the other hand, when considering rainfall averages and cyclone intensities, a linear relationship was found between rainfall and cyclone intensity. Regardless of their intensity, cyclones have been shown to play a dominant role in regional precipitation with contributions exceeding $70 \%$ of the annual total (Hawcroft et al., 2012; Pfahl and Wernli, 2012). Concerning extremes, Pfahl et al. (2014) and Flaounas et al. (2016) analysed climatological datasets from reanalysis and regional climate models to show that, depending on the region, intense cyclones may contribute $60 \%$ and up to more than $90 \%$ of regional extreme rainfall. The processes that produce heavy precipitation and relevant extremes might differ from case to case. In a global analysis Pfahl et al. (2014) showed that about $40 \%$ to $50 \%$ of the regional extremes can be attributed solely to WCBs in the Mediterranean (feature 5 in Fig. 3), while Flaounas et al. (2018) showed that WCBs typically produce more than twice the precipitation amounts related to deep convection (features 6,7 and 8 in Fig. 3). These two different processes of precipitation production were analysed in two contrasting case studies that took place during the SOP1 campaign of HyMeX in October 2012 and were both located in the West Mediterranean, close to the Alps (Flaounas et al., 2016). Figure 8 shows similar daily precipitation amounts in different areas of the West Mediterranean. However, high precipitation amounts in the first cyclone were mainly produced by deep convection, depicted in Fig. 8a, b and c by intense lightning activity and diagnostics from satellite retrievals. On the other hand, deep convection in the second case was scarce (Fig. 8d) since high precipitation amounts were mainly due to stratiform rainfall produced by WCBs.

Heavy precipitation in the region requires large amounts of water vapour at low- and mid-tropospheric levels, favouring atmospheric instability and the deepening of systems leading to intense rainfall events (Reale and Lionello, 2013; Khodayar et al., 2018b). Using composite fields based on mesoscale reanalyses, Ricard et al. (2012) showed that heavy precipitation events over southern France are associated with instability and moisture located upstream over the Mediterranean Sea and transported by a low-level jet constrained by both the synoptic pattern and the local orographic effects. Khodayar et al. (2018a) further demonstrated, using high-resolution seasonal simulations in the western Mediterranean, that the latter association also holds for other heavy precipitation hotspots in the western Mediterranean such as northern and southern Italy, eastern Spain, and North Africa. Additionally, they pointed out that the significant increase in atmospheric moisture and instability prior to heavy precipitation occurrence could be traced back to at least 6-24 h before the initiation stage for the majority of events. The Mediterranean Sea but also the tropical and extratropical Atlantic Ocean and tropical Africa have been identified as potential sources of moisture (Winschall et al., 2014; Chazette et al., 2016; Lee et al., 2017; Raveh-Rubin and Wernli, 2016; Duffourg et al., 2018), whose transport may be organised in atmospheric rivers (Krichak et al., 2016). In a recent study, Davolio et al. (2020) showed how an explosive deepening Mediterranean cyclone steered an atmospheric river towards the Alpine slope (Fig. 9) where one of the most severe precipitation events of the last century in Italy occurred (Giovannini et al., 2021). The computation of the atmospheric water budget over the Mediterranean basin showed that the local contribution of evaporation from the sea was much less important than the moisture transported from the tropical Atlantic through Africa. Flaounas et al. (2019) also quantified the water vapour amount feeding Mediterranean cyclones, through a Lagrangian approach applied to 100 cyclone events. Results showed a higher contribution from the Mediterranean Sea, while the Atlantic Ocean appeared as a secondary but nevertheless important source for water vapour. Similar results were reached by Raveh-Rubin and Wernli (2016) who analysed the water sources for five selected cases of intense Mediterranean cyclones that produced high-impact weather. Finally, Flaounas et al. (2019) analysed cyclones with respect to their precipitation efficiency, defined as the ratio of precipitation to integrated rainwater in the atmospheric column. Precipitation efficiency was shown to be systematically higher over land than over maritime areas, suggesting that the relationship between cyclone intensity and precipitation is further perplexed by the underlying surface.

In the framework of MEDEX, societal impact research has focused on flood events, populating the first database of its kind for the region. This database has been the basis for other relevant works in the framework of HyMeX, which resulted in the FLOODHYMEX database (Llasat et al., 2013; Papagiannaki et al., 2013). This effort has been recently updated and extended to the Mediterranean Flood Fatalities (MEFF) database spanning from 1980 to 2015 (Petrucci et al., 2019). Vinet et al. (2019) and Petrucci et al. (2019), based on the MEFF database and its extended version EUFF (European Flood Fatalities) covering the period 1980-2018, have shown that the flood-related mortality mainly occurs during early autumn in the western Mediterranean and during late autumn and winter in the eastern Mediterranean. This seasonal preference of flood-induced fatalities is correlated with the climatological patterns of heavy precipitation and implicitly with Mediterranean cyclone occurrences (RavehRubin and Wernli, 2015). In fact, most of the floods resulting from torrential rain in the region, both in the western and eastern Mediterranean, are associated with organised convec- 
(a)

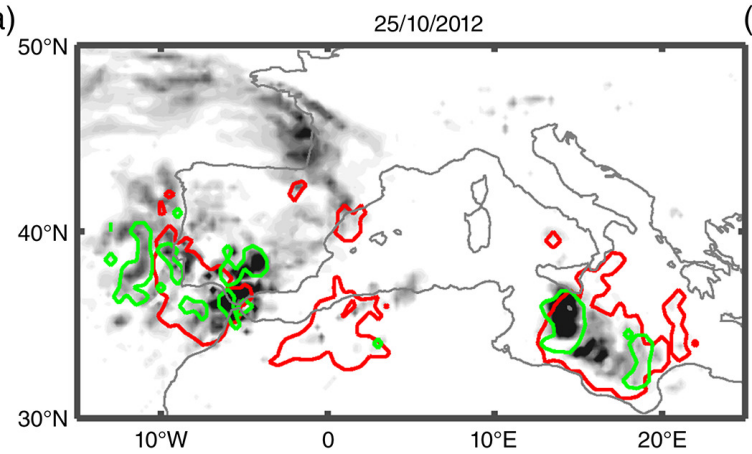

(c)

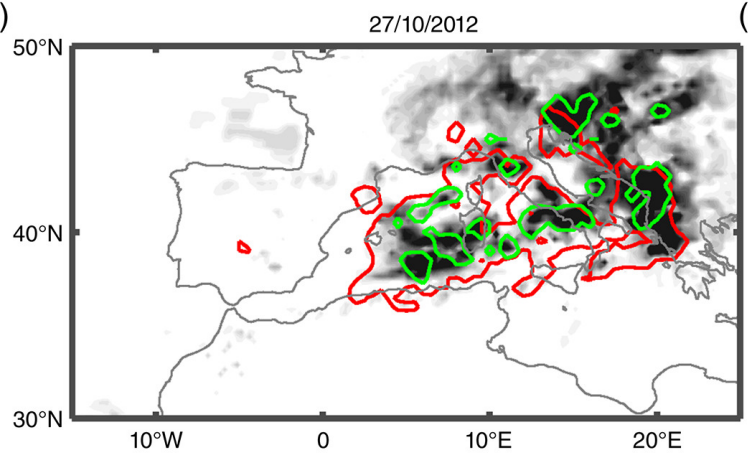

(b)

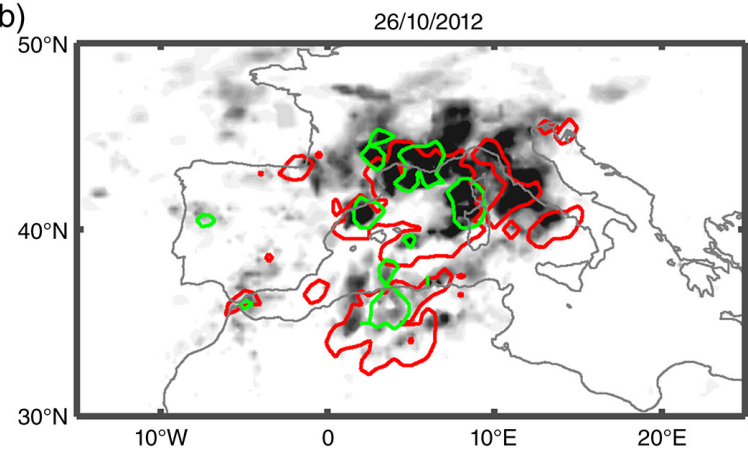

(d)

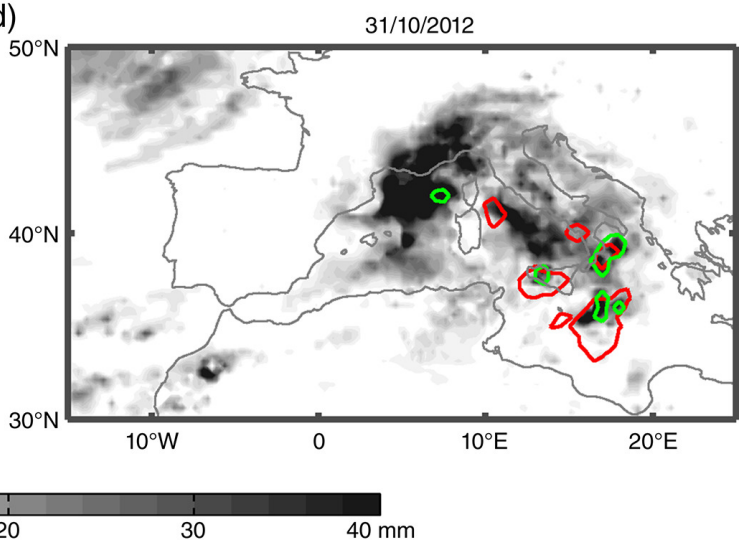

Figure 8. The $24 \mathrm{~h}$ accumulated precipitation (grey shading) provided by the Tropical Rainfall Measuring Mission (TRMM), areas of lightning activity (red contours, denoting areas with at least five impacts) from ZEUS (National Observatory of Athens) and areas of deep convection (green contours) as diagnosed from the microwave humidity sounder (MHS) radiometer. Reprinted from Flaounas et al. (2016) with permission.

tive systems or orographic precipitation due to synoptic-scale forcing rather than intense isolated convective cells. In fact, Michaelides et al. (2018) showed that most of the flash floods in the Mediterranean are related to heavy precipitation produced by relatively weak cyclones but with long-lasting embedded mesoscale convective systems that interact with the topography. From the non-exhaustive list provided of catastrophic floods that spread across the Mediterranean, it can be inferred that most floods - if not all them - were related to the presence of a cyclone. However, a quantitative attribution of the role of Mediterranean cyclones to flood occurrence has not yet been performed. In this context, intense or long-lasting rainfall is also considered as a frequent factor for landslides. Rainfall-induced landslides have been reported in the literature across the Mediterranean countries (Trigo et al., 2005; Gariano et al., 2015; Polemio and Petrucci, 2010); however, to our knowledge no direct attribution of the triggering of the observed landslides to Mediterranean cyclone activity has yet been published.

Finally, a relatively under-addressed issue of convectionrelated risks concerns the contribution of cyclones to Mediterranean electrical activity. Galanaki et al. (2016) quantified this contribution combining lightning observations and reanalysis. Results showed higher contributions in autumn and winter, i.e. when intense cyclogenesis presents the highest rate of occurrence, accounting for $5 \%-30 \%$ of the observed lightning over the Mediterranean Sea. These percentages are much higher in winter, especially in northern Africa where cyclone contribution to lightning occurrence reaches up to $60 \%$. It is however noteworthy that the study of Galanaki et al. (2016) was limited to intense cyclones, while lightning activity was only attributed to cyclone centres, excluding, for example, fronts. Therefore, more studies need to address this issue with more explicit methods that combine identification of frontal structures, cyclone tracks and ensembles of lightning observations.

\subsection{Wind-induced risks}

\subsubsection{Windstorms}

Many of the strong winds observed in the Mediterranean have been traditionally considered to belong to the category of local winds, like Mistral, Tramontana or Sirocco. However, several of these winds are provoked by Mediterranean cyclones or cyclones play a primary role in their intensity. For instance, the intensity of the Mistral winds depends on 

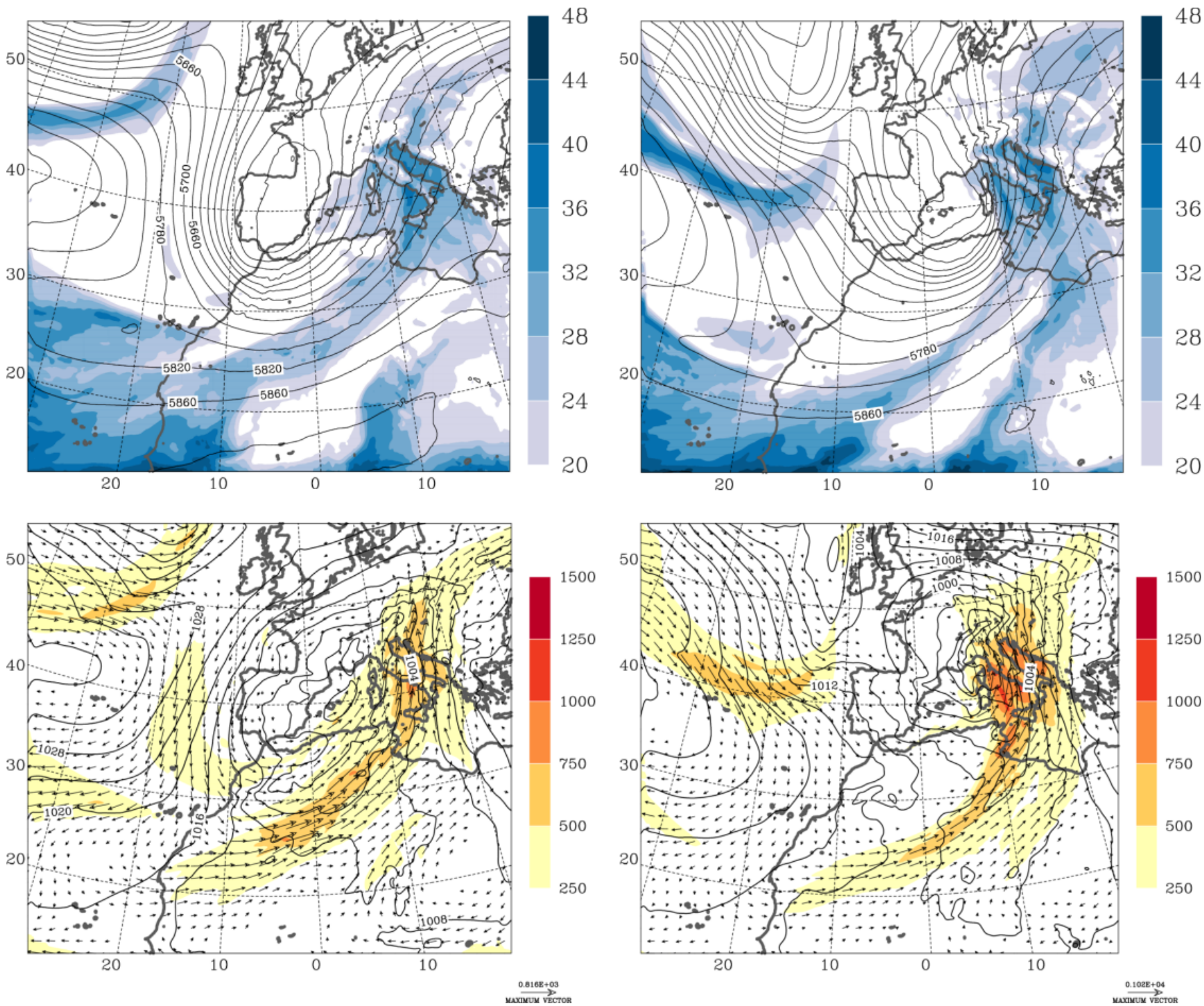

Figure 9. The top row shows integrated water vapour (mm; colour shading) and geopotential height at $500 \mathrm{hPa}$ (m; contours) and the bottom integrated vapour transport $\left(\mathrm{kg} \mathrm{m}^{-1} \mathrm{~s}^{-1}\right.$; colour shading and arrows) and mean sea-level pressure (hPa; contours) at 12:00 UTC (left) on 28 October and (right) 29 October 2018, as simulated by BOLogna Limited Area Model (BOLAM) numerical weather prediction model (C) American Meteorological Society. Used with permission).

Genoa cyclones and their upper-tropospheric PV anomaly (Givon et al., 2021). In another example, the presence of low pressure over the Tyrrhenian Sea was responsible for an exceptional Sirocco storm in the Adriatic basin and eastern Alps (Giovannini et al., 2021). Regardless of their relationship to local winds, Mediterranean cyclones are directly related to windstorms, either by enhancing local winds or due to their cyclonic circulation. Nissen et al. (2010) were among the first to perform a climatological analysis of windstorm tracks over the Mediterranean and found that cyclones are responsible for the quasi-total of wind extremes. In fact, $42 \%$ of these cyclones formed within the region, while the rest intruded into the Mediterranean from the Atlantic Ocean.
Recently, the environmental conditions associated with extratropical cyclones responsible for tornadoes in Italy have been analysed (Tochimoto et al., 2021), showing that tornadoes concentrate mainly in the warm sector and, secondarily, along the cold front.

\subsubsection{Storm surges and sea waves}

A direct risk of cyclone-induced windstorms is the formation of storm surges and the consequent coastal flooding. In fact, the combination of high wind speed, significant sea waves and consequent storm surges, along with heavy precipitation, suggest increased risk for compound events, especially for compound flooding (Bevacqua et al., 2019). The role of 
cyclones in raising the sea level in coastal regions is added to background conditions. These conditions include changes in the surface heat flux, the advection of heat by currents, and the seasonal changes and climatic variations in the sea level, tides, infragravity waves and wave set-up due to the dissipation of waves reaching the nearshore area. It is within this complex scheme of interacting processes that cyclones may produce extreme waves that, combined with heavy rainfall, can dramatically impact coastal areas with flooding and erosion. For instance, the city of Venice in northern Italy is particularly vulnerable to flooding due to storm surges (Cavaleri et al., 2019; Lionello et al., 2019); the most intense one in the recent past was associated with a small-scale cyclone travelling northward along the northern Adriatic basin (Ferrarin et al., 2021). The recent medicane Ianos (September 2020) was responsible for storm surges in Greece due to sustained winds of $\sim 40 \mathrm{~m} \mathrm{~s}^{-1}$ (e.g. Smart, 2020; Lagouvardos et al., 2021), while Patlakas et al. (2020) showed a substantial contribution of medicanes to high sea waves and wind speeds. As an example, Fig. 10 shows, during the lifetime of Qendresa (November 2014), the time duration over which $925 \mathrm{hPa}$ wind speed and wave height exceeded the thresholds of $17.2 \mathrm{~m} \mathrm{~s}^{-1}$ and $4 \mathrm{~m}$, respectively. A few studies have analysed the impact of the sea state to ship accidents in the region. In particular, Bertotti and Cavaleri (2008) and Cavaleri et al. (2012) analyse two case studies in which sea waves under the influence of intense Mediterranean cyclones were responsible for two ship accidents in February 2005 and March 2010, respectively. In both cases, waves of more than $10 \mathrm{~m}$ were reported to hit the vessels and cause substantial damage and loss of human life. More recently, Zhang and $\mathrm{Li} \mathrm{(2017)} \mathrm{used} \mathrm{the} \mathrm{International} \mathrm{Maritime} \mathrm{Organization}$ (IMO) database for ship accidents in the period 2001-2010 and showed that the Mediterranean Sea is one of the main regions in the globe with more frequent ship accidents induced by sea waves. Despite the direct relationship of cyclones to wind speed extremes in the region, a more thorough study is needed to better determine whether cyclones have indeed led to these accidents.

A few studies have been performed on Mediterranean storm surges, mostly focusing on variability and trends under the current and future climate (Marcos et al., 2011; Androulidakis et al., 2015). In particular, Lionello et al. (2019) used model hindcast to show a link between cyclones intruding into the region from the Atlantic and positive sealevel anomalies along the western Mediterranean coastlines. In contrast, high sea levels in the southeast and northwest parts of the basin are associated with cyclones that originate from the western basin, while high sea levels near North African and eastern basin coastlines are affected by cyclones formed over northern Africa and the Levantine basin. In a recent study, Tadesse et al. (2020) used data-driven modelling to quantify the relationship between the storm-surges and relevant predictors such as the wind speed and mean sea-level pressure at global scale. Storm surges strongly rely on drag (a)

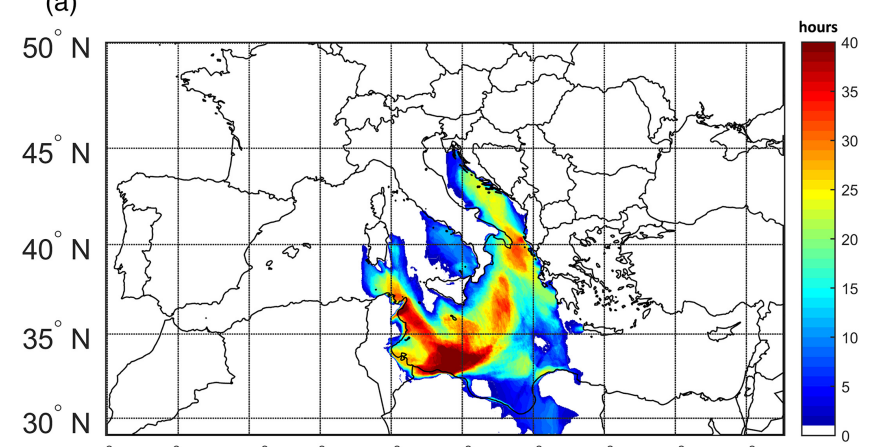

$10^{\circ} \mathrm{W} 5^{\circ} \mathrm{W} 0^{\circ} 5^{\circ} \mathrm{E} 10^{\circ} \mathrm{E} 15^{\circ} \mathrm{E} 20^{\circ} \mathrm{E} 25^{\circ} \mathrm{E} 30^{\circ} \mathrm{E} 35^{\circ} \mathrm{E}$

(b)

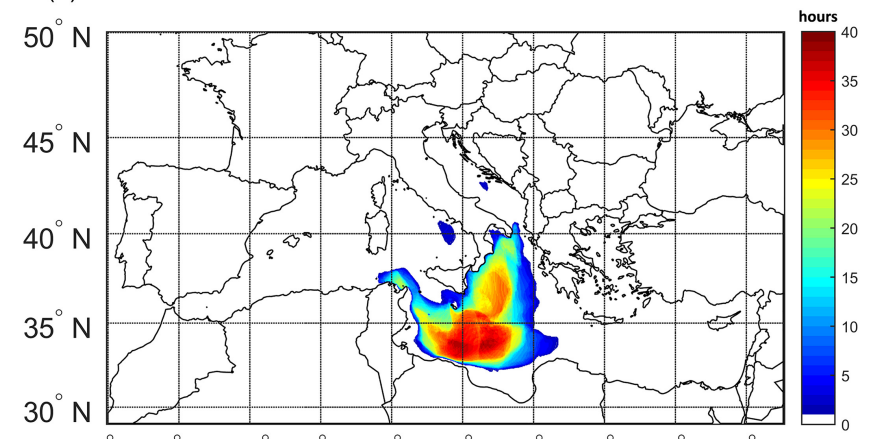

$10^{\circ} \mathrm{W} 5^{\circ} \mathrm{W} \quad 0^{\circ} 5^{\circ} \mathrm{E} 10^{\circ} \mathrm{E} 15^{\circ} \mathrm{E} 20^{\circ} \mathrm{E} 25^{\circ} \mathrm{E} 30^{\circ} \mathrm{E} 35^{\circ} \mathrm{E}$

(c)

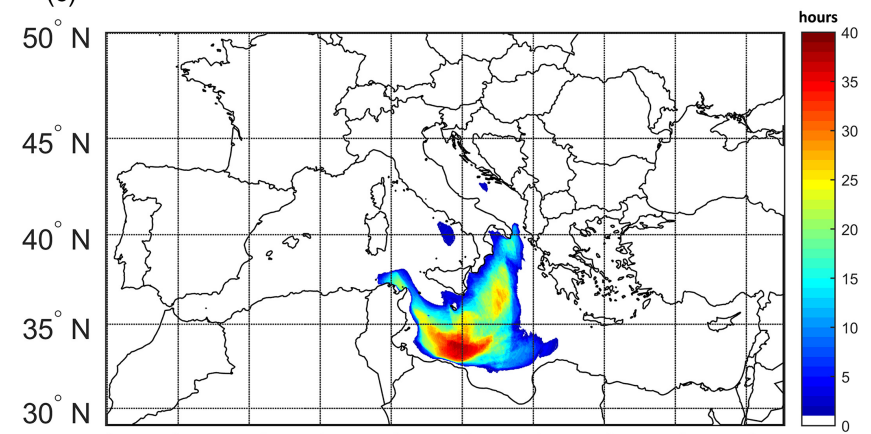

$10^{\circ} \mathrm{W} 5^{\circ} \mathrm{W} \quad 0^{\circ} 5^{\circ} \mathrm{E} 10^{\circ} \mathrm{E} 15^{\circ} \mathrm{E} 20^{\circ} \mathrm{E} 25^{\circ} \mathrm{E} 30^{\circ} \mathrm{E} 35^{\circ} \mathrm{E}$

Figure 10. (a) Duration in hours per grid point where $925 \mathrm{hPa}$ wind speed exceeds the threshold of $17.5 \mathrm{~m} \mathrm{~s}^{-1}$ during the lifetime of medicane Qendresa (2014). Panel (b) like in (a) but for significant wave height exceeding $4 \mathrm{~m}$. Panel (c) like in (a) but for the combined threshold values of both wind speeds and wave height. Fields are derived from coupled wave-atmosphere model. Reprinted from Patlakas et al. (2020) with permission.

coefficient and thus on the surface wind speed. However, there is a considerable lack of in situ observations that renders the understanding of storm surges an open question, especially when wind speeds are higher than $30 \mathrm{~m} \mathrm{~s}^{-1}$, in these cases the theoretical framework is not well known. Moreover, storm surges are impacted by swell propagation across different sectors of the cyclone and indirectly by the rain that 
affects the development of the wind waves. Currently, little is known about these mechanisms in the Mediterranean region.

\subsubsection{Dust transport and episodes of particulate matter}

Several studies have assessed the relationship between mineral dust mobilisation, transport and synoptic-to-global-scale weather systems. Satellite data and model simulations have identified baroclinicity and cyclogenesis processes as significant meteorological patterns that result in dust uplift due to the strong surface wind fields (Schepanski et al., 2009). In most cases Mediterranean cyclones can develop close to dust sources, with their core being either over the African continent or further north in the Mediterranean Sea (Schepanski and Knippertz, 2011). Dayan et al. (2008) used 37 years of visibility observations correlated with $\mathrm{PM}_{10}$ dust concentrations to examine the annual and inter-annual occurrences of dust events over Israel. They reported a significant correlation between dust and cyclonic activity in the eastern Mediterranean. Kalkstein et al. (2020) further demonstrate the link between the highest $\mathrm{PM}_{10}$ concentrations in Israel and intense Cyprus Lows. Using reanalysis and satellite retrievals of aerosol optical depth, Flaounas et al. (2015) found that cyclones contribute $10 \%-25 \%$ of the total number of days with dust over the eastern Mediterranean, while this percentage rises to $30 \%-70 \%$ when considering only extreme dust events. Categorising Saharan dust events into synoptic meteorological types, Varga (2020) reported that welldeveloped Mediterranean cyclones drive almost a quarter of these, mobilising and transporting dust through the southerly warm advection ahead of the cold front of the eastwardmoving low-pressure systems. As an exemplary case, Figure 11 shows satellite observations of a severe dust transport event due to a cyclone in March 2016, analysed by Rizza et al. (2018a). The relationship between the cold front and dust transport is clearly visible in the satellite pictures of Fig. 11, which presents different time instances of a major dust transport event due to a cyclone in March 2016. Close to the time of the cyclone's mature stage (Fig. 11b), the cyclone centre is located to the north of Tunisia, where cloud coverage (brown colours) is wrapping cyclonically. In parallel, the cold front forms a comma-shaped cloud coverage (brown colours), organised along a meridional direction over the Ionian and Adriatic seas preceded by an also meridionally oriented filament of dust (pink colours). Clearly dust is taken up during the cyclone formation over North Africa (Fig. 11a) and continuously interacts with clouds even at subsequent times after the mature stage (Fig. 11c). The high contribution of cyclones to dust events was also confirmed in a series of case studies (Varga et al., 2014; Fiedler et al., 2014; Schepanski et al., 2009). Finally, cyclones were also identified for facilitating the long-range transport of giant mineral dust particles ( $>75 \mu \mathrm{m}$ in diameter). This has an important effect on the radiation balance of the atmosphere, cloud and precipitation processes, and the ocean carbon cycle (Ryder et al.,
2013; Van der Jagt et al., 2018). The assessment of the size distribution of mineral dust particles under cyclonic circulation conditions could prove an important, currently underaddressed, research objective.

\section{Open questions and research perspectives in the broader field of Mediterranean cyclones}

This article has presented the community's efforts over the last decades to advance the field of Mediterranean cyclones. Our review focused on cyclone climatology (Sect. 2) and on cyclone dynamics (Sect. 3), in particular on the processes that play an important role in the development of cyclones, along with the different cyclone subtypes met in the Mediterranean region. A special emphasis was given to medicanes since they have recently attracted a lot of attention within the scientific community. Upper-tropospheric forcing, baroclinic instability in the presence of orography and diabatic processes are certainly key issues for cyclone dynamics. Acquiring insights into these processes is the fundamental step to better understand the issues implicated in forecasting cyclogenesis and relevant impacts. Therefore, Sect. 5 addressed the recent advancements in forecasting Mediterranean cyclogenesis, highlighting the importance of large-scale dynamics for a skilful prediction of cyclones, especially of RWB over the Atlantic Ocean. Furthermore, we discussed recent strategies for the probabilistic forecasting of cyclone impacts and the latest modelling efforts in this direction, including resolution issues and coupled modelling. Finally, Sect. 6 provided an overview of high-impact weather events. In particular, we discussed cyclones' contribution to heavy precipitation events, windstorms, severe dust episodes, storm surges and high sea waves. The overall field of Mediterranean cyclones experienced substantial advances in the last decades, especially in recent years in the framework of MEDEX and HyMeX international programmes. However, several open questions are yet to be addressed by the community as highlighted in the following, in eight subsections, each devoted to a broad thematic.

\subsection{Disentangling Mediterranean cyclone dynamics across spatial scales}

The morphological characteristics of the PV streamers and cut-off lows, as well as their role in cyclone development when interacting with the subtropical jet, are still an open question. More research efforts need to further address the relationship between cyclone development and the amplitude of induced PV anomalies, their spatial extent and depth in the troposphere. The interaction of convection with uppertropospheric systems is also an under-addressed issue. It is rather unclear how typical it is for explosive cyclogenesis to take place due to a PV streamer triggering deep convection, as described in Fita and Flaounas (2018), or for a cyclone to 

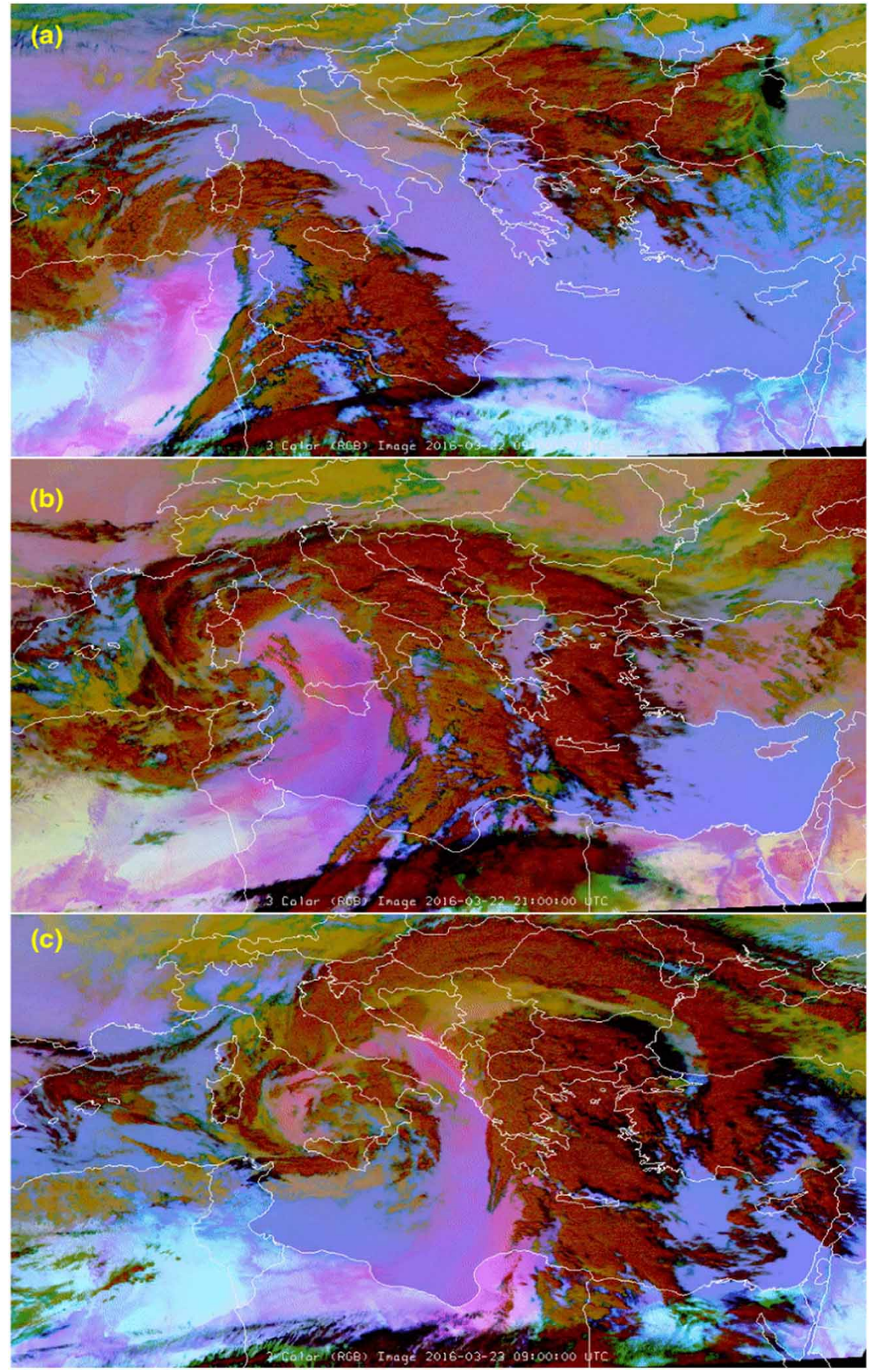

Figure 11. MSG-SEVIRI (Spinning Enhanced Visible and InfraRed Imager) dust product, showing dust (pink/purple), clouds (brown/orange) and differences in surface emissivity retrieved in the absence of dust or clouds (light blue/blue) on (a) 22 March at 09:00 UTC, (b) 22 March at 21:00 UTC, and (c) 22 March at 09:00 UTC of 2016. Rizza et al. (2018a) with permission.

deepen abruptly due to the synergy of a PV streamer and preexisting convection, as described in Chaboureau et al. (2012). The proper representation of the scale interplay by atmospheric models, e.g. between large-scale, upper-tropospheric systems and organised convection, is crucial for the under- standing of frontal structures and relevant airstreams. The latter is a relatively under-addressed issue, with few studies performing systematic identification of fronts and their role in cyclone dynamics and impacts. Later efforts on the identification of fronts in the Mediterranean (e.g. Bitsa et al., 
2019) need to be further related to cyclonic systems and relevant impacts. Furthermore, the field suffers from the lack of dedicated, systematic analyses of mesoscale airstreams (WCBs, CCBs, DIs and sting jets). These are two main issues in which the field of Mediterranean cyclones lags behind the one of mid-latitude storms developing over open oceans. Finally, a remaining issue deserving clarification is the PVtopography interaction in the case of lee cyclogenesis, which is how the secondary lee cyclone circulation feeds back and modifies the upper-PV primary anomaly.

\subsection{Identifying the specific characteristics of medicanes}

Several issues on medicanes remain the subject of debate in the scientific community. Indeed, open questions on processes still concern the role of vertical wind shear (especially under the presence of superposed jets) and the potential of tropical transition taking place in the region. The latter includes the investigation of DI's implication in warm seclusion (e.g. Miglietta et al., 2021), the role of frontal structures and the possible role of convection in sustaining the cyclonic circulation alone (Dafis et al., 2020). In addition to open questions on atmospheric processes, other subjects range from the criteria for the reliable definition of medicanes to their classification, both as a particular category and as a member of the broad category of subtropical cyclones, with the possibility of acquiring a tropical cyclone structure in a few cases. In this context, concepts such as WISHE, a cloudless "eye" and tropical transition should be used with caution when applied to medicanes. Indeed, medicanes are still physically ill-defined systems, and their dynamics present case-by-case variability. It is thus important for coordinated research to develop new diagnostic tools that take into account the unique dynamics and physical characteristics of Mediterranean cyclones.

\subsection{Understanding coupled processes in Mediterranean cyclones}

Including missing coupled processes in modelling approaches is an important step to advance our understanding of cyclone dynamics. For instance, the role of dust and other particulate matter in modulating cyclone dynamics is still an open question, especially in the Mediterranean, a region that hosts abundant concentrations of aerosols (Lelieveld et al., 2002) and where cyclones are responsible for major events of dust transport (Flaounas et al., 2015; Rizza et al., 2017). In these regards, the direct effect of dust and other particulate matter on radiation and the indirect effect on microphysics is not yet systematically addressed in the context of cyclone development. In addition to dust, air-sea interactions are also an issue that deserves more attention. Despite the limited effect of explicitly resolved air-sea interactions on certain medicane cases, it is still imperative to test the performance of coupled models to a wider range of cyclones. For instance, we need more studies on three-way atmosphere-ocean-wave coupling to understand and better forecast the fine-scale dynamics of cyclones and their consequent impacts on coastal areas and shipping. In the same context, aerosol-aware microphysics parameterisations, including sea salt emissions, are also important since they affect the intensity of cyclones and the consequent precipitation (Pravia-Sarabia et al., 2021; Rizza et al., 2018b, 2021; Varlas et al., 2021). Such efforts will evolve to a full-scale modelling framework that can address a wide range of coupled processes with substantial applications to numerical weather prediction. However, the use of coupled models is still relatively limited in the field of Mediterranean cyclone dynamics and has to be further promoted through interdisciplinary studies.

\subsection{Solving resolution and parameterisation issues for cyclone modelling}

Due to the variety of processes that interact at different spatio-temporal scales and affect cyclone dynamics, the use of high-resolution models is vital to advance our understanding and perform skilful forecasts of cyclones and their relevant impacts. The complex geographical characteristics of the region and the relatively small size of Mediterranean cyclones would demand a considerable increase in resolution compared to current operational models for the area. Therefore, new studies should promote systematic analysis of cyclone dynamics using convection-permitting resolution. This would waive inherent uncertainties in convection parameterisations and would provide considerable insights into the local impacts of cyclones. In addition, higher resolution would provide further insights into the extent of the impact of processes already resolved even in coarse resolutions. For instance, orography representation is still a source of uncertainty in the prediction of lee cyclones since it limits the correct description of the mesoscale forcing. The spatial orographic scales that affect cyclone dynamics are still an open question, and it is rather uncertain whether higher resolution is increasing the amplitude of topographic-produced PV anomalies. Such processes might prove more important than the secondary role considered in past studies. In this context, new studies should re-examine results of already analysed cases or further refine the conclusions by highlighting fine-scale atmospheric processes. However, it is important to stress that waiving the use of convection parameterisation is still not assuring the reliable reproduction of latent heat and relevant forcing to cyclone dynamics. In fact, cyclone tracks and other cyclone characteristics such as intensity are highly dependent on model microphysics (e.g. Miglietta et al., 2015; Pytharoulis et al., 2018), and thus higher resolutions and the use of coupled models should advance in parallel to the representation of inherent uncertainties in physical parameterisations. In particular, further studies are necessary to assess the performance of two-moment versus one-moment microphysics schemes. Differences in the processes of vapour de- 
position on hydrometeors in cold and mixed-phase clouds can lead to differences in heating rate along the WCBs. Additionally, the representation of turbulent mixing has to be improved not only in the planetary boundary layer but also in the free troposphere as the strong wind gradients associated with cyclones can be a source of severe turbulence.

\subsection{Enhancing the use of observations and diagnostic tools}

In contrast to the wide availability of modelling techniques, the field of Mediterranean cyclone dynamics suffers from the lack of observations. Satellite data can provide useful information over the Mediterranean; for example, the wind products from the Aeolus Doppler wind lidar satellite mission are expected to improve the understanding of atmospheric processes and the quality of weather forecasts (Baars et al., 2020) through data assimilation (Horányi et al., 2015). The sharp land-sea transitions and the scattered islands might offer an advantage in acquiring ground-based observations, as in the case of cyclone Qendresa passing over Malta but also a relatively wide radar coverage (e.g. McTaggart-Cowan et al., 2010). On the other hand, observation campaigns are rare and seldom dedicated to cyclones. Consequently, it is a challenge to validate the capabilities of simulations or even to validate important cyclone characteristics such as central pressure, profiles of the atmospheric state and frontal structures. Two other important issues regarding observations are accessibility and lack of spatial homogeneity. For instance, observations over North Africa are scarce and not easily accessible due to the lack of participation in joint international projects. This poses a challenge for understanding the uptaking of dust by cyclones and its interactions with cyclone dynamics. Inclusiveness and international coordination should be prioritised in future projects. A final issue concerns the direct transposition of diagnostics and concepts from the fields of tropical cyclones and mid-latitude storms to Mediterranean cyclones. For instance, cyclone phase-space analysis (Hart, 2003) needs to be adapted to the latitude and size of Mediterranean cyclones (Picornell et al., 2014) but also to the finer horizontal resolutions used by state-of-the-art models and reanalysis. In addition, the direct applicability of WISHE and tropical transition theories to medicanes should be revised according to recent results. New research efforts should address these issues, taking advantage of the increasing availability of gridded observations and new reanalysis at fine grid spacings. This renders the systematic analysis of cyclone dynamics and processes more accessible than a decade ago and opens new opportunities for the analysis of cyclone dynamics, data assimilation and model validation.

\subsection{Reducing error and uncertainty in numerical weather prediction}

As numerical model resolution increases and non-linear cyclogenetic processes become explicitly resolved, new strategies to short- and long-term observation targeting for Mediterranean cyclones are needed. Indeed, although baroclinic processes have a substantial linear component, the aforementioned determinant role of non-linear diabatic processes in the precise evolution of mature Mediterranean cyclones sets new challenges. New sensitivity calculation methods must account for non-linear links between predictions and predictors (Jourdan and Loubière, 2020) and most likely exploit the advances in artificial intelligence to uproot complex sensitivity links from high-resolution ensembles. Furthermore, most case studies up to now have focused on medicanes only and are based on the ECMWF ensemble forecasting system solely. This calls for a comparative study of the predictability of different types of Mediterranean cyclones and in different forecasting systems. In fact, case studies based on complex modelling strategies are still necessary to better understand processes but do not necessarily help to improve forecasts, which remain insufficiently constrained. Relevant mesoscale observations may be lacking to prescribe initial conditions which are often downscaled from global models in the absence of appropriate data assimilation systems. Therefore, uncertainty might be high in the large-scale conditions, jeopardising both the accuracy and reliability of cyclogenesis. This calls for more research to identify sources of uncertainty for Mediterranean cyclones. In these regards, stochastic methods should focus more on the specific processes that hold high uncertainty in cyclone dynamics but also on the exchanged variables at the interface of coupled models. Finally, new research is also needed to identify useful observation operators and covariance relationships that help extract more accurate information from new observational means (mostly remote sensing) and produce better descriptions of maritime environments of Mediterranean cyclones.

\subsection{Extending the scope of climatological studies for Mediterranean cyclones}

The analysis of Mediterranean cyclone tracks in a climatological context has been one of the most investigated topics. Despite the different approaches, reanalysis datasets and cyclone tracking methods, recent studies present high agreement on the tracks density, seasonal cycle and favourite locations of cyclogenesis. Several subtypes of cyclones have also been identified, and a high number of studies have addressed their climatological aspects. Nevertheless, open questions still remain on the future evolution of Mediterranean cyclogenesis and associated impacts. In these regards, the special case of medicanes has drawn most of the attention using a plethora of different criteria for their detection. However, the 
rarity of medicanes and the lack of agreement in their physical definition prohibits a solid interpretation of the results. Furthermore, such high focus on medicanes has eclipsed the importance of analysing the future trend of other intense Mediterranean cyclones. New studies need to focus on the multiscale processes that affect the development of Mediterranean cyclones. This notably includes the future evolution of the large-scale conditions leading to RWB and the resulting southern deviations of the polar jet. Although this is the main mechanism triggering Mediterranean cyclogenesis, its systematic analysis is still missing from the state of the art. Finally, new studies should also focus on the contribution of cyclones to the variability in and extremes of the regional climate. This includes the establishment of cyclones' relationship to the regional water cycle and risks related to heavy precipitation events, dust transport and storm surges.

\subsection{Assessing the various impacts of Mediterranean cyclones}

Impacts are inevitable if an intense cyclone occurs in areas of high vulnerability. The recent medicane Ianos is a characteristic example, affecting Greece on 18-19 September 2020 with four fatalities and devastating impacts due to heavy rainfall, gusty winds and high waves (Lagouvardos et al., 2021). However, the relationship between cyclone intensity and the severity of impacts is not linear. Various factors and characteristics should be considered, and therefore an improved knowledge about the intrinsic relationship between Mediterranean cyclones and high-impact weather is needed. In this context, the state of the art suffers from the lack of systematic quantification of cyclones' contribution to Mediterranean high-impact weather. In fact, there are many studies focusing on heavy precipitation events and cyclones; conversely, other relevant risks associated with cyclones, such as windstorms and sea state, have gained less attention. Especially concerning the sea state, few studies on air-sea interactions focused on impacts. For instance, the sea wave field associated with cyclones is usually a mixture of wind and swell due to the spatial inhomogeneity of intense surface winds and their directional variability among the different cyclone sectors (Ponce de León and Bettencourt, 2019). Extreme storm surges may result from the superposition of different factors directly related to cyclones, such as pressure drop, winds, meteotsunamis and waves, superimposed on the astronomical tide (Lionello et al., 2021; Ferrarin et al., 2021). In addition, intense rainfall interacts with the waves attenuating the development of shorter waves at the high-frequency tail (Cavaleri and Bertotti, 2017). The complexity of in-cyclone wave patterns is still an open question that calls for extensive research to increase predictability and assess the risk of high waves in maritime transportation and coastal structures. Considering the high impacts that Mediterranean cyclones produce in terms of human losses, property and infrastructure damage, the need to step from hazard forecasts (such as heavy rainfall, wind gusts, etc.) to impact-based forecasts is essential (Taylor et al., 2018; Zhang et al., 2019). In this context, the World Meteorological Organisation (WMO, 2015) World Weather Research Programme (WWRP) launched in 2015 the High-Impact Weather Project (HIWeather; http: //hiweather.net, last access: 28 January 2022) that aims at enhancing the communication of the high-impact weather forecasts to increase resilience of societies. Societies resilient against high-impact weather need impact-based warning systems, structural protection, and proper training and education. This is imperative to reduce fatalities and facilitate recovery from the consequences of high-impact weather events, including those related to Mediterranean cyclones.

\section{Conclusion}

This article performed a review of the status of knowledge in the broader field of Mediterranean cyclones and outlined future research directions. The coordination of community efforts is deemed necessary to advance the field of Mediterranean cyclones as a whole, and, in most cases, these efforts need to include interdisciplinary approaches. Such approaches would demand collaboration between climate and weather communities but also between researchers working on oceanography and atmospheric composition and dynamics. The combination of existing knowledge, tools and methods could balance the asymmetric progress in different subdomains of the field and in different regions within the Mediterranean. For instance, cyclone prediction on both weather and climate scales is strongly dependent on models. However, forecasting cyclones is still lacking the substantial amount of multi-model approaches that have been performed in climatological studies. In parallel, new methods need to be developed for newly identified challenges in the field, or rather under-addressed research topics need to be addressed. Among others, the understanding of dust or sea wave interactions with cyclone dynamics and their consequent impacts demand dedicated observations and model adaptations, both performed in an interdisciplinary framework. Therefore, the main contribution of this article is to highlight the research topics that deepen our knowledge on Mediterranean cyclones and to provide useful guidelines to the international community efforts, especially those that have been coordinated in the framework of the COST Action CA19109 MedCyclones (European network for Mediterranean cyclones in weather and climate), recently started.

Code and data availability. No new analysis has been performed in this article. All presented results are already published in previous papers. 
Author contributions. The first five authors (EF, SD, SRR, FP and MMM) conceptualised the structure, organised the content of the article and reviewed the original draft. In particular, EF edited the original draft, contributed to writing most of Sect. 7 on open questions in the broader field of Mediterranean cyclones and contributed with FP, SD, SRR and MMM to writing the sections on cyclone dynamics. MAG, MH and MR contributed to sections devoted to cyclones climatology. FP, VH and DR contributed to sections on numerical weather prediction, and finally, SK, GK, VK and JK contributed to writing sections on cyclone impacts.

Competing interests. At least one of the (co-)authors is a member of the editorial board of Weather and Climate Dynamics. The peerreview process was guided by an independent editor, and the authors also have no other competing interests to declare.

Disclaimer. Publisher's note: Copernicus Publications remains neutral with regard to jurisdictional claims in published maps and institutional affiliations.

Acknowledgements. The authors are thankful to three anonymous reviewers and Tim Woollings for their encouraging reviews, the constructive comments and all suggestions that greatly improved the manuscript. This article is based upon work from COST Action CA19109 "MedCyclones", supported by COST - European Cooperation in Science and Technology (http://www.cost.eu, last access: 28 January 2022).

Financial support. Silvio Davolio and Mario Marcello Miglietta were supported by the project "Climate change: risk mitigation for sustainable development" funded by the Italian Ministry for Education, University and Research (MIUR). Miguel Angel Gaertner has been supported by the Spanish Ministry of Science, Innovation and Universities, the Spanish State Research Agency, and the European Regional Development Fund through grant CGL201789583-R (IBERTROPIC project). Samira Khodayar is supported by the Talented Researchers Support Programme - Pla GenT CIDEGENT by the Ministry of Innovation, Universities, Science and Digital Society, Generalitat Valenciana (GVA), project MEDEXTREME (CIDEGENT/2018/017). Marco Reale has been supported in this work by OGS and CINECA under HPC-TRES award number 2015-07 and by the project FAIRSEA (Fisheries in the Adriatic Region - a Shared Ecosystem Approach) funded by the 2014-2020 Interreg V-A Italy-Croatia CBC Programme (standard project ID 10046951). Victor Homar has been supported by the Spanish Ministry of Science, Innovation and Universities, the Spanish State Research Agency, and the European Regional Development Fund through grant CGL2017-82868-R (COASTEPS). Shira Raveh-Rubin has been supported by the De Botton Center for Marine Science. Jonilda Kushta's contribution has been supported by the EMME-CARE project, which has received funding from the European Union's Horizon 2020 Research and Innovation Programme (under grant agreement no. 856612) and the Cyprus Government.
Review statement. This paper was edited by Tim Woollings and reviewed by three anonymous referees.

\section{References}

Aebischer, U. and Schär, C.: Low-level potential vorticity and cyclogenesis to the lee of the Alps, J. Atmos. Sci., 55, 186-207, 1998.

Ahmadi-Givi, F., Nasr-Esfahany, M., and Mohebalhojeh, A. R.: Interaction of North Atlantic baroclinic wave packets and the Mediterranean storm track: Interaction of baroclinic wave packets and storm tracks, Q. J. Roy. Meteorol. Soc., 140, 754-765, https://doi.org/10.1002/qj.2171, 2014.

Aksoy, A., Dowell, D. C., and Snyder, C.: A Multicase Comparative Assessment of the Ensemble Kalman Filter for Assimilation of Radar Observations. Part II: Short-Range Ensemble Forecasts, Mon. Weather Rev., 138, 1273-1292, https://doi.org/10.1175/2009MWR3086.1, 2010.

Alpert, P. and Ziv, B.: The Sharav Cyclone: Observations and some theoretical considerations, J. Geophys. Res., 94, 18495, https://doi.org/10.1029/JD094iD15p18495, 1989.

Alpert, P., Neeman, B. U., and Shay-El, Y.: Climatological analysis of Mediterranean cyclones using ECMWF data, Tellus A, 42, 6577, https://doi.org/10.1034/j.1600-0870.1990.00007.x, 1990.

Amengual, A., Carrió, D. S., Ravazzani, G., and Homar, V.: A Comparison of Ensemble Strategies for Flash Flood Forecasting: The 12 October 2007 Case Study in Valencia, Spain, J. Hydrometeorol., 18, 1143-1166, https://doi.org/10.1175/JHM-D-16-0281.1, 2017.

Androulidakis, Y. S., Kombiadou, K. D., Makris, C. V., Baltikas, V. N., and Krestenitis, Y. N.: Storm surges in the Mediterranean Sea: Variability and trends under future climatic conditions, Dynam. Atmos. Oceans, 71, 56-82, https://doi.org/10.1016/j.dynatmoce.2015.06.001, 2015.

Anwender, D., Harr, P. A., and Jones, S. C.: Predictability Associated with the Downstream Impacts of the Extratropical Transition of Tropical Cyclones: Case Studies, Mon. Weather Rev., 136, 3226-3247, https://doi.org/10.1175/2008MWR2249.1, 2008.

Argence, S., Lambert, D., Richard, E., Chaboureau, J. P., and Söhne, N.: Impact of initial condition uncertainties on the predictability of heavy rainfall in the Mediterranean: A case study, Q. J. Roy. Meteorol. Soc., 134, 1775-1788, https://doi.org/10.1002/qj.314, 2008.

Baars, H., Herzog, A., Heese, B., Ohneiser, K., Hanbuch, K., Hofer, J., Yin, Z., Engelmann, R., and Wandinger, U.: Validation of Aeolus wind products above the Atlantic Ocean, Atmos. Meas. Tech., 13, 6007-6024, https://doi.org/10.5194/amt13-6007-2020, 2020.

Bartholy, J., Pongrácz, R., and Pattantyús-Ábrahám, M.: Analyzing the genesis, intensity, and tracks of western Mediterranean cyclones, Theor. Appl. Climatol., 96, 133-144, https://doi.org/10.1007/s00704-008-0082-9, 2009.

Bengtsson, L., Hodges, K. I., and Roeckner, E.: Storm Tracks and Climate Change, J. Climate, 19, 3518-3543, https://doi.org/10.1175/JCLI3815.1, 2006. 
Bertotti, L. and Cavaleri, L.: The predictability of the "Voyager" accident, Nat. Hazards Earth Syst. Sci., 8, 533-537, https://doi.org/10.5194/nhess-8-533-2008, 2008.

Bevacqua, E., Maraun, D., Vousdoukas, M. I., Voukouvalas, E., Vrac, M., Mentaschi, L., and Widmann, M.: Higher probability of compound flooding from precipitation and storm surge in Europe under anthropogenic climate change, Sci. Adv., 5, eaw5531, https://doi.org/10.1126/sciadv.aaw5531, 2019.

Bitsa, E., Flocas, H., Kouroutzoglou, J., Hatzaki, M., Rudeva, I., and Simmonds, I.: Development of a Front Identification Scheme for Compiling a Cold Front Climatology of the Mediterranean, Climate, 7, 130, https://doi.org/10.3390/cli7110130, 2019.

Bladé, I., Liebmann, B., Fortuny, D., and van Oldenborgh, G. J.: Observed and simulated impacts of the summer NAO in Europe: implications for projected drying in the Mediterranean region, Clim. Dynam., 39, 709-727, https://doi.org/10.1007/s00382011-1195-x, 2012.

Bouin, M.-N. and Lebeaupin Brossier, C.: Impact of a medicane on the oceanic surface layer from a coupled, kilometre-scale simulation, Ocean Sci., 16, 1125-1142, https://doi.org/10.5194/os16-1125-2020, 2020.

Bou Karam, D., Flamant, C., Cuesta, J., Pelon, J., and Williams, E.: Dust emission and transport associated with a Saharan depression: February 2007 case, J. Geophys. Res., 115, D00H27, https://doi.org/10.1029/2009JD012390, 2010.

Bouttier, F., Raynaud, L., Nuissier, O., and Ménétrier, B.: Sensitivity of the AROME ensemble to initial and surface perturbations during HyMeX, Q. J. Roy. Meteorol. Soc., 142, 390-403, https://doi.org/10.1002/qj.2622, 2016.

Brâncuş, M., Schultz, D. M., Antonescu, B., Dearden, C., and Ştefan, S.: Origin of Strong Winds in an Explosive Mediterranean Extratropical Cyclone, Mon. Weather Rev., 147, 3649-3671, https://doi.org/10.1175/MWR-D-19-0009.1, 2019.

Buzzi, A.: Synoptic scale variability in the Mediterranean, Proc. of 2010 ECMWF Annual Seminar, 6-9 September 2012, Reading, UK, ECMWF, 16 pp., available at: https://www.ecmwf.int/sites/default/files/elibrary/2012/

8502-synoptic-scale-variability-mediterranean.pdf (last access: 30 June 2021), 2012.

Buzzi, A. and Tibaldi, S.: Cyclogenesis in the lee of the Alps: a case study, Q. J. Roy. Meteorol. Soc., 104, 271-287, 1978.

Buzzi, A., D'Isidoro, M., and Davolio, S.: A case study of an orographic cyclone formation south of the Alps during the MAPSOP, Q. J. Roy. Meteorol. Soc., 129, 1795-1818, 2003

Buzzi, A., Davolio, S., and Fantini, M.: Cyclogenesis in the lee of the Alps: a review of theories, Bull. Atmos. Sci. Technol., 1, 433457, https://doi.org/10.1007/s42865-020-00021-6, 2020.

Čampa, J. and Wernli, H.: A PV Perspective on the Vertical Structure of Mature Midlatitude Cyclones in the Northern Hemisphere, J. Atmos. Sci., 69, 725-740, https://doi.org/10.1175/JASD-11-050.1, 2012.

Campins, J., Genovìes, A., Jansà, A., Guijarroa, J. A., and Ramis,C.: A catalogue and a classification of surface ciclones for theWestern Mediterranean, Int. J. Climatol., 20, 969-984, 2000.

Campins, J., Genoveìs, A., Picornell, M. A., and Jansà, A.: Climatology of Mediterranean cyclones using the ERA-40 dataset, Int. J. Climatol., 31, 1596-1614, https://doi.org/10.1002/joc.2183, 2011.
Campins, J., Navascués, B., Santos, C., and Amo-Baladrón, A.: Influence of targeted observations on short-term forecasts of high-impact weather events in the Mediterranean, Nat. Hazards Earth Syst. Sci., 13, 2891-2910, https://doi.org/10.5194/nhess13-2891-2013, 2013.

Carlson, T. N.: Airflow through midlatitude cyclones and the comma cloud pattern, Mon. Weather Rev., 108, 1498-1509, 1980.

Carrió, D. S. and Homar, V.: Potential of sequential EnKF for the short-range prediction of a maritime severe weather event, Atmos. Res., 178-179, 426-444, https://doi.org/10.1016/j.atmosres.2016.04.011, 2016.

Carrió, D. S., Homar, V., Jansa, A., Romero, R., and Picornell, M. A.: Tropicalization process of the 7 November 2014 Mediterranean cyclone: Numerical sensitivity study, Atmos. Res., 197, 300-312, https://doi.org/10.1016/j.atmosres.2017.07.018, 2017.

Carrió, D. S., Homar, V., and Wheatley, D. M.: Potential of an EnKF Storm-Scale Data Assimilation System Over Sparse Observation Regions with Complex Orography, Atmos. Res., 216, 186-206, https://doi.org/10.1016/j.atmosres.2018.10.004, 2019.

Carrió, D. S., Homar, V., Jansà, A., Picornell, M. A., and Campins, J.: Diagnosis of a high-impact secondary cyclone during HyMeX-SOP1 IOP18, Atmos. Res., 242, 104983, https://doi.org/10.1016/j.atmosres.2020.104983, 2020.

Catto, J. L. and Raveh-Rubin, S.: Climatology and dynamics of the link between dry intrusions and cold fronts during winter. Part I: global climatology, Clim. Dynam., 53, 1873-1892, 2019.

Cavaleri, L. and Bertotti, L.: The Attenuation of Swell Waves by Rain: The Attenuation of Swell Waves by Rain, Geophys. Res. Lett., 44, 10504-10510, https://doi.org/10.1002/2017GL075458, 2017.

Cavaleri, L., Bertotti, L., Torrisi, L., Bitner-Gregersen, E., Serio, M., and Onorato, M.: Rogue waves in crossing seas: The Louis Majesty accident, J. Geophys. Res., 117, C00J10, https://doi.org/10.1029/2012JC007923, 2012.

Cavaleri, L., Barbariol, F., Bastianini, M., Benetazzo, A., Bertotti, L., Bajo, M., Chiggiato, J., Davolio, S., Ferrarin, C., Magnusson, L., Papa, A., Pezzutto, P., Pomaro, A., and Umgiesser, G.: The October 29, 2018 storm in Northern Italy - an exceptional event and its modeling, Prog. Oceanogr., 178, 102178, https://doi.org/10.1016/j.pocean.2019.102178, 2019.

Cavicchia, L., von Storch, H., and Gualdi, S.: A long-term climatology of medicanes, Clim. Dynam., 43, 1183-1195, 2014a.

Cavicchia, L., von Storch, H., and Gualdi, S.: Mediterranean Tropical-Like Cyclones in Present and Future Climate, J. Climate, 27, 7493-7501, 2014b.

Chaboureau, J. P., Pantillon, F., Lambert, D., Richard, E., and Claud, C.: Tropical transition of a Mediterranean storm by jet crossing, Q. J. Roy. Meteorol. Soc., 138, 596-611, https://doi.org/10.1002/qj.960, 2012.

Chazette, P., Flamant, C., Raut, J.-C., Totems, J., and Shang, X.: Tropical moisture enriched storm tracks over the Mediterranean and their link with intense rainfall in the Cevennes-Vivarais area during HyMeX, Q. J. Roy. Meteorol. Soc., 142, 320-334, https://doi.org/10.1002/qj.2674, 2016.

Chronis, T., Raitsos, D. E., Kassis, D., and Sarantopoulos, A.: The Summer North Atlantic Oscillation Influence on the Eastern Mediterranean, J. Climate, 24, 5584-5596, https://doi.org/10.1175/2011JCLI3839.1, 2011. 
Cioni, G., Malguzzi, P., and Buzzi, A.: Thermal structure and dynamical precursor of a Mediterranean tropicallike cyclone, Q. J. Roy. Meteorol. Soc., 142, 1757-1766, https://doi.org/10.1002/qj.2773, 2016.

Cioni, G., Cerrai, D., and Klocke, D.: Investigating the predictability of a Mediterranean tropical-like cyclone using a stormresolving model, Q. J. Roy. Meteorol. Soc., 144, 1598-1610, https://doi.org/10.1002/qj.3322, 2018.

Clark, P. A. and Gray, S. L.: Sting jets in extratropical cyclones: a review, Q. J. Roy. Meteorol. Soc., 144, 943-969, 2018.

Clark, P. A., Browning, K. A., and Wang, C.: The sting at the end of the tail: Model diagnostics of fine-scale three-dimensional structure of the cloud head, Q. J. Roy. Meteorol. Soc., 131, 22632292, https://doi.org/10.1256/qj.04.36, 2005.

Claud, C., Alhammoud, B., Funatsu, B. M., and Chaboureau, J.-P.: Mediterranean hurricanes: large-scale environment and convective and precipitating areas from satellite microwave observations, Nat. Hazards Earth Syst. Sci., 10, 2199-2213, https://doi.org/10.5194/nhess-10-2199-2010, 2010.

Dafis, S., Rysman, J., Claud, C., and Flaounas, E.: Remote sensing of deep convection within a tropical-like cyclone over the Mediterranean Sea, Atmos. Sci. Lett., 19, e823, https://doi.org/10.1002/as1.823, 2018.

Dafis, S., Claud, C., Kotroni, V., Lagouvardos, K., and Rysman, J.: Insights into the convective evolution of Mediterranean tropicallike cyclones, Q. J. Roy. Meteorol. Soc., 146, 4147-4169, https://doi.org/10.1002/qj.3896, 2020.

Davis, C. A. and Bosart, L. F.: The TT problem: forecasting thetropical transition of cyclones, B. Am. Meteorol. Soc., 85, 16571662, 2004.

Davolio, S., Volontè, A., Manzato, A., Pucillo, A., Cicogna, A., and Ferrario, M. E.: Mechanisms producing different precipitation patterns over North-Eastern Italy: insights from HyMeX-SOP1 and previous events, Q. J. Roy. Meteorol. Soc., 142, 188-205, https://doi.org/10.1002/qj.2731, 2016.

Davolio, S., Della Fera, S., Laviola, S., Miglietta, M. M., and Levizzani, V.: Heavy precipitation over Italy from the Mediterranean storm "Vaia" in October 2018: Assessing the role of an atmospheric river, Mon. Weather Rev., 148, 3571-3588, 2020.

Dayan, U., Ziv, B., Shoob, T., and Enzel, Y.: Suspended dust over southeastern Mediterranean and its relation to atmospheric circulations, Int. J. Climatol., 28, 915-924, https://doi.org/10.1002/joc.1587, 2008.

Dee, D. P., Uppala, S. M., Simmons, A. J., Berrisford, P., Poli, P., Kobayashi, S., Andrae, U., Balmaseda, M. A., Balsamo, G., Bauer, P., Bechtold, P., Beljaars, A. C. M., van de Berg, L., Bidlot, J., Bormann, N., Delsol, C., Dragani, R., Fuentes, M., Geer, A. J., Haimberger, L., Healy, S. B., Hersbach, H., Hólm, E. V., Isaksen, L., Kållberg, P., Köhler, M., Matricardi, M., McNally, A. P., Monge-Sanz, B. M., Morcrette, J.-J., Park, B.-K., Peubey, C., de Rosnay, P., Tavolato, C., Thépaut, J.-N., and Vitart, F.: The ERA-Interim reanalysis: configuration and performance of the data assimilation system, Q. J. Roy. Meteorol. Soc., 137, 553597, https://doi.org/10.1002/qj.828, 2011.

de la Vara, A., Gutiérrez-Fernández, J., González-Alemán, J. J., and Gaertner, M. Á.: Characterization of medicanes with a minimal number of geopotential levels, Int. J. Climatol., 41, 3300-3316, https://doi.org/10.1002/joc.7020, 2021.
Delrieu, G., Nicol, J., Yates, E., Kirstetter, P.-E., Creutin, J.D., Anquetin, S., Obled, C., Saulnier, G.-M., Ducrocq, V., Gaume, E., Payrastre, O., Andrieu, H., Ayral, P.-A., Bouvier, C., Neppel, L., Livet, M., Lang, M., du-Châtelet, J. P., Walpersdorf, A., and Wobrock, W.: The Catastrophic FlashFlood Event of 8-9 September 2002 in the Gard Region, France: A First Case Study for the Cévennes-Vivarais Mediterranean Hydrometeorological Observatory, J. Hydrometeorol., 6, 34-52, https://doi.org/10.1175/JHM-400.1, 2005.

Di Muzio, E., Riemer, M., Fink, A. H., and Maier-Gerber, M.: Assessing the predictability of Medicanes in ECMWF ensemble forecasts using an object-based approach, Q. J. Roy. Meteorol. Soc., 145, 1202-1217, https://doi.org/10.1002/qj.3489, 2019.

Dong, B., Sutton, R. T., Woollings, T., and Hodges, K.: Variability of the North Atlantic summer storm track: mechanisms and impacts on European climate, Environ. Res. Lett., 8, 034037, https://doi.org/10.1088/1748-9326/8/3/034037, 2013.

Drobinski, P., Ducrocq, V., Alpert, P., Anagnostou, E., Béranger, K., Borga, M., Braud, I., Chanzy, A., Davolio, S., Delrieu, G., Estournel, C., Boubrahmi, N. F., Font, J., Grubišić, V., Gualdi, S., Homar, V., Ivančan-Picek, B., Kottmeier, C., Kotroni, V., Lagouvardos, K., Lionello, P., Llasat, M. C., Ludwig, W., Lutoff, C., Mariotti, A., Richard, E., Romero, R., Rotunno, R., Roussot, O., Ruin, I., Somot, S., Taupier-Letage, I., Tintore, J., Uijlenhoet, R., and Wernli, H.: HyMeX, a 10-year multidisciplinary program on the Mediterranean water cycle, B. Am. Meteorol. Soc., 95, 10631082, https://doi.org/10.1175/BAMS-D-12-00242.1, 2014.

Ducrocq, V., Braud, I., Davolio, S., Ferretti, R., Flamant, C., Jansa, A., Kalthoff, N., Richard, E., Taupier-Letage, I., Ayral, P.-A., Belamari, S., Berne, A., Borga, M., Boudevillain, B., Bock, O., Boichard, J.-L., Bouin, M.-N., Bousquet, O., Bouvier, C., Chiggiato, J., Cimini, D., Corsmeier, U., Coppola, L., Cocquerez, P., Defer, E., Delanoë, J., Di Girolamo, P., Doerenbecher, A., Drobinski, P., Dufournet, Y., Fourrié, N., Gourley, J. J., Labatut, L., Lambert, D., Le Coz, J., Marzano, F. S., Molinié, G., Montani, A., Nord, G., Nuret, M., Ramage, K., Rison, W., Roussot, O., Said, F., Schwarzenboeck, A., Testor, P., Van Baelen, J., Vincendon, B., Aran, M., and Tamayo, J.: HyMeX-SOP1: The field campaign dedicated to heavy precipitation and flash flooding in the northwestern Mediterranean, B. Am. Meteorol. Soc., 95, 1083-1100, 2014.

Duffourg, F., Lee, K. O., Ducrocq, V., Flamant, C., Chazette, P., and Di Girolamo, P.: Role of moisture patterns in the backbuilding formation of HyMeX IOP13 Heavy Precipitating Systems, Q. J. Roy. Meteor. Soc., 144, 291-303, https://doi.org/10.1002/qj.3201, 2018.

Egger, J., Alpert, P., Tafferner, A., and Ziv, B.: Numerical experiments on the genesis of Sharav cyclones: idealized simulations, Tellus A, 47, 162-174, https://doi.org/10.1034/j.16000870.1995.t01-1-00002.x, 1995.

Emanuel, K.: Genesis and maintenance of Mediterranean hurricanes, Adv. Geosci., 2, 217-220, 2005.

Emanuel, K. A.: An air-sea interaction theory for tropical cyclones. Part I: Steady-state maintenance, J. Atmos. Sci., 43, 585-604, 1986.

Fantini, M. and Davolio, S.: Instability of Neutral Eady Waves and orography, J. Atmos. Sci., 58, 1146-1154, 2001.

Ferrarin, C., Bajo, M., Benetazzo, A., Cavaleri, L., Chiggiato, J., Davison, S., Davolio S., Lionello, P., Orlić, M., and Umgiesser, 
G: Local and large-scale controls of the exceptional Venice floods of November 2019, Prog. Oceanogr., 197, 102628, https://doi.org/10.1016/j.pocean.2021.102628, 2021.

Fiedler, S., Schepanski, K., Knippertz, P., Heinold, B., and Tegen, I.: How important are atmospheric depressions and mobile cyclones for emitting mineral dust aerosol in North Africa?, Atmos. Chem. Phys., 14, 8983-9000, https://doi.org/10.5194/acp14-8983-2014, 2014.

Fita, L. and Flaounas, E.: Medicanes as subtropical cyclones: the December 2005 case from the perspective of surface pressure tendency diagnostics and atmospheric water budget, Q. J. Roy. Meteorol. Soc., 144, 1028-1044, https://doi.org/10.1002/qj.3273, 2018.

Fita, L., Romero, R., and Ramis, C.: Intercomparison of intense cyclogenesis events over the Mediterranean basin based on baroclinic and diabatic influences, Adv. Geosci., 7, 333-342, https://doi.org/10.5194/adgeo-7-333-2006, 2006.

Fita, L., Romero, R., Luque, A., Emanuel, K., and Ramis, C.: Analysis of the environments of seven Mediterranean tropicallike storms using an axisymmetric, nonhydrostatic, cloud resolving model, Nat. Hazards Earth Syst. Sci., 7, 41-56, https://doi.org/10.5194/nhess-7-41-2007, 2007.

Flaounas, E., Drobinski, P., and Bastin, S.: Dynamical downscaling of IPSL-CM5 CMIP5 historical simulations over the Mediterranean: benefits on the representation of regional surface winds and cyclogenesis, Clim. Dynam., 40, 2497-2513, https://doi.org/10.1007/s00382-012-1606-7, 2013.

Flaounas, E., Kotroni, V., Lagouvardos, K., and Flaounas, I.: CycloTRACK (v1.0) - tracking winter extratropical cyclones based on relative vorticity: sensitivity to data filtering and other relevant parameters, Geosci. Model Dev., 7, 1841-1853, https://doi.org/10.5194/gmd-7-1841-2014, 2014.

Flaounas, E., Raveh-Rubin, S., Wernli, H., Drobinski, P., and Bastin, S.: The dynamical structure of intense Mediterranean cyclones, Clim. Dynam., 44, 2411-2427, https://doi.org/10.1007/s00382-014-2330-2, 2015.

Flaounas, E., Lagouvardos, K., Kotroni, V., Claud, C., Delanoë, J., Flamant, C., and Wernli, H.: Processes leading to heavy precipitation associated with two Mediterranean cyclones observed during the HyMeX SOP1, Q. J. Roy. Meteorol. Soc., 142, 275-286, 2016.

Flaounas, E., Kotroni, V., Lagouvardos, K., Gray, S. L., Rysman, J.-F., and Claud, C.: Heavy rainfall in Mediterranean cyclones. Part I: contribution of deep convection and warm conveyor belt, Clim. Dynam., 50, 2935-2949, https://doi.org/10.1007/s00382017-3783-x, 2018.

Flaounas, E., Fita, L., Lagouvardos, K., and Kotroni, V.: Heavy rainfall in Mediterranean cyclones, Part II: Water budget, precipitation efficiency and remote water sources, Clim. Dynam., 53, 2539-2555, https://doi.org/10.1007/s00382-019-04639-x, 2019.

Flaounas, E., Gray, S. L., and Teubler, F.: A process-based anatomy of Mediterranean cyclones: from baroclinic lows to tropical-like systems, Weather Clim. Dynam., 2, 255-279, https://doi.org/10.5194/wcd-2-255-2021, 2021.

Flocas, H. A.: Diagnostics of cyclogenesis over the Aegean sea using potential vorticity inversion, Meteorol. Atmos. Phys., 73, 25 33, https://doi.org/10.1007/s007030050061, 2000.

Flocas, H. A., Simmonds, I., Kouroutzoglou, J., Keay, K., Hatzaki, M., Bricolas, V., and Asimakopoulos, D.: On Cyclonic Tracks over the Eastern Mediterranean, J. Climate, 23, 5243-5257, https://doi.org/10.1175/2010JCLI3426.1, 2010.

Fourrié, N., Bresson, É., Nuret, M., Jany, C., Brousseau, P., Doerenbecher, A., Kreitz, M., Nuissier, O., Sevault, E., Bénichou, H., Amodei, M., and Pouponneau, F.: AROME-WMED, a real-time mesoscale model designed for the HyMeX special observation periods, Geosci. Model Dev., 8, 1919-1941, https://doi.org/10.5194/gmd-8-1919-2015, 2015.

Fourrié, N., Nuret, M., Brousseau, P., Caumont, O., Doerenbecher, A., Wattrelot, E., Moll, P., Bénichou, H., Puech, D., Bock, O., Bosser, P., Chazette, P., Flamant, C., Di Girolamo, P., Richard, E., and Saïd, F.: The AROME-WMED reanalyses of the first special observation period of the Hydrological cycle in the Mediterranean experiment (HyMeX), Geosci. Model Dev., 12, $2657-$ 2678, https://doi.org/10.5194/gmd-12-2657-2019, 2019.

Fourrié, N., Nuret, M., Brousseau, P., and Caumont, O.: Data assimilation impact studies with the AROME-WMED reanalysis of the first special observation period of the Hydrological cycle in the Mediterranean Experiment, Nat. Hazards Earth Syst. Sci., 21, 463-480, https://doi.org/10.5194/nhess-21-463-2021, 2021.

Gaertner, M. A., Jacob, D., Gil, V., Domínguez, M., Padorno, E., Sánchez, E., and Castro, M.: Tropical cyclones over the Mediterranean Sea in climate change simulations, Geophys. Res. Lett., 34, L14711, https://doi.org/10.1029/2007GL029977, 2007.

Gaertner, M. A., González-Alemán, J.J., Romera, R., Domínguez, M., Gil, V., Sánchez, E., Gallardo, C., Miglietta, M., Walsh, K.J.E., Sein, D.V., Somot, S., Dell'Aquila, A., Teichmann, C., Ahrens, B., Buonomo, E., Colette, A., Bastin, S., van Meijgaard, E., and Nikulin, G.: Simulation of medicanes over the Mediterranean Sea in a regional climate model ensemble: impact of ocean-atmosphere coupling and increased resolution, Clim. Dynam., 51, 1041-1057, 2018.

Galanaki, E., Flaounas, E., Kotroni, V., Lagouvardos, K., and Argiriou, A.: Lightning activity in the Mediterranean: quantification of cyclones contribution and relation to their intensity, Atmos. Sci. Lett., 17, 510-516, https://doi.org/10.1002/asl.685, 2016.

Garcies, L. and Homar, V.: Ensemble sensitivities of the real atmosphere: application to Mediterranean intense cyclones, Tellus A, 61, 394-406, https://doi.org/10.1111/j.1600-0870.2009.00392.x, 2009.

Garcies, L. and Homar, V.: An optimized ensemble sensitivity climatology of Mediterranean intense cyclones, Nat. Hazards Earth Syst. Sci., 10, 2441-2450, https://doi.org/10.5194/nhess10-2441-2010, 2010.

Garcies, L. and Homar, V.: Are current sensitivity products sufficiently informative in targeting campaigns? A DTSMEDEX-2009 case study: Testing DTS-MEDEX-2009 Sensitivity Products, Q. J. Roy. Meteorol. Soc., 140, 525-538, https://doi.org/10.1002/qj.2148, 2014.

Gariano, S. L., Petrucci, O., and Guzzetti, F.: Changes in the occurrence of rainfall-induced landslides in Calabria, southern Italy, in the 20th century, Nat. Hazards Earth Syst. Sci., 15, 2313-2330, https://doi.org/10.5194/nhess-15-2313-2015, 2015.

Giorgi, F.: Climate change hot-spots, Geophys. Res. Lett., 33, L08707, https://doi.org/10.1029/2006GL025734, 2006.

Giovannini, L., Davolio, S., Zaramella, M., Zardi, D., and Borga, M.,: Multi-model convection-resolving simulations of the October 2018 Vaia storm over northeastern Italy, Atmos. Res., 253 105455, https://doi.org/10.1016/j.atmosres.2021.105455, 2021. 
Givon, Y., Keller Jr., D., Silverman, V., Pennel, R., Drobinski, P., and Raveh-Rubin, S.: Large-scale drivers of the mistral wind: link to Rossby wave life cycles and seasonal variability, Weather Clim. Dynam., 2, 609-630, https://doi.org/10.5194/wcd-2-6092021, 2021.

Goldreich, Y.: Climatic Forecast, in: The Climate of Israel, Springer US, Boston, MA, 173-181, https://doi.org/10.1007/978-1-46150697-3_10, 2003.

González-Alemán, J. J., Pascale, S., Gutierrez-Fernandez, J., Murakami, H., Gaertner, M. A., and Vecchi, G. A.: Potential increase in hazard from Mediterranean hurricane activity with global warming. Geophys. Res. Lett., 46, 1754-1764, 2019.

Grams, C. M., Wernli, H., Böttcher, M., Čampa, J., Corsmeier, U., Jones, S. C., Keller, J. H., Lenz, C.-J., and Wiegand, L.: The key role of diabatic processes in modifying the upper-tropospheric wave guide: a North Atlantic case-study, Q. J. Roy. Meteorol. Soc., 137, 2174-2193, https://doi.org/10.1002/qj.891, 2011.

Gutiérrez-Fernández, J., González-Alemán, J. J., de la Vara, A., Cabos, W., Sein, D. V., and Gaertner, M. Á.: Impact of ocean-atmosphere coupling on future projection of Medicanes in the Mediterranean sea. Int. J. Climatol., 41, 2226-2238, https://doi.org/10.1002/joc.6955, 2021.

Hakim, G. J.: Developing Wave Packets in the North Pacific Storm Track, Mon. Weather Rev., 131, 2824-2837, https://doi.org/10.1175/15200493(2003)131<2824:DWPITN>2.0.CO;2, 2003.

Hart, R. E.: A cyclone phase space derived from thermal wind andthermal asymmetry, Mon. Weather Rev., 131, 585-616, 2003.

Hawcroft, M. K., Shaffrey, L. C., Hodges, K. I., and Dacre, H. F.: How much Northern Hemisphere precipitation is associated with extratropical cyclones?, Geophys. Res. Lett., 39, 2012GL053866, https://doi.org/10.1029/2012GL053866, 2012.

Hermoso, A., Homar, V., Greybush, S. J., and Stensrud, D. J.: Tailored Ensemble Prediction Systems: Application of Seamless Scale Bred Vectors, J. Meteorol. Soc. Jpn., 98, 1029-1050, https://doi.org/10.2151/jmsj.2020-053, 2020.

Hermoso, A., Homar, V., and Amengual, A.: The Sequence of Heavy Precipitation and Flash Flooding of 12 and 13 September 2019 in Eastern Spain. Part I: Mesoscale Diagnostic and Sensitivity Analysis of Precipitation, J. Hydrometeorol., 22, 1117-1138, https://doi.org/10.1175/JHM-D-20-0182.1, 2021.

HMSO: Weather in the Mediterranean I: General Meteorology, 2nd edn., Her Majesty's Stationery Office, 362 pp., OCLC 637451093, 1962.

Hochman, A., Harpaz, T., Saaroni, H., and Alpert, P.: Synoptic classification in 21st century CMIP5 predictions over the Eastern Mediterranean with focus on cyclones, Int. J. Climatol., 38, 1476-1483, https://doi.org/10.1002/joc.5260, 2018.

Hofstätter, M. and Blöschl, G.: Vb cyclones synchronized with the Arctic-/North Atlantic Oscillation, J. Geophys. Res., 124, 32593278, https://doi.org/10.1029/2018JD029420, 2019.

Homar, V., Ramis, C., and Alonso, S.: A deep cyclone of African origin over the Western Mediterranean: diagnosis and numerical simulation, Ann. Geophys., 20, 93-106, https://doi.org/10.5194/angeo-20-93-2002, 2002.

Homar, V., Romero R., Stensrud, D. J., Ramis C., and Alonso, S.: Numerical diagnosis of a small, quasi-tropical cyclone over the western Mediterranean: Dynamical vs. boundary factors, Q. J. Roy. Meteorol. Soc., 129, 1469-1490, 2003.
Homar, V., Jansà, A., Campins, J., and Ramis, C.: Towards a climatology of sensitivities of Mediterranean high impact weather - first approach, Adv Geosci., 7, 259-267, 2006.

Homar, V., Jansà, A., Campins, J., Genovés, A., and Ramis, C.: Towards a systematic climatology of sensitivities of Mediterranean high impact weather: a contribution based on intense cyclones, Nat. Hazards Earth Syst. Sci., 7, 445-454, https://doi.org/10.5194/nhess-7-445-2007, 2007.

Horányi, A., Cardinali, C., Rennie, M., and Isaksen, L.: The assimilation of horizontal line-of-sight wind information into the ECMWF data assimilation and forecasting system. Part I: The assessment of wind impact, Q. J. Roy. Meteorol. Soc., 141, 12231232, https://doi.org/10.1002/qj.2430, 2015.

Horvath, K., Lin, Y.-L., and Ivančan-Picek, B.: Classification of cyclone tracks over the Apennines and the Adriatic Sea, Mon. Weather Rev., 136, 2210-2227, 2008.

Hurrell, J. W. and van Loon, H.: Decadal variations in climate associated with the north Atlantic oscillation, Climatic Change, 36, 301-326, 1997.

IPCC: Climate Change 2021: The Physical Science Basis. Contribution of Working Group I to the Sixth Assessment Report of the Intergovernmental Panel on Climate Change, edited by: Masson-Delmotte, V., Zhai, P., Pirani, A., Connors, S. L., Péan, C., Berger, S., Caud, N., Chen, Y., Goldfarb, L., Gomis, M. I., Huang, M., Leitzell, K., Lonnoy, E., Matthews, J. B. R., Maycock, T. K., Waterfield, T., Yelekçi, O., Yu, R., and Zhou, B., Cambridge University Press, 2021.

Jansa, A., Genoves, A., Picornell, M. A., Campins, J., Riosalido, R., and Carretero, O.: Western Mediterranean cyclones and heavy rain. Part 2: Statistical approach, Meteorol. Appl., 8, 43-56, https://doi.org/10.1017/S1350482701001049, 2001.

Jansa, A., Alpert, P., Arbogast, P., Buzzi, A., Ivancan-Picek, B., Kotroni, V., Llasat, M. C., Ramis, C., Richard, E., Romero, R., and Speranza, A.: MEDEX: a general overview, Nat. Hazards Earth Syst. Sci., 14, 1965-1984, https://doi.org/10.5194/nhess14-1965-2014, 2014.

Joos, H. and Forbes, R. M.: Impact of different IFS microphysics on a warm conveyor belt and the downstream flow evolution, Q. J. Roy. Meteorol. Soc., 142, 2727-2739, https://doi.org/10.1002/qj.2863, 2016.

Joos, H. and Wernli, H.: Influence of microphysical processes on the potential vorticity development in a warm conveyor belt: A casestudy with the limited-area model COSMO, Q. J. Roy. Meteorol. Soc., 138, 407-418, 2012.

Jourdan, A. and Loubière, P.: Sensitivity Analysis, in: TORUS 1 Toward an Open Resource Using Services, edited by: Laffly, D., Wiley, 107-128, https://doi.org/10.1002/9781119720492.ch9, 2020.

Kalkstein, A. J, Rudich, Y., Raveh-Rubin, S., Kloog, I., and Novack, V.: A Closer Look at the Role of the Cyprus Low on Dust Events in the Negev Desert, Atmosphere, 11, 1020, https://doi.org/10.3390/atmos11101020, 2020.

Khodayar, S., Kalthoff, N., and Kottmeier, C.: Atmospheric conditions associated with heavy precipitation events in comparison to seasonal means in the western mediterranean region, Clim. Dynam., 51, 951-967, https://doi.org/10.1007/s00382-016-3058-y, 2018a.

Khodayar, S., Czajka, B., Caldas-Alvarez, A., Helgert, S., Flamant, C., Di Girolamo, P., Bock, O., and Chazette, P.: Multi-scale 
observations of atmospheric moisture variability in relation to heavy precipitating systems in the northwestern Mediterranean during HyMeX IOP12, Q. J. Roy. Meteorol. Soc., 144, 27612780, https://doi.org/10.1002/qj.3402, 2018b.

Koseki, S., Mooney, P. A., Cabos, W., Gaertner, M. Á., de la Vara, A., and González-Alemán, J. J.: Modelling a tropicallike cyclone in the Mediterranean Sea under present and warmer climate, Nat. Hazards Earth Syst. Sci., 21, 53-71, https://doi.org/10.5194/nhess-21-53-2021, 2021.

Kouroutzoglou, J., Flocas, H. A., Keay, K., Simmonds, I., and Hatzaki, M.: Climatological aspects of explosive cyclones in the Mediterranean, Int. J. Climatol., 31, 1785-1802, https://doi.org/10.1002/joc.2203, 2011.

Kouroutzoglou, J., Flocas, H. A., Keay, K., Simmonds, I., and Hatzaki, M.: On the vertical structure of Mediterranean explosive cyclones, Theor. Appl. Climatol., 110, 155-176, https://doi.org/10.1007/s00704-012-0620-3, 2012.

Krichak, S. O. and Alpert, P.: Signatures of the NAO in the atmospheric circulation during wet winter months over the Mediterranean region, Theor. Appl. Climatol., 82, 27-39, 2005a.

Krichak, S. O. and Alpert, P.: Decadal trends in the EastAtlanticWest Russia pattern and the Mediterranean precipitation, Int. J. Climatol., 25, 183-192, 2005b.

Krichak, S. O., Feldstein, S. B., Alpert, P., Gualdi, S., Scoccimarro, E., and Yano, J.-I.: Discussing the role of tropical and subtropical moisture sources in cold season extreme precipitation events in the Mediterranean region from a climate change perspective, Nat. Hazards Earth Syst. Sci., 16, 269-285, https://doi.org/10.5194/nhess-16-269-2016, 2016.

Lagouvardos, K., Kotroni, V., and Defer, E.: The 21-22 January 2004 explosive cyclogenesis over the Aegean Sea: Observations and model analysis, Q. J. Roy. Meteorol. Soc., 133, 1519-1531, https://doi.org/10.1002/qj.121, 2007.

Lagouvardos, K., Kotroni, V., Defer E., and Bousquet, O.: Study of a heavy precipitation event over southern France, in the frame of HYMEX project: Observational analysis and model results using assimilation of lightning, Atmos. Res., 134, 45-55, 2013.

Lagouvardos, K., Karagiannidis, A., Dafis, S., Kalimeris, T., and Kotroni, V.: Ianos - A hurricane in the Mediterranean, B. Am. Meteorol. Soc., 1-31, https://doi.org/10.1175/BAMS-D-200274.1, online first, 2021.

Lee, K.-O., Flamant, C., Ducrocq, V., Duffourg, F., Fourrié, N., Delanoë, J., and Bech, J.: Initiation and development of a mesoscale convective system in the Ebro River Valley and related heavy precipitation over north-eastern Spain during HyMeX IOP 15a, Q. J. Roy. Meteor. Soc., 143, 942-956, https://doi.org/10.1002/qj.2978, 2017.

Lelieveld, J., Berresheim, H., Borrmann, S., Crutzen, P. J., Dentener, F. J., Fischer, H., Feichter, J., Flatau, P. J., Heland, J., Holzinger, R., Korrmann, R., Lawrence, M. G., Levin, Z., Markowicz, K. M., Mihalopoulos, N., Minikin, A., Ramanathan, V., de Reus, M., Roelofs, G. J., Scheeren, H. A., Sciare, J., Schlager, H., Schultz, M., Siegmund, P., Steil, B., Stephanou, E. G., Stier, P., Traub, M., Warneke, C., Williams, J., and Ziereis, H.: Global Air Pollution Crossroads over the Mediterranean, Science, 298, 794-799, https://doi.org/10.1126/science.1075457, 2002.
Liberato, M. L.: The 19 January 2013 windstorm over the North Atlantic: large-scale dynamics and impacts on Iberia, Weather and Climate Extremes, 5, 16-28, 2014.

Liberato, M. L., Pinto, J. G., Trigo, I. F., and Trigo, R. M.: Klausan exceptional winter storm over northern Iberia and southern France, Weather, 66, 330-334, 2011.

Lin, Y.: Mesoscale Dynamics, Cambridge University Press, https://doi.org/10.1017/CBO9780511619649, 2007.

Lionello, P. and Giorgi, F.: Winter precipitation and cyclones in the Mediterranean region: future climate scenarios in a regional simulation, Adv. Geosci., 12, 153-158, https://doi.org/10.5194/adgeo-12-153-2007, 2007.

Lionello, P., Dalan, F., and Elvini, E.: Cyclones in the Mediterranean region: the present and the doubled $\mathrm{CO}_{2}$ climate scenarios, Clim. Res., 22, 147-159, https://doi.org/10.3354/cr022147, 2002.

Lionello, P., Bhend, J., Buzzi, A., Della-Marta, P. M., Krichak, S. O., Jansà, A., Maheras, P., Sanna, A., Trigo, I. F., and Trigo, R.: Chapter 6 Cyclones in the Mediterranean region: Climatology and effects on the environment, Developments in Earth and Environmental Sciences, 4, 325-372, https://doi.org/10.1016/S15719197(06)80009-1, 2006.

Lionello, P., Trig,o I. F., Gil, V., Liberato, M. L. R., Nissen, K. M., Pinto, J. G., Raible, C. C., Reale M., Tanzarella, A., Trigo, R. M., Ulbrich, S., and Ulbrich, U.: Objective climatology of cyclones in the Mediterranean region: a consensus view among methods with different system identification and tracking criteria, Tellus A, 68, 29391, https://doi.org/10.3402/tellusa.v68.29391, 2016.

Lionello, P., Conte, D., and Reale, M.: The effect of cyclones crossing the Mediterranean region on sea level anomalies on the Mediterranean Sea coast, Nat. Hazards Earth Syst. Sci., 19, 1541-1564, https://doi.org/10.5194/nhess-19-1541-2019, 2019.

Lionello, P., Barriopedro, D., Ferrarin, C., Nicholls, R. J., Orlić, M., Raicich, F., Reale, M., Umgiesser, G., Vousdoukas, M., and Zanchettin, D.: Extreme floods of Venice: characteristics, dynamics, past and future evolution (review article), Nat. Hazards Earth Syst. Sci., 21, 2705-2731, https://doi.org/10.5194/nhess21-2705-2021, 2021.

Llasat, M. C., Llasat-Botija, M., Petrucci, O., Pasqua, A. A., Rosselló, J., Vinet, F., and Boissier, L.: Towards a database on societal impact of Mediterranean floods within the framework of the HYMEX project, Nat. Hazards Earth Syst. Sci., 13, 13371350, https://doi.org/10.5194/nhess-13-1337-2013, 2013.

Lorenzo-Lacruz, J., Amengual, A., Garcia, C., Morán-Tejeda, E., Homar, V., Maimó-Far, A., Hermoso, A., Ramis, C., and Romero, R.: Hydro-meteorological reconstruction and geomorphological impact assessment of the October 2018 catastrophic flash flood at Sant Llorenç, Mallorca (Spain), Nat. Hazards Earth Syst. Sci., 19, 2597-2617, https://doi.org/10.5194/nhess19-2597-2019, 2019.

Maheras, P., Flocas, H., Patrikas, I., and Anagnostopoulou, C.: A 40 year objective climatology of surface cyclones in the Mediterranean region: spatial and temporal distribution, Int. J. Climatol., 21, 109-130, 2001.

Marcos, M., Jordà, G., Gomis, D., and Pérez, B.: Changes in storm surges in southern Europe from a regional model under climate change scenarios, Global Planet. Change, 77, 116-128, https://doi.org/10.1016/j.gloplacha.2011.04.002, 2011. 
Martius, O. and Wernli, H.: A Trajectory-Based Investigation of Physical and Dynamical Processes That Govern the Temporal Evolution of the Subtropical Jet Streams over Africa, J. Atmos. Sci., 69, 1602-1616, https://doi.org/10.1175/JAS-D-11-0190.1, 2012.

Massacand, A. C., Wernli, H., and Davies, H. C.: Influence of Upstream Diabatic Heating upon an Alpine Event of Heavy Precipitation, Mon. Weather Rev., 129, 2822-2828, 2001.

Mazoyer, M., Ricard D., Rivière, G., Delanoë, J., Arbogast, P., Vié, B., Lac, C., Cazenave, Q., and Pelon, J.: Microphysics impacts on the warm conveyor belt and ridge building of the NAWDEX IOP6 cyclone, Mon. Weather Rev., 149, 3961-3980, 2021.

Mazza, E., Ulbrich, U., and Klein, R.: The Tropical Transition of the October 1996 Medicane in the Western Mediterranean Sea: A Warm Seclusion Event, Mon. Weather Rev., 145, 2575-2595, https://doi.org/10.1175/MWR-D-16-0474.1, 2017.

McTaggart-Cowan, R., Galarneau, T. J., Bosart, L. F., and Milbrandt, J. A.: Development and tropical transition of an Alpine lee cyclone. Part II: orographic influence on the development pathway. Mon. Weather Rev., 138, 2308-2326, 2010.

McTaggart-Cowan, R., Davies, E. L., Fairman Jr., J. G., Galarneau Jr., T. J., and Schultz, D. M.: Revisiting the $26.5^{\circ} \mathrm{C}$ Sea Surface Temperature Threshold for Tropical Cyclone Development, B. Am. Meteorol. Soc., 96, 1929-1943, 2015.

Messmer, M., Gómez-Navarro, J. J., and Raible, C. C.: Climatology of $\mathrm{Vb}$ cyclones, physical mechanisms and their impact on extreme precipitation over Central Europe, Earth Syst. Dynam., 6, 541-553, https://doi.org/10.5194/esd-6-541-2015, 2015.

Messmer, M., Gómez-Navarro, J. J., and Raible, C. C.: Sensitivity experiments on the response of $\mathrm{Vb}$ cyclones to sea surface temperature and soil moisture changes, Earth Syst. Dynam., 8, 477-493, https://doi.org/10.5194/esd-8-477-2017, 2017.

Michaelides, S., Karacostas, T., Sánchez, J. L., Retalis, A., Pytharoulis, I., Homar, V., Romero, R., Zanis, P., Giannakopoulos, C., Bühl, J., Ansmann, A., Merino, A., Melcón, P., Lagouvardos, K., Kotroni, V., Bruggeman, A., López-Moreno, J. I., Berthet, C., Katragkou, E., Tymvios, F., Hadjimitsis, D. G., Mamouri, R.-E., and Nisantzi, A.: Reviews and perspectives of high impact atmospheric processes in the Mediterranean, Atmos. Res., 208, 4-44, https://doi.org/10.1016/j.atmosres.2017.11.022, 2018.

Miglietta, M. M.: Mediterranean tropical-like cyclones (Medicanes), Atmosphere, 10, 206, https://doi.org/10.3390/atmos10040206, 2019.

Miglietta, M. M. and Rotunno, R.: Development mechanisms for Mediterranean tropical-like cyclones (Medicanes), Q. J. Roy. Meteorol. Soc., 145, 1444-1460, https://doi.org/10.1002/qj.3503, 2019.

Miglietta, M. M., Moscatello, A., Conte, D., Mannarini, G., Lacorata, G., and Rotunno, R.: Numerical analysis of a Mediterranean "hurricane" over south-eastern Italy: Sensitivity experiments to sea surface temperature, Atmos. Res., 101, 412-426, 2011.

Miglietta, M. M., Laviola, S., Malvaldi, A., Conte, D., Levizzani, V., and Price, C.: Analysis of tropical-like cyclones over the Mediterranean Sea through a combined modelling and satellite approach, Geophys. Res. Lett., 40, 2400-2405, https://doi.org/10.1002/grl.50432, 2013.

Miglietta, M. M., Mastrangelo, D., and Conte, D.: Influence of physics parameterization schemes on the simulation of a tropical- like cyclone in the Mediterranean Sea, Atmos. Res., 153, 360375, https://doi.org/10.1016/j.atmosres.2014.09.008, 2015.

Miglietta, M. M., Cerrai, D., Laviola, S., Cattani, E., and Levizzani, V.: Potential vorticity patterns in Mediterranean "hurricanes", Geophys. Res. Lett., 44, 2537-2545, https://doi.org/10.1002/2017GL072670, 2017.

Miglietta, M. M., Carnevale, D., Levizzani, V., and Rotunno, R.: Role of moist and dry air advection in the development of Mediterranean Tropical-Like Cyclones (Medicanes), Q. J. Roy. Meteor. Soc., 147, 876-899, https://doi.org/10.1002/qj.3951, 2021.

Moscatello, A., Miglietta, M. M., and Rotunno, R.: Numerical analysis of a Mediterranean "hurricane" over southeastern Italy, Mon. Weather Rev., 136, 4373-4397, https://doi.org/10.1175/2008MWR2512.1, 2008.

Munich Re: Natural disasters of 2019 in figures, available at: https://www.munichre.com/topics-online/en/climate-changeand-natural-disasters/natural-disasters/natural-disasters-of2019-in-figures-tropical-cyclones-cause-highest-losses.html, last access: 31 January 2022.

Mylonas, M. P., Douvis, K. C., Polychroni, I. D., Politi, N., and Nastos, P. T.: Analysis of a Mediterranean Tropical-Like Cyclone, Sensitivity to WRF Parameterizations and Horizontal Resolution, Atmosphere, 10, 425, https://doi.org/10.3390/atmos10080425, 2019.

Nasr-Esfahany, M. A., Ahmadi-Givi, F., and Mohebalhojeh, A. R.: An energetic view of the relation between the Mediterranean storm track and the North Atlantic Oscillation, Q. J. Roy. Meteorol. Soc., 137, 749-756, https://doi.org/10.1002/qj.794, 2011.

Neu, U., Akperov, M. G., Bellenbaum, N., Benestad, R., Blender, R., Caballero, R., Cocozza, A., Dacre, H. F., Feng, Y., Fraedrich, K., Grieger, J., Gulev, S., Hanley, J., Hewson, T., Inatsu, M., Keay, K., Kew, S. F., Kindem, I., Leckebusch, G. C., Liberato, M. L. R., Lionello, P., Mokhov, I. I., Pinto, J. G., Raible, C. C., Reale, M., Rudeva, I., Schuster, M., Simmonds, I., Sinclair, M., Sprenger, M., Tilinina, N. D., Trigo, I. F., Ulbrich, S., Ulbrich, U., Wang, X. L., and Wernli, H.: IMILAST: A Community Effort to Intercompare Extratropical Cyclone Detection and Tracking Algorithms, B. Am. Meteorol. Soc., 94, 529-547, https://doi.org/10.1175/BAMS-D-11-00154.1, 2013.

Nicolaides, K. A., Michalelides, S. C., and Karacostas, T.: Synoptic and dynamic characteristics of selected deep depressions over Cyprus, Adv. Geosci., 7, 175-180, https://doi.org/10.5194/adgeo-7-175-2006, 2006.

Nigam, S. and Baxter, S.: General Circulation of the Atmosphere, Teleconnections, edited by: North, G. R., Pyle, J., and Zhang, F., Encyclopedia of Atmospheric Sciences, 2nd edn., Academic Press, 90-109, https://doi.org/10.1016/B978-012-382225-3.00400-X, 2015.

Nissen, K. M., Leckebusch, G. C., Pinto, J. G., Renggli, D., Ulbrich, S., and Ulbrich, U.: Cyclones causing wind storms in the Mediterranean: characteristics, trends and links to largescale patterns, Nat. Hazards Earth Syst. Sci., 10, 1379-1391, https://doi.org/10.5194/nhess-10-1379-2010, 2010.

Nissen, K. M., Ulbrich, U., and Leckebusch, G. C.: Vb cyclones and associated rainfall extremes over Central Europe under present day and climate change conditions, Meteorol. Z., 22, 649-660, https://doi.org/10.1127/0941-2948/2013/0514, 2013. 
Nissen, K. M., Leckebusch, G. C., Pinto, J. G., and Ulbrich, U.: Mediterranean cyclones and windstorms in a changing climate, Reg. Environ. Change, 14, 1873-1890, https://doi.org/10.1007/s10113-012-0400-8, 2014.

Nuissier, O., Marsigli, C., Vincendon, B., Hally, A., Bouttier, F.,Montani, A., and Paccagnella, T.: Evaluation of two convection-permitting ensemble systems in the HyMeX Special Observation Period (SOP1) framework, Q. J. Roy. Meteor. Soc., 142, 404-418, https://doi.org/10.1002/qj.2859, 2016.

Palmén, E.: On the formation and structure of tropical hurricanes, Geophysica, 3, 26-38, 1948.

Pantillon, F., Chaboureau, J.-P., Lac, C., and Mascart, P.: On therole of a Rossby wave train during the extratropical transition of hurricane Helene (2006), Q. J. Roy. Meteorol. Soc., 139, 370-386, https://doi.org/10.1002/qj.1974, 2013.

Papagiannaki, K., Lagouvardos, K., and Kotroni, V.: A database of high-impact weather events in Greece: a descriptive impact analysis for the period 2001-2011, Nat. Hazards Earth Syst. Sci., 13, 727-736, https://doi.org/10.5194/nhess-13-727-2013, 2013.

Patlakas, P., Stathopoulos, C., Tsalis, C., and Kallos, G.: Wind and wave extremes associated with tropical-like cyclones in the Mediterranean basin, Int. J. Climatol., 41, 1-22, https://doi.org/10.1002/joc.6795, 2020.

Pedgley, D.: Desert depression over northeast Africa, Meteorol. Mag., 101, 228-244, 1972.

Petrucci, O., Papagiannaki, K., Aceto, L., Boissier, L., Kotroni, V., Grimalt, M., Llasat, Montserrat Llasat-Botija, M. C., Rosselló, J., Pasqua, A. A., and Vinet, F.: MEFF: the database of Mediterranean Flood fatalities (1980 to 2015), J. Flood Risk Manag., 12, e12461, https://doi.org/10.1111/jfr3.12461, 2019.

Petterssen, S.: Weather analysis and forecasting, vol 1., McGrawHill, New York, USA, 1956.

Petterssen, S. and Smebye, S. J.: On the development of extratropical cyclones, Q. J. Roy. Meteorol. Soc., 97, 457-482, 1971.

Pfahl, S. and Wernli, H.: Quantifying the Relevance of Cyclones for Precipitation Extremes, J. Climate, 25, 6770-6780, https://doi.org/10.1175/JCLI-D-11-00705.1, 2012.

Pfahl, S., Madonna, E., Boettcher, M., Joos, H., and Wernli, H.: Warm conveyor belts in the ERA-Interim dataset (1979-2010). Part II: Moisture origin and relevance for precipitation, J. Climate, 27, 27-40, 2014.

Picornell, M. A., Jansà, A., Genovés, A., and Campins, J.: Automated database of mesocyclones from the HIRLAM(INM)- $0.5^{\circ}$ analyses in the western Mediterranean, Int. J. Climatol., 21, 335354, https://doi.org/10.1002/joc.621, 2001.

Picornell, M. A., Jansà, A., and Genovés, A.: A tool for assessing the quality of the Mediterranean cyclone forecast: a numerical index, Nat. Hazards Earth Syst. Sci., 11, 1787-1794, https://doi.org/10.5194/nhess-11-1787-2011, 2011.

Picornell, M. A., Campins, J., and Jansà, A.: Detection and thermal description of medicanes from numerical simulation, Nat. Hazards Earth Syst. Sci., 14, 1059-1070, https://doi.org/10.5194/nhess-14-1059-2014, 2014.

Pinto, J. G., Zacharias, S., Fink, A. H., Leckebusch, G. C., and U1brich, U.: Factors contributing to the development of extreme North Atlantic cyclones and their relationship with the NAO, Clim. Dynam., 32, 711-737, https://doi.org/10.1007/s00382008-0396-4, 2009.
Pisarski, A.: The Mediterranean cyclones and their impact on the weather in Bulgaria (in Bulgarian) Hydrology and Meteorology, issue of the Bulgarian Institute of Meteorology and Hydrology, vol II, no. 6, 1955.

Polemio, M. and Petrucci, O.: Occurrence of landslide events and the role of climate in the twentieth century in Calabria, southern Italy, Q. J. Eng. Geol. Hydroge., 43, 403-415, https://doi.org/10.1144/1470-9236/09-006, 2010.

Ponce de León, S. and Bettencourt, J. H.: Composite analysis of North Atlantic extra-tropical cyclone waves from satellite altimetry observations, Adv. Space Res., 68, 762-772, https://doi.org/10.1016/j.asr.2019.07.021, 2019.

Porcù, F., Carrassi, A., Medaglia, C. M., Prodi, F., and Mugnai, A.: A study on cut-off low vertical structure and precipitation in the Mediterranean region, Meteorol. Atmos. Phys., 96, 121-140, https://doi.org/10.1007/s00703-006-0224-5, 2007.

Portmann, R., González-Alemán, J. J., Sprenger, M., and Wernli, H.: How an uncertain short-wave perturbation on the North Atlantic wave guide affects the forecast of an intense Mediterranean cyclone (Medicane Zorbas), Weather Clim. Dynam., 1, 597-615, https://doi.org/10.5194/wcd-1-597-2020, 2020.

Portmann, R., Sprenger, M., and Wernli, H.: The three-dimensional life cycles of potential vorticity cutoffs: a global and selected regional climatologies in ERA-Interim (1979-2018), Weather Clim. Dynam., 2, 507-534, https://doi.org/10.5194/wcd-2-5072021, 2021.

Pravia-Sarabia, E., Gómez-Navarro, J. J., Jiménez-Guerrero, P., and Montávez, J. P.: Influence of sea salt aerosols on the development of Mediterranean tropical-like cyclones, Atmos. Chem. Phys., 21, 13353-13368, https://doi.org/10.5194/acp-21-133532021, 2021.

Prezerakos, N. G. and Flocas, H. A.: The formation of a dynamically unstable ridge at $500 \mathrm{hPa}$ as a precursor of surface cyclogenesis in the central Mediterranean, Meteorol. Appl., 3, 101-111, https://doi.org/10.1002/met.5060030201, 1996.

Prezerakos, N. G., Flocas, H. A., and Brikas, D.: The role of the interaction between polar and subtropical jet in a case of depression rejuvenation over the Eastern Mediterranean, Meteorol. Atmos. Phys., 92, 139-151, https://doi.org/10.1007/s00703-005-0142-y, 2006.

Pytharoulis, I.: Analysis of a Mediterranean tropical-like cyclone and its sensitivity to the sea surface temperatures, Atmos. Res., 208, 167-179, 2018.

Pytharoulis, I., Kartsios, S., Tegoulias, I., Feidas, H., Miglietta, M., Matsangouras, I., and Karacostas, T.: Sensitivity of a Mediterranean Tropical-Like Cyclone to Physical Parameterizations, Atmosphere, 9, 436, https://doi.org/10.3390/atmos9110436, 2018.

Radinović, D.: Cyclonic activity in Yugoslavia and surrounding areas, Arch. Meteor. Geophys. Bioklim., A14, 391-408, 1965.

Ragone, F., Mariotti, M., Parodi, A., Von Hardenberg, J., and Pasquero, C.: A climatological study of western mediterranean medicanes in numerical simulations with explicit and parameterized convection, Atmosphere, 9, 397, https://doi.org/10.3390/atmos9100397, 2018.

Raible, C. C.: On the relation between extremes of midlatitude cyclones and the atmospheric circulation using ERA40, Geophys. Res. Lett., 34, L07703, https://doi.org/10.1029/2006GL029084, 2007. 
Raible, C. C., Ziv, B., Saaroni, H., and Wild, M.: Winter synopticscale variability over the Mediterranean Basin under future climate conditions as simulated by the ECHAM5, Clim. Dynam., 35, 473-488, https://doi.org/10.1007/s00382-009-0678-5, 2010.

Rasmussen, E. and Zick, C.: A subsynoptic vortex over the Mediterranean with some resemblance to polar lows, Tellus A, 39A, 408-425, https://doi.org/10.1111/j.1600-0870.1987.tb00318.x, 1987.

Raveh-Rubin, S. and Flaounas, E.: A dynamical link between deep Atlantic extratropical cyclones and intense Mediterranean cyclones, Atmos. Sci. Lett., 18, 215-221, https://doi.org/10.1002/asl.745, 2017.

Raveh-Rubin, S. and Wernli, H.: Large-scale wind and precipitation extremes in the Mediterranean: A climatological analysis for 1979-2012, Q. J. Roy. Meteorol. Soc., 141, 2404-2417, https://doi.org/10.1002/qj.2531, 2015.

Raveh-Rubin, S. and Wernli, H.: Large-scale wind and precipitation extremes in the Mediterranean: dynamical aspects of five selected cyclone events, Q. J. Roy. Meteorol. Soc., 142, 30973114, https://doi.org/10.1002/qj.2891, 2016.

Reale, M. and Lionello, P.: Synoptic climatology of winter intense precipitation events along the Mediterranean coasts, Nat. Hazards Earth Syst. Sci., 13, 1707-1722, https://doi.org/10.5194/nhess-13-1707-2013, 2013.

Reale, M., Liberato, M. L. R., Lionello, P., Pinto, J. G., Salon, S., and Ulbrich, S.: A Global Climatology of Explosive Cyclones using a Multi-Tracking Approach, Tellus A, 71, 1611340, https://doi.org/10.1080/16000870.2019.1611340, 2019.

Reale, M., Cabos, W., Cavicchia, L., Conte, D., Coppola, E., Flaounas, E., Giorgi, F., Gualdi, S., Hochman, A., Li, L., Lionello, P., Podrascanin, Z., Salon, S., Sanchez, E., Scoccimarro, E., Sein, D., and Somot, S.: Future projections of Mediterranean cyclone characteristics using the Med-CORDEX ensemble of coupled regional climate system models, Clim. Dynam., https://doi.org/10.1007/s00382-021-06018-x, 2021.

Rezaeian, M., Mohebalhojeh, A. R., Ahmadi-Givi, F., and NasrEsfahany, M.: A wave-activity view of the relation between the Mediterranean storm track and the North Atlantic Oscillation in winter, Q. J. Roy. Meteorol. Soc., 142, 1662-1671, https://doi.org/10.1002/qj.2760, 2016.

Ricard, D., Ducrocq, V., and Auger, L.: A Climatology of the Mesoscale Environment Associated with Heavily Precipitating Events over a Northwestern Mediterranean Area, J. Appl. Meteorol. Climatol., 51, 468-488, 2012.

Ricchi, A.,Miglietta, M. M., Barbariol, F., Benetazzo, A., Bergamasco, A., Bonaldo, D., Cassardo, C., Falcieri, F. M., Modugno, G., Russo, A., Sclavo, M., and Carniel, S.: Sensitivity of a Mediterranean tropical-like cyclone to different model configurations and coupling strategies, Atmosphere, 8, 1-32, https://doi.org/10.3390/atmos8050092, 2017.

Rizza, U., Barnaba, F., Miglietta, M. M., Mangia, C., Di Liberto, L., Dionisi, D., Costabile, F., Grasso, F., and Gobbi, G. P.: WRF-Chem model simulations of a dust outbreak over the central Mediterranean and comparison with multi-sensor desert dust observations, Atmos. Chem. Phys., 17, 93-115, https://doi.org/10.5194/acp-17-93-2017, 2017.

Rizza, U., Miglietta, M. M., Mangia, C., Ielpo, P., Morichetti, M., Iachini, C., Virgili, S., and Passerini, G.: Sensitivity of WRFChem model to land surface schemes: Assessment in a severe dust outbreak episode in the Central Mediterranean (Apulia Region), Atmos. Res., 201, 168-180, 2018a.

Rizza, U., Canepa, E., Ricchi, A., Bonaldo, D., Carniel, S., Morichetti, M., Passerini, G., Santiloni, L., Scremin Puhales, F., and Miglietta, M. M.: Influence of Wave State and Sea Spray on the Roughness Length: Feedback on Medicanes, Atmosphere, 9, 301, https://doi.org/10.3390/atmos9080301, 2018b.

Rizza, U., Canepa, E., Miglietta, M. M., Passerini, G., Morichetti, M., Mancinelli, E., Virgili, S., Besio, G., De Leo, F., and Mazzino, A.: Evaluation of drag coefficients under medicane conditions: Coupling waves, sea spray and surface friction, Atmos. Res., 247, 105207, https://doi.org/10.1016/j.atmosres.2020.105207, 2021.

Rodwell, M. J., Magnusson, L., Bauer, P., Bechtold, P., Bonavita, M., Cardinali, C., Diamantakis, M., Earnshaw, P., GarciaMendez, A., Isaksen, L., Källén, E., Klocke, D., Lopez, P., McNally, T., Persson, A., Prates, F., and Wedi, N.: Characteristics of Occasional Poor Medium-Range Weather Forecasts for Europe, B. Am. Meteorol. Soc., 94, 1393-1405, 2013.

Romaniello, V., Oddo, P., Tonani, M., Torrisi, L., Grandi, A., and Pinardi, N.: Impact of sea surface temperature on COSMO forecasts of a Medicane over the western Mediterranean Sea, J. Earth Sci. Engineering, 5, 338-348, 2015.

Romera, R., Gaertner, M. Á., Sánchez, E., Domínguez, M., González-Alemán, J. J., and Miglietta, M. M.: Climate change projections of medicanes with a large multi-model ensemble of regional climate models, Global Planet. Change, 151, 134-143, 2017.

Romero, R. and Emanuel, K.: Medicane risk in a changing climate, J. Geophys. Res.-Atmos., 118, 5992-6001, 2013.

Romero, R. and Emanuel, K.: Climate change and Hurricane-like extratropical cyclones: Projections for North Atlantic polar lows and medicanes based on CMIP5 models, J. Climate, 30, 279299, 2017.

Rotunno, R. and Emanuel, K.: An Air-Sea Interaction Theory forTropical Cyclones. Part II: Evolutionary Study Using a Nonhy-drostatic Axisymmetric Numerical Model, J. Atmos. Sci., 44, 542-561, 1987.

Ruti, P. M., Somot, S., Giorgi, F., Dubois, C., Flaounas, E., Obermann, A., Dell'Aquila, A., Pisacane, G., Harzallah, A., Lombardi, E., Ahrens, B., Akhtar, N., Alias, A., Arsouze, T., Aznar, R., Bastin, S., Bartholy, J., Béranger, K., Beuvier, J., BouffiesCloché, S., Brauch, J., Cabos, W., Calmanti, S., Calvet, J.-C., Carillo, A., Conte, D., Coppola, E., Djurdjevic, V., Drobinski, P., Elizalde-Arellano, A., Gaertner, M., Galàn, P., Gallardo, C., Gualdi, S., Goncalves, M., Jorba, O., Jordà, G., L'Heveder, B., Lebeaupin-Brossier, C., Li, L., Liguori, G., Lionello, P., Maciàs, D., Nabat, P., Önol, B., Raikovic, B., Ramage, K., Sevault, F., Sannino, G., Struglia, M. V., Sanna, A., Torma, C., and Vervatis, V.: Med-CORDEX Initiative for Mediterranean Climate Studies, B. Am. Meteorol. Soc., 97, 1187-1208, https://doi.org/10.1175/BAMS-D-14-00176.1, 2016.

Ryder, C. L., Highwood, E. J., Rosenberg, P. D., Trembath, J., Brooke, J. K., Bart, M., Dean, A., Crosier, J., Dorsey, J., Brindley, H., Banks, J., Marsham, J. H., McQuaid, J. B., Sodemann, H., and Washington, R.: Optical properties of Saharan dust aerosol and contribution from the coarse mode as measured during the Fennec 2011 aircraft campaign, Atmos. Chem. Phys., 13, 303325, https://doi.org/10.5194/acp-13-303-2013, 2013. 
Saaroni, H., Ziv, B., Bitan, A., and Alpert, P.: Easterly Wind Storms over Israel, Theor. Appl. Climatol., 59, 61-77, https://doi.org/10.1007/s007040050013, 1998.

Saaroni, H., Halfon, N., Ziv, B., Alpert, P., and Kutiel, H.: Links between the rainfall regime in Israel and location and intensity of Cyprus lows, Int. J. Climatol., 30, 1014-1025, 2010.

Saaroni, H., Harpaz, T., and Ziv, B.: A new classification algorithm for daughter cyclone formation with respect to the parent's frontal system - application for the Mediterranean Basin, Int. J. Climatol., 37, 1050-1065, https://doi.org/10.1002/joc.4759, 2017

Schäfler, A., Craig, G., Wernli, H., Arbogast, P., Doyle, J. D., McTaggart-Cowan, R., Methven, J., Rivière, G., Ament, F., Boettcher, M., Bramberger, M., Cazenave, Q., Cotton, R., Crewell, S., Delanoë, J., Dörnbrack, A., Ehrlich, A., Ewald, F., Fix, A., Grams, C. M., Gray, S. L., Grob, H., Groß, S., Hagen, M., Harvey, B., Hirsch, L., Jacob, M., Kölling, T., Konow, H., Lemmerz, C., Lux, O., Magnusson, L., Mayer, B., Mech, M., Moore, R., Pelon, J., Quinting, J., Rahm, S., Rapp, M., Rautenhaus, M., Reitebuch, O., Reynolds, C. A., Sodemann, H., Spengler, T., Vaughan, G., Wendisch, M., Wirth, M., Witschas, B., Wolf, K., and Zinner, T.: The North Atlantic Waveguide and Downstream Impact Experiment, B. Am. Meteorol. Soc., 99, 16071637, https://doi.org/10.1175/BAMS-D-17-0003.1, 2018.

Schär, C., Frei, C., Lüthi, D., and Davies, H. C.: Surrogate climatechange scenarios for regional climate models, Geophys. Res. Lett., 23, 669-672, 1996.

Schepanski, K. and Knippertz, P.: Soudano-Saharan depressions and their importance for precipitation and dust: a new perspective on a classical synoptic concept: Soudano-Saharan Depressions: A New Perspective, Q. J. Roy. Meteorol. Soc., 137, 1431-1445, https://doi.org/10.1002/qj.850, 2011.

Schepanski, K., Tegen, I., Todd, M. C., Heinold, B., Bönisch, G., Laurent, B., and Macke, A.: Meteorological processes forcing Saharan dust emission inferred from MSGSEVIRI observations of subdaily dust source activation and numerical models, J. Geophys. Res., 114, D10201, https://doi.org/10.1029/2008JD010325, 2009.

Smart, D.: Medicane "Ianos" over the central Mediterranean 14-20 September 2020, Weather, 75, 352-353, https://doi.org/10.1002/wea.3871, 2020.

Solomon, S., Qin, D., Manning, M., Alley, R. B., Berntsen, T., Bindoff, N. L., Chen, Z., Chidthaisong, A., Gregory, J. M., Hegerl, G. C., Heimann, M., Hewitson, B., Hoskins, B. J., Joos, F., Jouzel, J., Kattsov, V., Lohmann, U., Matsuno, T., Molina, M., Nicholls, N., Overpeck, J., Raga, G., Ramaswamy, V., Ren, J., Rusticucci, M., Somerville, R., Stocker, T. F., Whetton, P., Wood, R. A., and Wratt, D.: Technical Summary, in: Climate Change2007: The Physical Science Basis, Contribution of Working Group I to the Fourth Assessment Report of the Intergovernmental Panel on Climate Change, edited by: Solomon, S., Qin, D., Manning, M., Chen, Z., Marquis, M., Averyt, K. B., Tignor, M., and Miller, H. L., Cambridge University Press, UK, 2007.

Sotillo, M., Ramis, C., Romero, R., Alonso, S., and Homar, V.: Role of orography in the spatial distribution of precipitation over the Spanish Mediterranean zone, Clim. Res., 23, 247-261, https://doi.org/10.3354/cr023247, 2003.

Stathopoulos, C., Patlakas, P., Tsalis, C., and Kallos, G.: The Role of Sea Surface Temperature Forcing in the Life-
Cycle of Mediterranean Cyclones, Remote Sens., 12, 825, https://doi.org/10.3390/rs12050825, 2020.

Strauss, C., Ricard, D., Lac, C., and Verrelle, A.: Evaluation of turbulence parametrizations in convective clouds and their environment based on a large-eddy simulation, Q. J. Roy. Meteorol. Soc., 145, 3195-3217, https://doi.org/10.1002/qj.3614, 2019.

Tadesse, M., Wahl, T., and Cid, A.: Data-driven modeling of global storm surges, Frontiers in Marine Science, 7, 260, https://doi.org/10.3389/fmars.2020.00260, 2020.

Taylor, A. L., Kox, T., and Johnston, D.: Communicating high impact weather: Improving warnings and decision making processes, Int. J. Disast. Risk Re., 30, 1-4, https://doi.org/10.1016/j.ijdrr.2018.04.002, 2018.

Thorncroft, C. D. and Flocas, H. A.: A case study of Saharan cyclogenesis, Mon. Weather Rev., 125, 1147-1165, 1997.

Thorncroft, C. D., Hoskins, B. J., and McIntyre, M. E.: Two paradigms of baroclinic-wave life-cycle behaviour, Q. J. Roy. Meteorol. Soc., 119, 17-55, 1993.

Tochimoto, E., Miglietta, M. M., Bagaglini, L., Ingrosso, R., and Niino, H.: Characteristics of Extratropical Cyclones That Cause Tornadoes in Italy: A Preliminary Study, Atmosphere, 12, 180, https://doi.org/10.3390/atmos12020180, 2021.

Tous, M., Romero, R., and Ramis, C.: Surface heat fluxes influence on medicane trajectories and intensification, Atmos. Res., 123, 400-411, https://doi.org/10.1016/j.atmosres.2012.05.022, 2013.

Tous, M., Zappa, G., Romero, R., Shaffrey, L., and Vidale, P. L.: Projected changes in medicanes in the HadGEM3 N512 highresolution global climate model, Clim. Dynam., 47, 1913-1924, 2016.

Trigo, I. F.: Climatology and interannual variability of stormtracks in the Euro-Atlantic sector: a comparison between ERA40 and NCEP/NCAR reanalyses, Clim. Dynam., 26, 127-143, https://doi.org/10.1007/s00382-005-0065-9, 2006.

Trigo, I. F., Davies, T. D., and Bigg, G. R.: Objective climatology of cyclones in the Mediterranean region, J. Climate, 12, 1685-1696, 1999.

Trigo, I. F., Davies, T. D., and Bigg, G. R.: Decline in Mediterranean rainfall caused by weakening of Mediterranean cyclones, Geophys. Res. Lett., 27, 2913-2916, https://doi.org/10.1029/2000GL011526, 2000.

Trigo, I. F., Bigg, G. R., and Davies, T. D.: Climatology of cyclogenesis mechanisms in the Mediterranean, Mon. Weather Rev., 130, 549-569, 2002.

Trigo, R. M., Zezere, J. L., Rodrigues, M. L., and Trigo, I. F.: The influence of the North Atlantic Oscillation on rainfall triggering of landslides near Lisbon, Nat. Hazards, 36, 331-354, 2005.

Trigo, R. M., Valente, M. A., Trigo, I. F., Miranda, P. M. A., Ramos, A. M., Paredes, D., and García-Herrera, R.: The Impact of North Atlantic Wind and Cyclone Trends on European Precipitation and Significant Wave Height in the Atlantic, Ann. N.Y. Acad. Sci., 1146, 212-234, https://doi.org/10.1196/annals.1446.014, 2008.

Tsidulko, M. and Alpert, P.: Synergism of upper level potential vorticity and mountains in Genoa lee cyclogenesis - a numerical study, Meteorol. Atmos. Phys., 78, 261-285, 2001.

Ulbrich, U., Lionello, P., Belušić, D., Jacobeit, J., Knippertz, P., Kuglitsch, F. G., Leckebusch, G. C., Luterbacher, J., Maugeri, M., Maheras, P., Nissen, K. M., Pavan, V., Pinto, J. G., Saaroni, H., Seubert, S., Toreti, A., Xoplaki, E., and Ziv, B.: Cli- 
mate of the Mediterranean, in: The Climate of the Mediterranean Region, Elsevier, 301-346, https://doi.org/10.1016/B978-0-12416042-2.00005-7, 2012.

Van Bebber, W.: Die Zugstrassen der barometrischen Minima nach den Bahnenkarten der deutschen Seewarte für den Zeitraum 1875-1890, Meteorol. Z., 8, 361-366, 1891.

van der Jagt, H., Friese, C., Stuut, J.-B. W., Fischer, G., and Iversen, M. H.: The ballasting effect of Saharan dust deposition on aggregate dynamics and carbon export: Aggregation, settling, and scavenging potential of marine snow: Saharan dust ballasting of marine snow, Limnol. Oceanogr., 63, 1386-1394, https://doi.org/10.1002/lno.10779, 2018.

Varga, G.: Changing nature of Saharan dust deposition in the Carpathian Basin (Central Europe): 40 years of identified North African dust events (1979-2018), Environ. Int., 139, 105712, https://doi.org/10.1016/j.envint.2020.105712, 2020.

Varga, G., Újvári, G., and Kovács, J.: Spatiotemporal patterns of Saharan dust outbreaks in the Mediterranean Basin, Aeolian Res., 15, 151-160, https://doi.org/10.1016/j.aeolia.2014.06.005, 2014.

Varlas, G., Vervatis, V., Spyrou, C., Papadopoulou, E., Papadopoulos, A., and Katsafados, P.: Investigating the impact of atmosphere-wave-ocean interactions on a Mediterranean tropical-like cyclone, Ocean Model., 153, 101675, https://doi.org/10.1016/j.ocemod.2020.101675, 2020.

Varlas, G., Marinou, E., Gialitaki, A., Siomos, N., Tsarpalis, K., Kalivitis, N., Solomos, S., Tsekeri, A., Spyrou, C., Tsichla, M., Kampouri, A., Vervatis, V., Giannakaki, E., Amiridis, V., Mihalopoulos, N., Papadopoulos, A., and Katsafados, P.: Assessing Sea-State Effects on Sea-Salt Aerosol Modeling in the Lower Atmosphere Using Lidar and In-Situ Measurements, Remote Sens. 13, 614, https://doi.org/10.3390/rs13040614, 2021.

Verrelle, A., Ricard, D., and Lac, C.: Evaluation and Improvement of Turbulence Parameterization inside Deep Convective Clouds at Kilometer-Scale Resolution, Mon. Weather Rev., 145, 39473967, 2017.

Vich, M., Romero, R., and Homar, V.: Ensemble prediction of Mediterranean high-impact events using potential vorticity perturbations. Part II: Adjointderived sensitivity zones, Atmos. Res., 102, 311-319, https://doi.org/10.1016/j.atmosres.2011.07.016, 2011a.

Vich, M., Romero, R., and Brooks, H. E.: Ensemble prediction of Mediterranean high-impact events using potential vorticity perturbations. Part I: Comparison against the multiphysics approach, Atmos. Res., 102, 227-241, https://doi.org/10.1016/j.atmosres.2011.07.017, 2011b.

Vinet, F., Bigot, V., Petrucci, O., Papagiannaki, K., Llasat, M. C., Kotroni, V., Boissier, L., Aceto, L., Grimalt, M., Llasat-Botija, M., Pasqua, A. A., Rossello, J., Kılıç, O., Kahraman, A., and Tramblay, Y.: Mapping Flood-Related Mortality in the Mediterranean Basin. Results from the MEFF v2.0 DB, Water, 11, 2196, https://doi.org/10.3390/w11102196, 2019.

Walsh, K., Giorgi, F., and Coppola, E.: Mediterranean warm-core cyclones in a warmer world, Clim. Dynam., 42, 1053-1066, 2014.
Winschall, A., Sodemann, H., Pfahl, S., and Wernli, H.: How important is intensified evaporation for Mediterranean precipitation extremes?, J. Geophys. Res.-Atmos., 119, 5240-5256, https://doi.org/10.1002/2013JD021175, 2014.

Winstanley, D.: Sharav, Weather, 27, 146-160, https://doi.org/10.1002/j.1477-8696.1972.tb04279.x, 1972.

Winters, A. C., Keyser, D., Bosart, L. F., and Martin, J. E.: Composite Synoptic-Scale Environments Conducive to North American Polar-Subtropical Jet Superposition Events, Mon. Weather Rev., 148, 1987-2008, https://doi.org/10.1175/MWRD-19-0353.1, 2020.

WMO: WMO Guidelines on Multi-hazard Impact-based Forecast and Warning Services, Geneva, Switzerland, available at: https: //library.wmo.int/doc_num.php?explnum_id=7901 (last access: 31 January 2022), 2015.

Woollings, T. and Blackburn, M.: The North Atlantic Jet Stream under Climate Change and Its Relation to the NAO and EA Patterns, J. Climate, 25, 886-902, https://doi.org/10.1175/JCLI-D11-00087.1, 2012.

Zappa, G., Shaffrey, L. C., Hodges, K. I., Sansom, P. G., and Stephenson, D. B.: A Multimodel Assessment of Future Projections of North Atlantic and European Extratropical Cyclones in the CMIP5 Climate Models, J. Climate, 26, 5846-5862, https://doi.org/10.1175/JCLI-D-12-00573.1, 2013.

Zappa, G., Hawcroft, M. K., Shaffrey, L., Black, E., and Brayshaw, D. J.: Extratropical cyclones and the projected decline of winter Mediterranean precipitation in the CMIP5 models, Clim. Dynam., 45, 1727-1738, https://doi.org/10.1007/s00382-014-2426$8,2015$.

Zhang, Z. and Li, X.-M.: Global ship accidents and ocean swellrelated sea states, Nat. Hazards Earth Syst. Sci., 17, 2041-2051, https://doi.org/10.5194/nhess-17-2041-2017, 2017.

Zhang, Q., Li, L., Ebert, B., Golding, B., Johnston, D., Mills, B., Panchuk, S., Potter, S., Riemer, M., Sun, J., Taylor, A., Jones, S., Ruti, P., and Keller, J.: Increasing the value of weather-related warnings, Sci. Bull., 64, 647-649, https://doi.org/10.1016/j.scib.2019.04.003, 2019.

Zhang, W., Villarini, G., Scoccimarro, E., and Napolitano, F.: Examining the precipitation associated with medicanes in the highresolution ERA-5 reanalysis data, Int. J. Climatol., 41, 1-7, https://doi.org/10.1002/joc.6669, 2020.

Ziv, B., Saaroni, H., Romem, M., Heifetz, E., Harnik, N., and Baharad, A.: Analysis of conveyor belts in winter Mediterranean cyclones, Theor. Appl. Climatol., 99, 441-455, https://doi.org/10.1007/s00704-009-0150-9, 2010.

Ziv, B., Harpaz, T., Saaroni, H., and Blender, R.:A new methodology for identifying daughter cyclogenesis: application for the Mediterranean Basin, Int. J. Climatol., 35, 3847-3861, https://doi.org/10.1002/joc.4250, 2015. 